University of Nebraska - Lincoln

DigitalCommons@University of Nebraska - Lincoln

1936

\title{
Relative Efficiency of Roots and Tops of Plants in Protecting . the Soil from Erosion
}

Joseph Kramer

University of Nebraska

J. E. Weaver

University of Nebraska

Follow this and additional works at: https://digitalcommons.unl.edu/agronweaver

Part of the Terrestrial and Aquatic Ecology Commons

Kramer, Joseph and Weaver, J. E., "Relative Efficiency of Roots and Tops of Plants in Protecting . the Soil from Erosion" (1936). Papers of John E. Weaver (1884-1956). 4.

https://digitalcommons.unl.edu/agronweaver/4

This Article is brought to you for free and open access by the Agronomy and Horticulture Department at DigitalCommons@University of Nebraska - Lincoln. It has been accepted for inclusion in Papers of John E. Weaver (1884-1956) by an authorized administrator of DigitalCommons@University of Nebraska - Lincoln. 


\title{
Relative Efficiency of Roots and Tops of Plants in Protecting the Soil from Erosion
}

\author{
BY \\ Joseph Kramer, Assistant in Botany \\ AND \\ J. E. Weaver, Professor of Plant Ecology \\ DEPARTMENT OF BOTANY \\ THE UNIVERSITY OF NEBRASKA \\ BULLETIN 12 \\ CONSERVATION DEPARTMENT \\ OF THE \\ CONSERVATION AND SURVEY DIVISION \\ UNIVERSITY OF NEBRASKA \\ CONTRIBUTION FROM \\ THE DEPARTMENT OF BOTANY NO. 99
}

Printed by Authority of the State of Nobraska

January, 1936 


\title{
Relative Efficiency of Roots and Tops of Plants in Protecting the Soil from Erosion
}

\author{
BY \\ Joseph Kramer, Assistant in Botany \\ AND \\ J. E. Weaver, Professor of Plant Ecology \\ DEPARTMENT OF BOTANY \\ THE UNIVERSITY OF NEBRASKA \\ BULLETIN 12 \\ CONSERVATION DEPARTMENT \\ OF THE \\ CONSERVATION AND SURVEY DIVISION \\ UNIVERSITY OF NEBRASKA \\ CONTRIBUTION FROM \\ THE DEPARTMENT OF BOTANY NO. 99
}

Printed by Authority of the State of Nebraska January, 1936 


\section{THE UNIVERSITY OF NEBRASKA}

Edgar A. Burnett, Chancellor

\section{BOARD OF REGENTS}

Hon. Earl Cline, Lincoln, President

Hon. A. C. Stokes, Omaha

Hon. Stani.ey D. Long, Grand Island

Hon. Frank Taylor, St. Paul

Hon. Marion A. Shaw, David City

Hon. Charles Y. Thompson, West Point

\section{CONSERVATION AND SURVEY DIVISION}

G. E. Condra, Dean and Director

As defined by law, the Conservation and Survey Division of the University includes the following state departments and surveys: Soil, Geological, Water, Biological, Industrial, Conservation, and Information Service. Its major purpose is to study and describe the state's resources and industries for use in development. Reports of the Division are published in three series, i.e., Nebraska Soil Survey, Nebraska Geological Survey, and the Conservation Department. 


\title{
FOREWORD
}

One of the duties of the Conservation and Survey Division of the University of Nebraska, as defined by the statutes, is to study and report upon the conservation problems of the state. In harmony with this requirement, some of the salient conservation problems of the state have been selected for careful investigation and various persons from the University are giving freely of their time to this research.

Soil conservation, which requires a factual basis, is an outstanding problem in parts of Nebraska. It is an involved subject, requiring, among other things, a close study of the relations of the prevailing kinds and conditions of plant cover to run-off and soil erosion.

Dr. J. E. Weaver of the Department of Botany, University of Nebraska, is one of the foremost plant ecologists of our country. $\mathrm{He}$ and his graduate students have made many technical environmental studies of the native grasses, trees, and farm crops, and have published extensively on these subjects.

During the past few years Dr. Weaver has organized and directed a number of investigations relating to run-off and the problem of erosion prevention. The Conservation and Survey Division has published three of these investigations under the titles:

The Environment of the Prairie. Bulletin 5, 1931.

Quantity of Living Plant Materials in Prairie Soils in Relation to Runoff and Soil Erosion. Bulletin 8, 1935.

Comparison of Runoff and Erosion in Prairie, Pasture, and Cultivated Land. Bulletin 11, 1935.

The Division presents herewith the report by Mr. Joseph Kramer and Dr. J. E. Weaver on relative efficiency of roots and tops of plants in protecting the soil from erosion, in the belief that it will be of use to ecologists and soil conservation workers.

\author{
G. E. CondrA \\ Dean and Director
}




\section{CONTENTS}

Board of Regents................................ 2

Foreword ..................................... 3

Table of Contents................................ 5

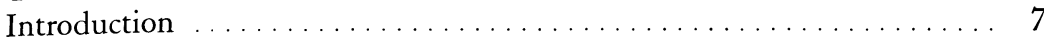

Methods ...................................... 8

Soils ...................................... 12

Experiments simulating rain ........................ 14

Experiments with sunflowers ....................... 14

Experiments with foxtail millet .................... 17

Experiments with Sudan grass. . . . . . . . . . . . . . . . . 17

Discussion and conclusions . . . . . . . . . . . . . . . . . . . 17

Experiments with field crops ......................... 18

Wheat on lowland soil ........................ 18

Discussion ................................... 25

Wheat on upland soil ........................ 26

Discussion ................................. 28

Oats on lowland soil .......................... 29

Discussion .................................. 31

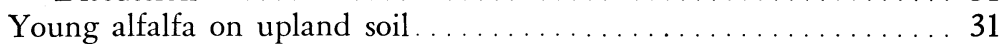

Discussion ............................... 34

Old alfalfa on lowland soil ....................... 35

Discussion .................................. 38

Sorghum on lowland and upland soils ................ 40

Discussion ............................... 42

Maize on lowland soil .......................... 42

Discussion ................................ 45

Conclusions ............................... 45

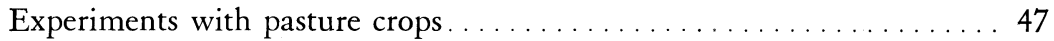

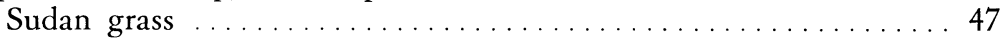

Discussion ................................. 51

Sweet clover ................................. 51

Rape .................................... 53

Discussion ................................ 53

Hungarian brome grass $\ldots \ldots \ldots \ldots \ldots \ldots \ldots \ldots \ldots \ldots$

Discussion ................................ 56

Rye ..................................... 57

Discussion ............................... 57

Conclusions ................................... 59

Experiments with garden crops ......................... 59

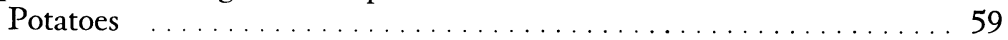

Sweet Potatoes ...................................661

Peas ...................................... 62 


\section{CONTENTS}

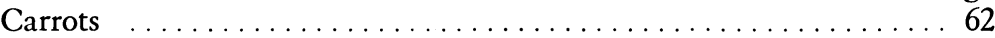

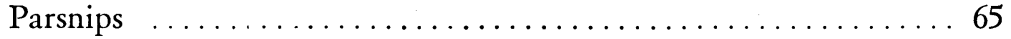

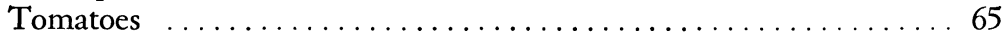

Discussion and conclusions .................. 67

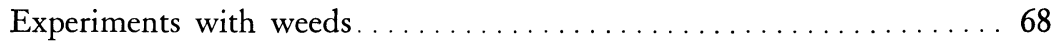

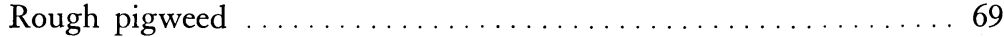

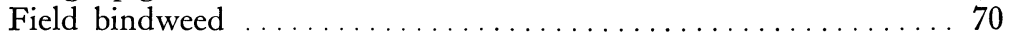

Knotweed ................................ 72

Little barley $\ldots \ldots \ldots \ldots \ldots \ldots \ldots \ldots \ldots \ldots \ldots \ldots \ldots \ldots \ldots$

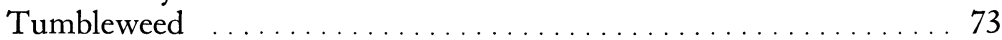

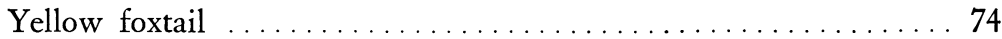

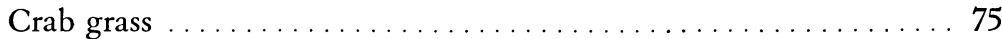

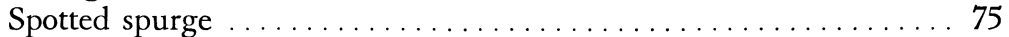

Dandelion ................................. 76

Discussion and conclusions .................. 76

Experiments with buckbrush and native grasses . . . . . . . . 80

Buckbrush ........................... 80

Bluegrass ............................ 81

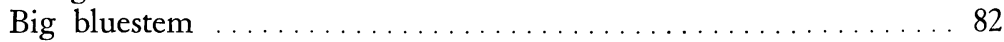

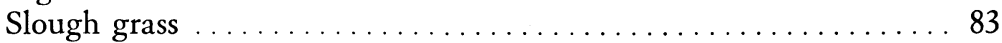

Discussion and conclusions................. 85

Relative amount of living underground plant materials . . . . . . . . 86

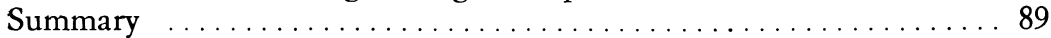

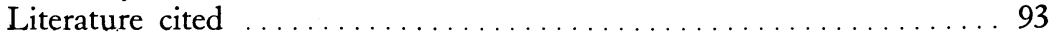




\title{
Relative Efficiency of Roots and Tops of Plants in Protecting the Soil from Erosion
}

\author{
INTRODUCTION
}

An increasing realization of the importance of preventing or controlling soil erosion has resulted in numerous scientific investigations. Some of these are concerned with soil characteristics which promote or retard erosivity (Middleton, '30; Middleton et al., '34; Lutz, '34; and Bouyoucos, '35). Many have to do with engineering methods of reducing soil wastage (Bates and Zeasman, '30; Ramser, '30; Roe, '33; and Bartel, '35). But perhaps most were planned to discover the effects of plants in protecting and binding the soil, reducing runoff, and consequent loss of soil and subsoil (Sampson and Weyl, '18; Duley and Miller, '23; Lowdermilk, '30; Forsling, '31; Miller and Krusekopf, '32; Bennett, '34; and Uhland, '35). ${ }^{1}$ Since a plant cover, either natural or cultural, is the main single controllable factor in erosion, an exact understanding of its effects is of extreme importance.

So far as the writers are aware, no attempt has been made to ascertain the rate of erosion of soil protected by both tops and roots of plants, or by underground plant parts alone, as compared with similar soil free from living plants.

Aside from the purely scientific aspects of the problem, immediate practical applications are found in crop growing, range and pasture management, orcharding, and most industries where production of crops is concerned.

In agricultural practice the tops of alfalfa, clover, and other mowed crops are removed close to the ground one or more times each growing season. Wheat and other small cereals may be headed and the straw left standing; the straw may be burned to the ground, or bound and removed in harvesting and accumulated in threshing into a single pile. Pastures and ranges may be so well managed that a covering of 15 to 25 per cent of the forage remains to protect the soil even at the end of the growing season, or so closely grazed and trampled as to leave the soil almost bare. Cover crops may or may not be used in orchards. Soil of gardens may be protected by dead plant remains, straw mulch, etc., or left bare and at the mercy of wind and water.

After a consideration of the problem of further analyzing the effects of plants, and the development of a successful method of attack (Weaver and Harmon, '35), the spring, summer, and fall of 1935 were devoted to this study.

1 In a recent publication (Weaver and Noll, '35) many of the more important researches on runoff and erosion have been discussed and the literature cited. 


\section{METHODS}

Stout frames one meter long and one-half meter wide inside, and ten centimeters deep (i.e. $393 / 8 \times 195 / 8 \times 4$ inches) were made of planed cypress lumber about one inch thick. The corners were firmly reinforced outside by angle irons held in place by screws. The frames were taken to the field and placed over the samples carefully selected as representative of the area. Pairs of samples were taken only a few inches to a few feet apart. Great care was taken that the tops of all plants rooted inside the half square meter were included and those rooted outside excluded. Tops of plants immediately surrounding the frames were then removed. Care was exercised not to damage the plants within one frame. With tall plants it was sometimes necessary to build a temporary supporting lattice. work about them or at least to tie the tops in such a manner that they gave each other mutual support. The tops from the second sample were removed close to the soil by clipping either at once or after the sample was excavated.

A spade with a sharp, straight blade was used in cutting the core of soil to a depth of 4 inches around the frame in such a manner that the frame could be forced to this depth in the soil, holding firmly the enclosed one-half square-meter sample. Where the tops of plants were removed at once, a temporary top to the frame was nailed in place to hold firmly the soil when the frame with the enclosed sample of soil was inverted. Laths nailed to the edges of the frame and between the rows of wheat, young alfalfa, tomatoes, etc., were used for the same purpose when the tops of plants were left intact.

The frame was next undermined by digging the soil from the ends and, especially, from both sides in such a manner that a blunt wedge was formed from the soil core protruding beneath the frame. The depth of the wedge varied with soil structure and water content.

The frame was then tipped carefully on its side, but only after a sufficient excavation had been made so that the tops of the brome grass, wheat, or other crop, sometimes over 3 feet tall, would not be crushed against the soil. Where the tops had been clipped the frame was entirely inverted, the soil cut evenly with its lower edge, a tight bottom nailed in place, and the frame then righted. After transporting to the greenhouse, the temporary top was removed. Where tops of the plants were intact, the excess soil was removed and the bottom very carefully fastened in place while the frame lay on its side. The whole process, although apparently simple, was successfully accomplished only after considerable experience and with the cooperation of two field men. After the sample was secured, it was transplanted in a normal, erect position (Fig. 1). 


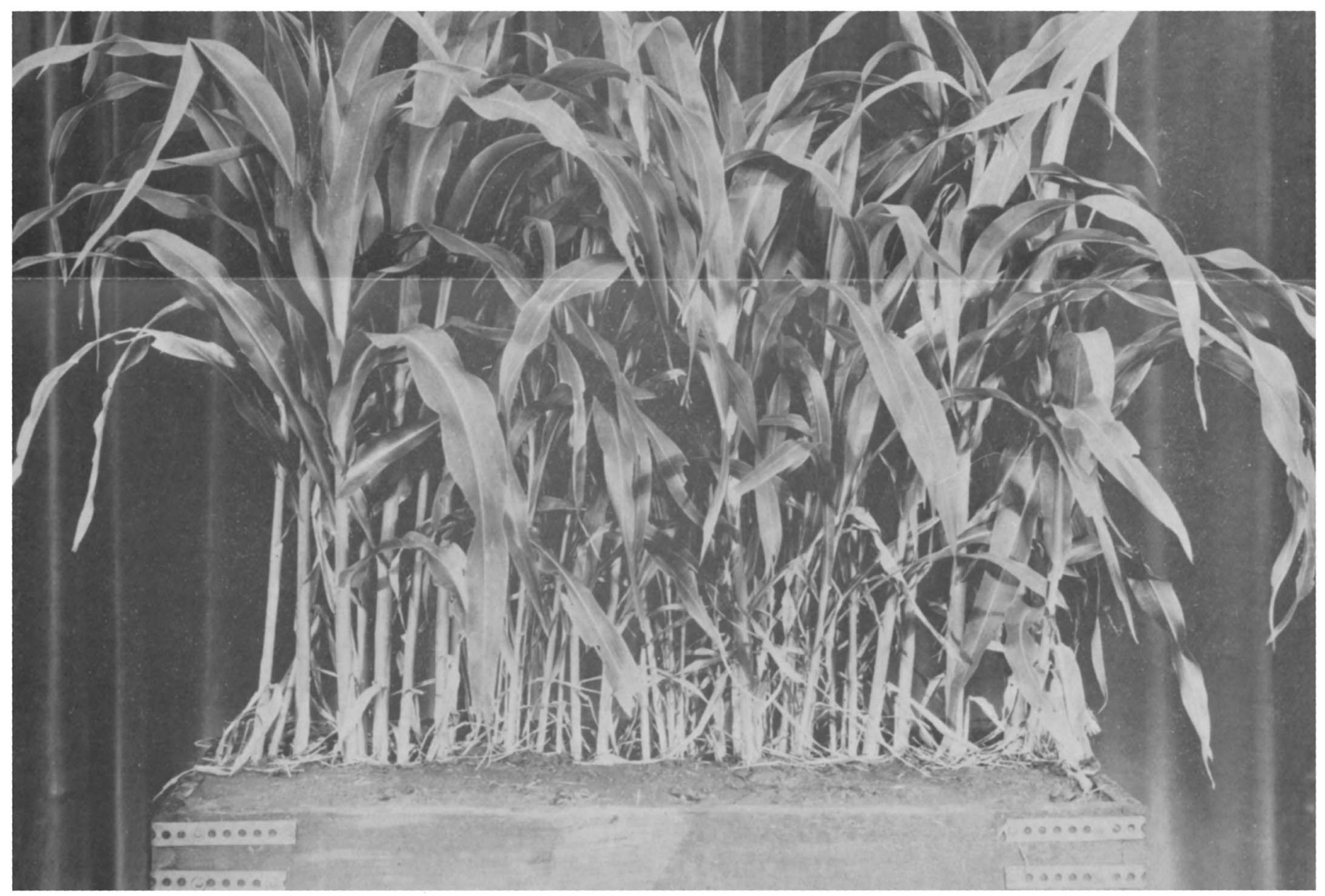

FIG. 1.-Insert-Sample of soil one-half square meter (5.38 sq. ft.) in area and 4 inches deep. It was secured without disturbing the structure of the soil or the sorgo plants rooted therein. 


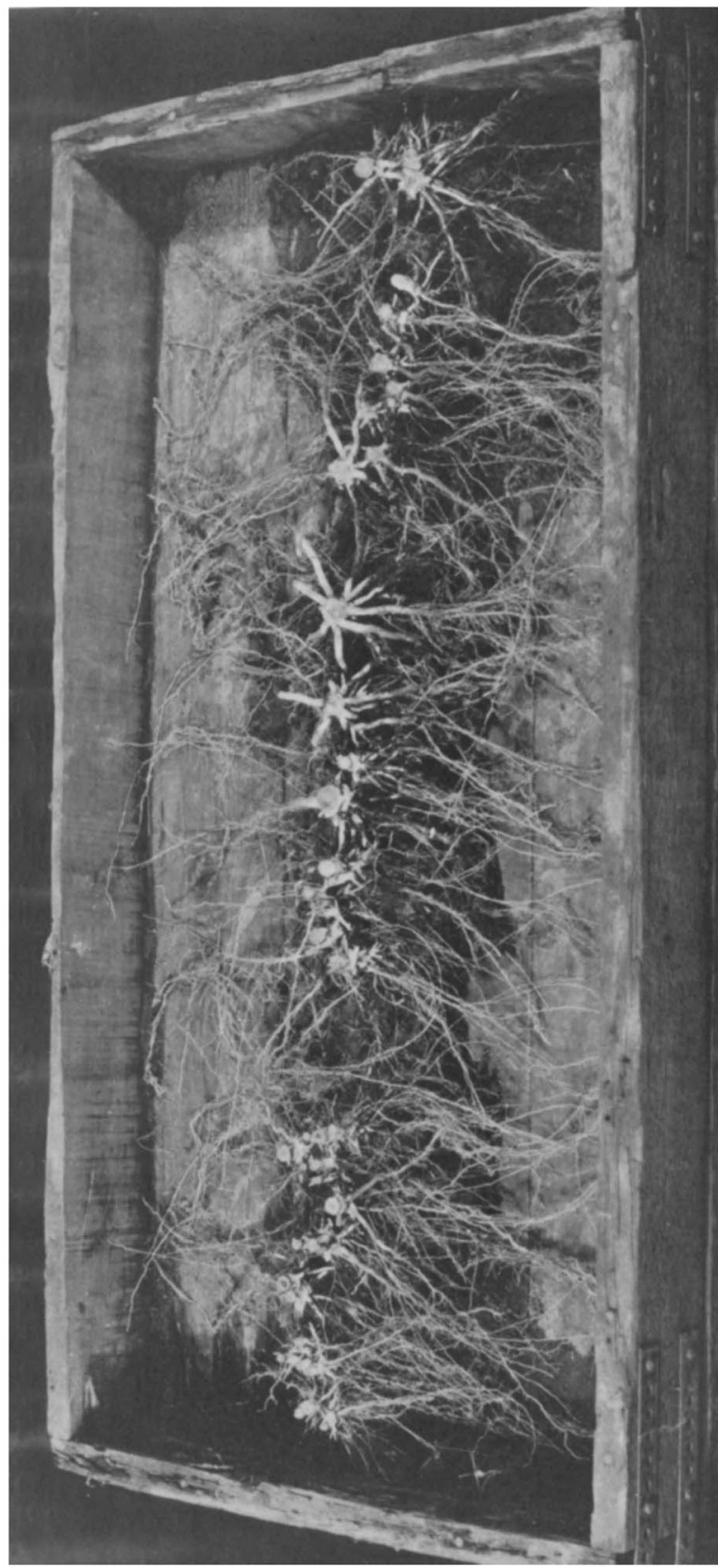

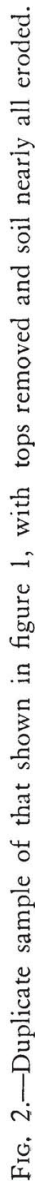


With a few crops, such as potatoes, sweet potatoes, and peas, where the soil had been ridged against the plants in tilling, a triangular strip of one-inch lumber was nailed upright to each end of the frame. This was 3 inches high in the middle but tapered to only one-eighth inch at the ends. Thus when the sides of the frame were sunk to a depth of 4 inches on each side of the row, the top when attached had the appearance of a roof, and held the soil in place around the bases of the plants.

Since each sample contained 1.79 cubic feet of soil of approximately 170 to 200 pounds in weight, securing it was arduous and painstaking work. If the soil were either too dry or too wet there was grave danger of breaking the column or of losing a part of the loose surface in securing the sample. After midsummer, preliminary watering was necessary in most cases. But with proper precautions borne of experience these difficulties were overcome, and no sample was used where soil structure was at all disturbed.

Upon reaching the greenhouse the soil was thoroughly watered, several times if necessary, until no dry soil remained. The frame was then placed lengthwise on a washing rack with a slope of $10^{\circ}$. A second frame of the same size but 12 inches deep was placed upon the first. It was held by a number of iron braces fitting over the frame beneath. A meter strip of wood, 1.25 inches wide and 3/16 inch thick, was permanently fastened within the frame, one on the lower side of each wall, so that its edge protected the soil in the lower frame. Thus in eroding the soil no water came directly in contact with the sides of the lower frame until at least the upper 2 or 3 inches of soil were removed. A strip one inch wide had been removed from the lower end of the upper frame to permit surface soil to escape during this process, and 4 one-inch holes were bored in the lower end of the lower frame to furnish an exit for the water and eroded soil after the top of the soil had been worn away.

Methods of eroding the soil were essentially the same as those employed by Weaver and Harmon ('35). Water was always supplied from the same hydrant with the same hose and nozzle and at a uniform distance of 2 feet (unless otherwise stated) from the surface of the soil. Care was taken to move the hose slowly back and forth in a regular manner so that the stream played for only an instant on any one portion of the soil. In nearly all cases with tilled crops, eroding was done without a nozzle, but in certain pasture and native grasses a nozzle was used to increase the force of the stream of water, at the same time reducing its size and volume. The open hose delivered 12.73 gallons of water per minute under a total force of about 1 pound over an area of approximately 1.5 square inches. When the nozzle was used the volume of water was reduced to 3.42 gallons per minute, and the force of 1.39 pounds was concentrated within an area of only about 0.11 square inch. Con- 
sequently it had a great erosive effect. These forces were measured directly by directing a stream from the hose on the pan of an appropriate balance sensitive to one gram. Slight variations in water pressure occurred from time to time but this was of little moment since pairs of samples were always eroded at the same time.

The objective sought was to erode the whole surface of the soil as uniformly as possible until the entire sample disappeared. This was especially difficult to accomplish where the soil was protected by a plant cover. If all of the soil had been eroded in places, obviously additional water on the bottom of the box would have merely prolonged the erosion time. Consequently, before this point was attained, a trained helper determined where ridges and columns of soil were holding longest and the operator directed the stream of water upon them. The necessary uniformity of method, essential to consistent results, was attained by the same investigator directing where the stream should fall.

Tall plants, such as oats, Sudan grass, etc., in lodging, frequently extended beyond the surface of the sample, especially at the lower end of the frame. The overlapping parts were removed by clipping and added to the upper end of the frame. This compensated the absence of tops of similar plants which would have normally lodged here. In other words, the cover was exactly the same as that of one-half square meter of a lodged crop taken from the field, only it consisted of all of the parts of the plants growing in this unit area. No trouble was experienced by the cut tops floating away. They remained in place as firmly as those rooted in the soil.

Roots and other underground plant materials were caught upon a large screen, with 11 meshes per inch, attached near the end of the box and through which all of the water and eroded soil had to pass. Repeated trials showed that practically no plant materials $-1 / 10$ of one per cent or less-were lost through the screen. Since tops and underground parts were usually inextricably mixed after eroding with the tops intact, both weight of roots and tops were nearly always determined separately from the companion sample (Fig. 2). The accuracy with which duplicate samples were selected was checked, however, by frequently comparing the combined weight of tops and underground parts of the pairs of samples. They always gave very similar results.

The bulk of the underground plant parts remained in the box after erosion was complete; a few washed away with the soil. Most of the roots remained attached to the base of the crowns. They were placed on a washing rack where a $11-\mathrm{mm}$. mesh screen, which could be moved about, was supported by a coarser one. The crowns were torn apart and all soil removed by a gentle stream of water or by washing in large tubs of water. Recovery of the remaining roots was far more difficult. These materials were placed in water in large containers and the water stirred 
vigorously. Much debris floated to the surface and was quickly removed. The operation was repeated several times and the soil washed away through a copper screen of 28 -inch mesh. Any remaining debris was retained with the roots on the screen. Abundant weed seeds were the most difficult to discard. Often the root-fragments were recovered by means of tweezers. With young crops complete separation of living roots from old dead ones and debris required many hours, but with older crops and improvement of method the time was greatly reduced.

Large taproots of sweet clover, carrots, alfalfa, etc., were separately weighed from the fibrous roots which were removed from them. Tops of all plants were washed free of soil or dust and, like the roots, dried at $105^{\circ} \mathrm{C}$. to a constant weight. After cooling in a desiccator the weight was determined to the nearest tenth gram.

In some experiments simulating rain, water was applied from a showerbath nozzle. This was held 4 feet directly above the frame. The full force of the water pressure was not used. Three and $1 / 10$ gallons of water were delivered per minute in 60 streams so gentle that each broke into a series of large drops just before striking the soil. They were spread over a circular area 13 inches in diameter which included 133 square inches. The total force with which the water struck the soil was $5 / 8$ pound. The hose was moved, as before, so that the water impinged for only an instant on any one part of the soil surface.

Soil from the surface 4 inches of fields was placed in the boxes in the greenhouse. A control was left unplanted, and the other boxes were planted to various crops. Repeated watering compacted the soil. In some cases mat-like or rosette plants from one-half square meter were removed at the soil surface and superimposed upon the soil, which was then eroded by sprinkling. It was soon found that this method, which more closely imitated nature's extremely variable phenomenon called rain, was far too slow (requiring 15 or more hours for seeedling crops) to employ over a wide range of plant cover.

\section{SOILS}

Although samples were taken from many different fields, gardens, pastures, and prairies, the soils are all included in two types, Carrington silt loam of the uplands and Wabash silt loam of the lower lands along the valley of Salt Creek and its tributary, Oak Creek. All samples were secured within a radius of about 3 miles of Lincoln, during the growing season of 1935. Both soil types occur widely in eastern Nebraska. Mechanical analyses from representative plats are given in Table 1 together with the moisture equivalents computed from the mechanical composition by the formula of Alway and Russel ('16). 
TABLE 1.-Mechanical analyses of representative soils near Lincoln.

\begin{tabular}{|c|c|c|c|c|c|c|c|c|c|}
\hline Depth of sample & $\begin{array}{c}\text { Coarse } \\
\text { gravel } \\
P . c t .\end{array}$ & $\begin{array}{l}\text { Fine } \\
\text { gravel } \\
\text { P.ct. }\end{array}$ & \begin{tabular}{|c} 
Coarse \\
sand \\
$P . c t$.
\end{tabular} & \begin{tabular}{|c} 
Medium \\
sand \\
$P . c t$. \\
\end{tabular} & $\begin{array}{l}\text { Fine } \\
\text { sand } \\
P . c t .\end{array}$ & $\begin{array}{l}\text { Very } \\
\text { fine } \\
\text { sand } \\
P . c t .\end{array}$ & $\begin{array}{c}\text { Silt } \\
P . c t .\end{array}$ & $\begin{array}{l}\text { Clay } \\
\text { P. ct. }\end{array}$ & $\begin{array}{c}\text { Moisture } \\
\text { equivalent } \\
\text { P.ct. }\end{array}$ \\
\hline $\begin{array}{c}\text { Carrington silt loam } \\
0.0 \text { to } 0.5 \text { foot. . } \\
0.5 \text { to } 1.0 \text { foot. . } \\
1 \text { to } 2 \text { feet. . } \\
2 \text { to } 3 \text { feet. . }\end{array}$ & $\begin{array}{r}0.0 \\
.0 \\
.0 \\
.0\end{array}$ & $\begin{array}{r}0.0 \\
.0 \\
.0 \\
.0\end{array}$ & $\begin{array}{r}0.3 \\
.2 \\
.1 \\
.1\end{array}$ & $\begin{array}{l}0.5 \\
.6 \\
.2 \\
.1\end{array}$ & $\begin{array}{l}1.6 \\
1.3 \\
0.8 \\
0.5\end{array}$ & $\begin{array}{l}19.8 \\
16.7 \\
16.7 \\
19.0\end{array}$ & $\begin{array}{l}48.6 \\
52.4 \\
55.6 \\
57.9\end{array}$ & $\begin{array}{l}29.2 \\
28.8 \\
26.6 \\
22.3\end{array}$ & $\begin{array}{l}31.4 \\
31.8 \\
31.5 \\
30.1\end{array}$ \\
\hline $\begin{array}{l}\text { Wabash silt loam } \\
0.0 \text { to } 0.5 \text { foot... } \\
0.5 \text { to } 1.0 \text { foot... } \\
1 \text { to } 2 \text { feet. . } \\
2 \text { to } 3 \text { feet. . }\end{array}$ & $\begin{array}{l}.1 \\
.3 \\
.2 \\
.0\end{array}$ & $\begin{array}{l}.4 \\
.7 \\
.3 \\
.1\end{array}$ & $\begin{array}{l}2.2 \\
2.1 \\
1.3 \\
0.4\end{array}$ & $\begin{array}{l}1.8 \\
2.2 \\
1.5 \\
0.5\end{array}$ & $\begin{array}{l}5.0 \\
5.0 \\
3.7 \\
1.7\end{array}$ & $\begin{array}{l}25.0 \\
25.4 \\
21.4 \\
19.2\end{array}$ & $\begin{array}{l}41.3 \\
38.8 \\
40.8 \\
43.4\end{array}$ & $\begin{array}{l}24.3 \\
25.8 \\
31.0 \\
34.7\end{array}$ & $\begin{array}{l}27.7 \\
27.9 \\
30.6 \\
32.9\end{array}$ \\
\hline
\end{tabular}

Data in Table 1 show that both soils are fine textured, being composed mostly of silt and clay. A study of the table shows that they are remarkably similar. In fact, the lowland soil is a colluvial phase of the Wabash silt loam type. Hygroscopic coefficients of these soils (first lines) together with those from certain other fields, where samples for erosion were taken, are given in Table 2 .

Data in Table 2 confirm those on physical analyses in showing that the soils are similar in texture, since hygroscopic coefficients afford an excellent criterion of this soil property. It seems probable that the slight inherent differences in texture are overbalanced by differences in structure as affected by time and method of cultivation, seedbed preparation, and previous type of cropping. Any apparent differences in soil compaction are consequently noted; they are practically similar in any pair of samples since the samples were taken very closely together.

TABLE 2.-Hygroscopic coefficients (per cent) of various upland and lowland soils.

\begin{tabular}{r|r|r|r|r|r}
\hline \hline Depth of sample & 0-6 in. & $6-12$ in. & $1-2 \mathrm{ft.}$ & $2-3 \mathrm{ft.}$ & $3-4 \mathrm{ft.}$ \\
\hline Carrington silt loam...... & 9.8 & 10.9 & 10.1 & 10.0 & 10.3 \\
Do, Upland alfalfa ...... & 10.4 & 12.5 & 13.2 & 12.0 & 12.0 \\
Do, Upland wheat ...... & 9.9 & 11.8 & 13.0 & 12.8 & 11.5 \\
Wabash silt loam ........ & 10.0 & 9.6 & 9.2 & 11.1 & 10.8 \\
Do, Sudan grass....... & 10.6 & 11.1 & 11.3 & 8.7 & 8.6 \\
\hline
\end{tabular}

Chemical composition of representative composite samples of soil at various depths from the two areas represented in Table 1 have been made. A study of these shows that the soils are not strikingly different. The lime content is about the same in both fields. However, the greater amount of volatile matter and the greater nitrogen-content at all depths indicate 
conditions more favorable for growth in the Wabash silt loam. Because of run-in water, water content of this soil is usually higher. The soils of both types showed medium acidity in the first foot, slight in the second, very slight in the third, while the fourth foot showed no acidity but was slightly calcareous. All of the soils sampled for erosion experiments, except those of pasture and prairie, have been cropped for many years.

\section{EXPERIMENTS SIMULATING RAIN}

Some preliminary experiments were performed with sunflowers, millet, and Sudan grass. The soil was obtained from an upland cornfield. It was screened to remove any coarse debris and the whole thoroughly mixed. The frames with bottoms attached were then filled, the crop planted, and the soil kept in a good condition of moisture until the experiment was begun. The plants were grown in a greenhouse.

\section{EXPERIMENTS WITH SUNFLOWERS}

Seeds of sunflower (Helianthus annuus L.) were planted at the rate of $30 \mathrm{lbs}$. per acre ( 35 plants per one-half square meter) in the greenhouse on August 12. A month later the plants were about 20 inches tall and each had 6 or 8 large leaves (Fig. 3). The bare soil was completely eroded in 18.5 minutes. A single elm leaf had blown into the box and it was noticed that the soil below it did not erode until a column over 3 inches high, capped by the leaf, had been formed. It was then undercut by the water and toppled over.

Water was then applied to the soil from which the tops of the plants had been removed. The bases stood firmly anchored by strong lateral roots radiating in all directions. Some of these roots extended horizontally the entire length and width of the box. Although the surface half-inch of soil was readily removed, the roots in the deeper layers were so numerous as to form a glistening white mat which effectively resisted the impact of the water (Fig. 4). Each of the stem-bases formed a miniature dam against which the soil was temporarily held. Not until water had been applied for 4 hours and 19 minutes was the soil entirely eroded. The tops yielded a dry weight of $52.5 \mathrm{gm}$., the taproots $3.4 \mathrm{gm}$., and their fibrous branches, which constituted most of the root mat, $7.7 \mathrm{gm}$.

In the undisturbed sample the tops lodged within 5 minutes, and after an hour, when the topsoil had been loosened, lay flattened on the soil. The 35 plants afforded much protection to the soil and broke the force of the water. After two hours the root-mass was fairly well exposed and furnished much additional protection to the deeper soil. The experiment was continued for 9 hours. The leaves and stems were still intact and with the roots had retained 1.5 inches ( 38 per cent) of bottom soil against erosion. 


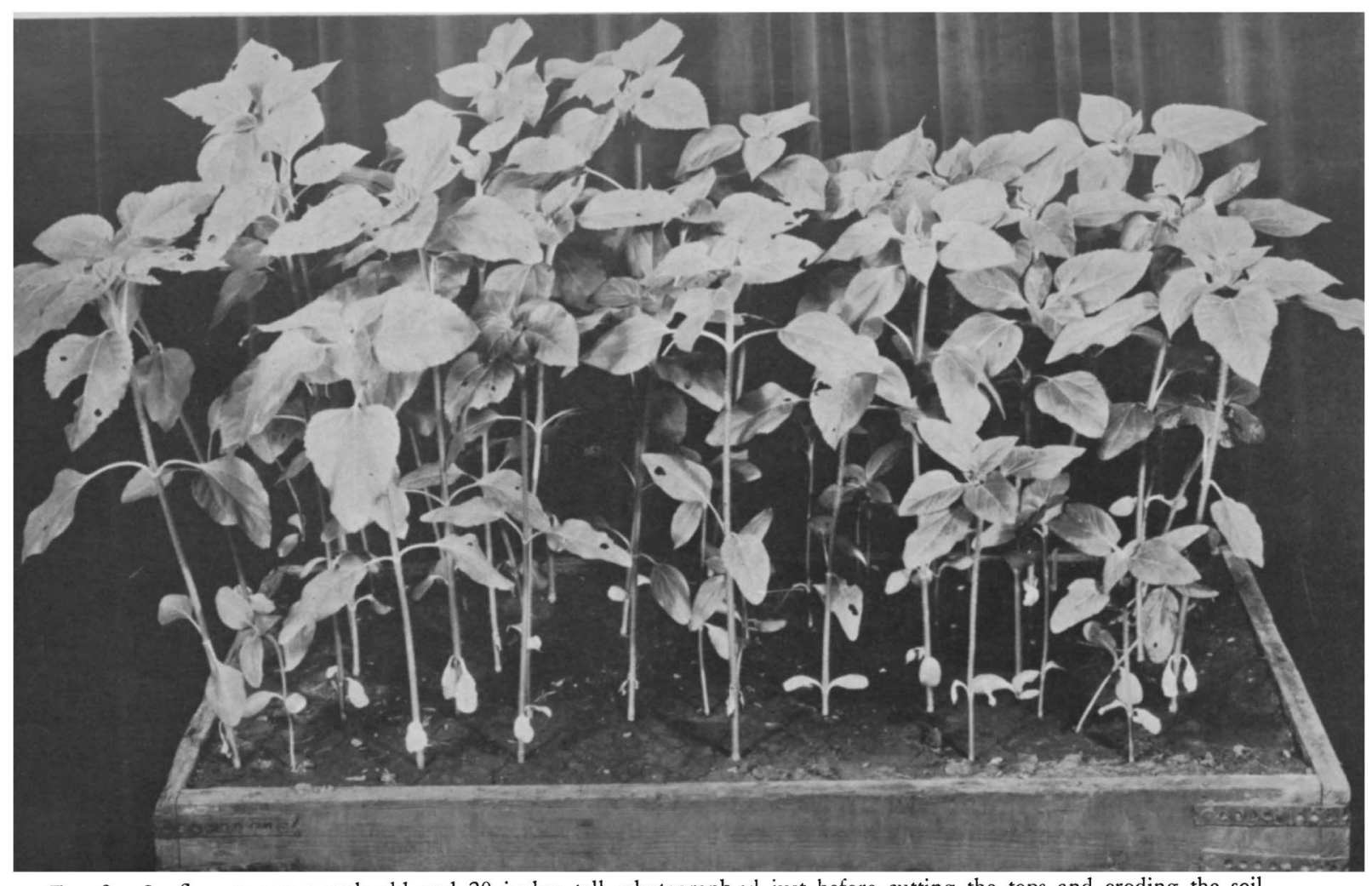

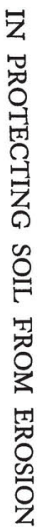

FIG. 3.- Sunflowers one month old and 20 inches tall, photograph $\epsilon \mathrm{d}$ just before cutting the tops and eroding the soil. 


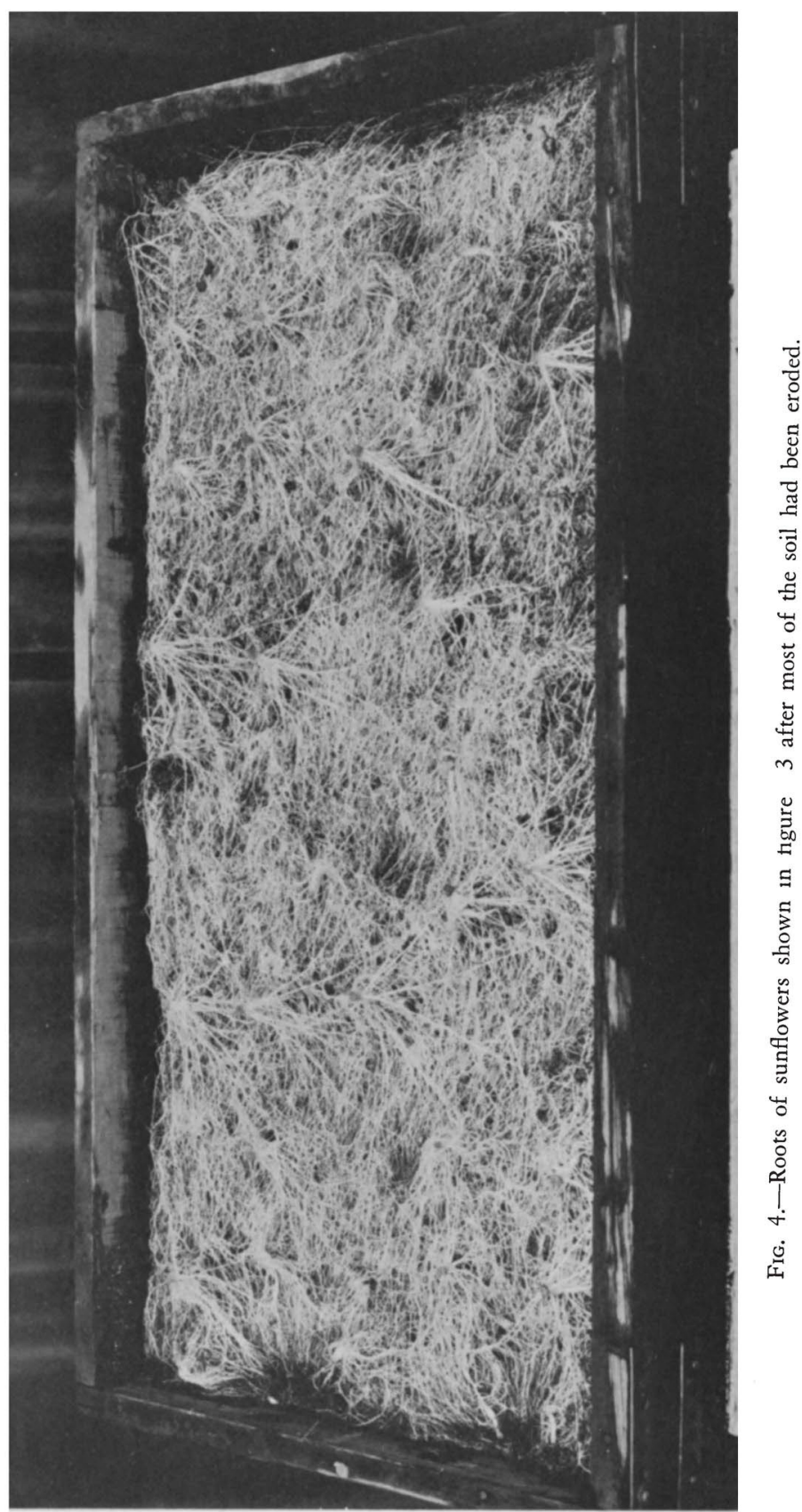




\section{EXPERIMENTS WITH FOXTAIL MILLET}

Millet (Setaria italica (L.) Beauv.) was sown at the rate of 25 lbs. per acre in the greenhouse on August 12. Thirty days later it presented a uniform stand of plants 11 inches tall, each with 5 to 7 leaves. The plants averaged nearly 1 per square inch. While the bare soil withstood erosion for only 18.5 minutes, that from which the tops of the plants had been removed held out for 112 minutes. This resulted from the network of fibrous roots which thoroughly threaded the soil. The stem-bases, although soon losing their erect position, served as efficient centers for root attachment.

The unclipped millet lodged immediately, the leaves and stems offering nearly complete protection to the soil beneath. In only a few places was the black soil visible. Hence erosion occurred slowly. Where a layer of cover the thickness of a single grass leaf intervened, erosion was indeed slow. The green carpet of plants sank slowly but kept intact as hour after hour passed. After 12 hours of erosion only $2 \frac{1}{8}$ inches of soil (53 per cent) had been removed. It seems certain that an additional 12 hours would have been necessary to complete the process.

\section{EXPERIMENTS WIITH SUDAN GRASS}

Seed of Sudan grass (Sorghum vulgare var. sudanense (Piper) Hitchc.) was sown on September 9. A month later the plants were in the fifthleaf stage of development and 5.5 inches tall. There were approximately 675 plants in each box which was somewhat less than 1 per square inch. Two boxes of bare soil eroded in 16 and 17 minutes, respectively. Where the $15.8 \mathrm{gm}$. (dry weight) of tops had been removed, time for complete erosion was extended to 2 hours and 41 minutes. This resulted from the protection and resistance offered by only $12.1 \mathrm{gm}$. of stem-bases and fine fibrous roots.

Erosion with tops intact took place very slowly and in the manner described for millet. After 12 hours, 1.4 inches or 35 per cent of the soil still remained. It was completely covered with the flattened tops and masses of roots. Upon removal of these, complete loss of the remaining soil occurred in 41 minutes.

\section{DISCUSSION AND CONCLUSIONS}

The results of these preliminary experiments are summarized in Table 3. The rapidity with which the bare soil was eroded is no less striking than is the effect of the roots and stem-bases in holding the soil in place. In this respect the better developed and more firmly anchored taproot system far exceeded that of the grasses. The rather unnatural condition of all of the roots being confined to the box did not increase their numbers. The same barriers that kept the roots from extending outward would have, under field conditions, kept the roots of neighboring plants from entering 
TABLE 3.-Rate of erosion of unprotected soil and soil protected by a crop.

\begin{tabular}{c|r|r|r|r|r|r|r|r}
\hline \hline \multirow{2}{*}{ Cover } & $\begin{array}{c}\text { No. } \\
\text { plants }\end{array}$ & $\begin{array}{c}\text { Height } \\
\text { in. }\end{array}$ & \multicolumn{2}{c|}{ Dry wt., gm. } & \multicolumn{4}{|c|}{ Erosion time } \\
\cline { 4 - 8 } & & $\begin{array}{c}\text { Roots, } \\
\text { etc. }\end{array}$ & $\begin{array}{c}\text { Bare } \\
\text { soil } \\
\text { Min. }\end{array}$ & $\begin{array}{c}\text { Without } \\
\text { tops } \\
\text { Hrs. Min. }\end{array}$ & $\begin{array}{c}\text { With tops } \\
\text { Soil left } \\
\text { P. ct. }\end{array}$ \\
\hline Sunflowers ... & 35 & 20.0 & 52.5 & 11.1 & 18.5 & 4 & 19 & $9+38$ \\
Millet ...... & 710 & 11.0 & 45.2 & 9.5 & 18.5 & 1 & 52 & $12+47$ \\
Sudan grass... & 675 & 5.5 & 15.8 & 12.1 & 16.5 & 2 & 41 & $12+35$ \\
\hline
\end{tabular}

the area. The most striking feature of all was the remarkable manner in which the tops of the young plants protected the surface of the soil for long periods of time. In this respect the grasses were somewhat more effective than the dicotyledonous species. This protection was due to a plant cover of only 282 to $807 \mathrm{lbs}$. per acre (dry weight) in case of the grasses, and $937 \mathrm{lbs}$. per acre of sunflowers. Completeness of cover was the cause of this remarkable resistance to erosion.

It was not the soil-binding effect of the roots that produced the utmost protection but the plant cover which did not permit most of the water to come in direct contact with the soil. With the cover intact, the considerable checking of erosion afforded by the roots was powerfully reinforced by the presence of the tops.

These experiments also clearly show the inadequacy of this method of applying water, because of the extreme slowness of erosion, where the relative efficiency of the tops and underground parts of the mature crops or well established grasses in preventing soil erosion are to be compared.

\section{EXPERIMENTS WITH FIELD CROPS}

\section{WHEAT ON LOWLAND SOIL}

A series of 8 pairs of samples of Turkey Red winter wheat (Triticum aestivum L.) was employed. The samples were taken from a field of lowland soil once in late fall and throughout spring and summer of 1935. The final samples were secured about a month after harvest.

The first pair was dug on November 10, when the plants were 2 inches tall. Although the plants had assumed the prostrate habit of winter, yet they covered only one-third of the soil. Samples were always taken parallel with the rows, each frame holding three rows one meter long, the outer rows being about 3 inches from the sides of the frame (Fig. 5). The depth and lateral spread of the root system at this stage of development is shown in Figure 6. Although some variation occurred in depth of planting, it may be seen from Figure 6 that there were very few underground parts to anchor the surface 2 inches of soil.

Upon applying water with the open hose the loose top soil quickly eroded to a depth of an inch, after which firmer soil was removed more slowly. Complete removal of the soil, where the tops of the plants had 


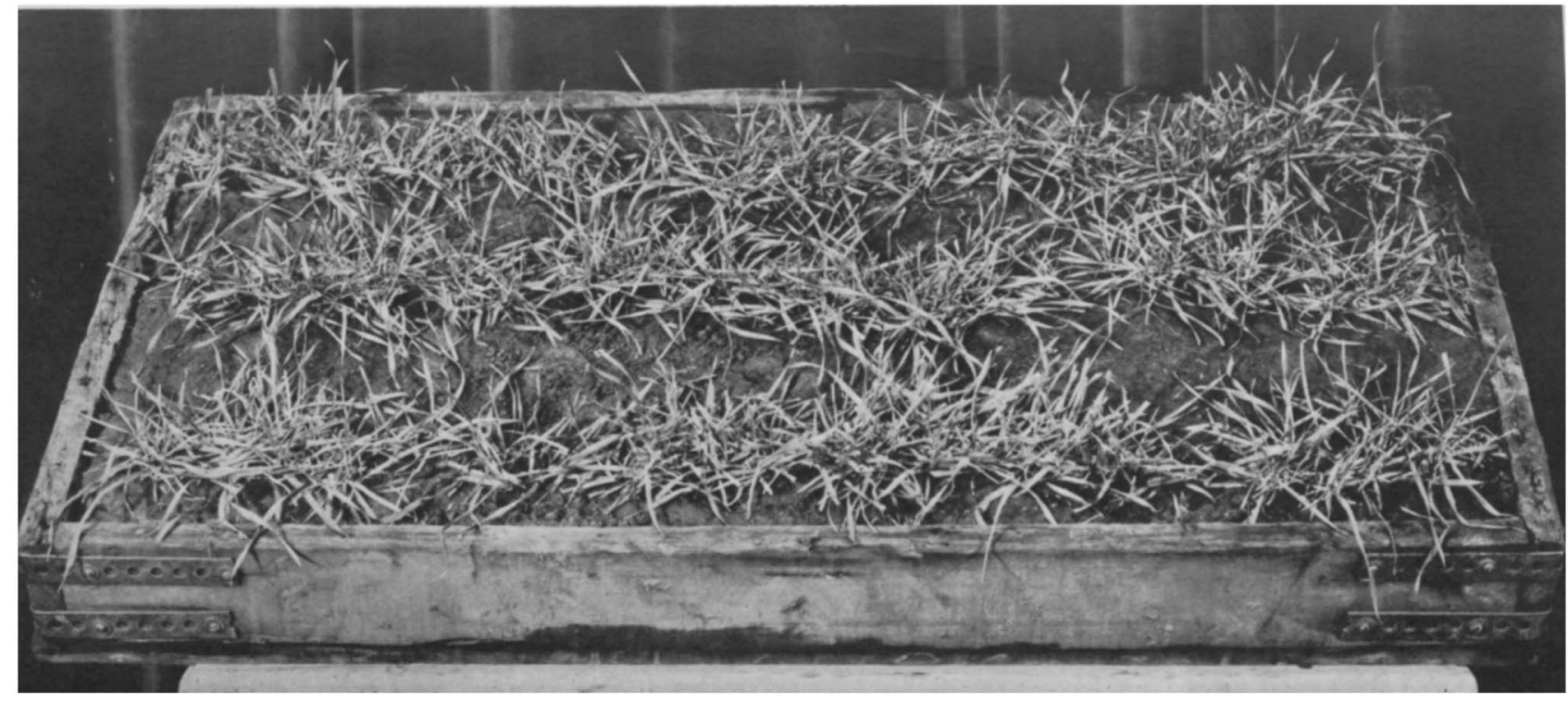

Fig. 5.-Sample of winter wheat taken on November 10. The plants are about 2 inches tall and much bare soil is exposed. 
been cut away, required a period of only 7 minutes. Some protection was afforded by the tops of even these young plants and where they were intact the erosion time was prolonged to 11 minutes. The dry weight

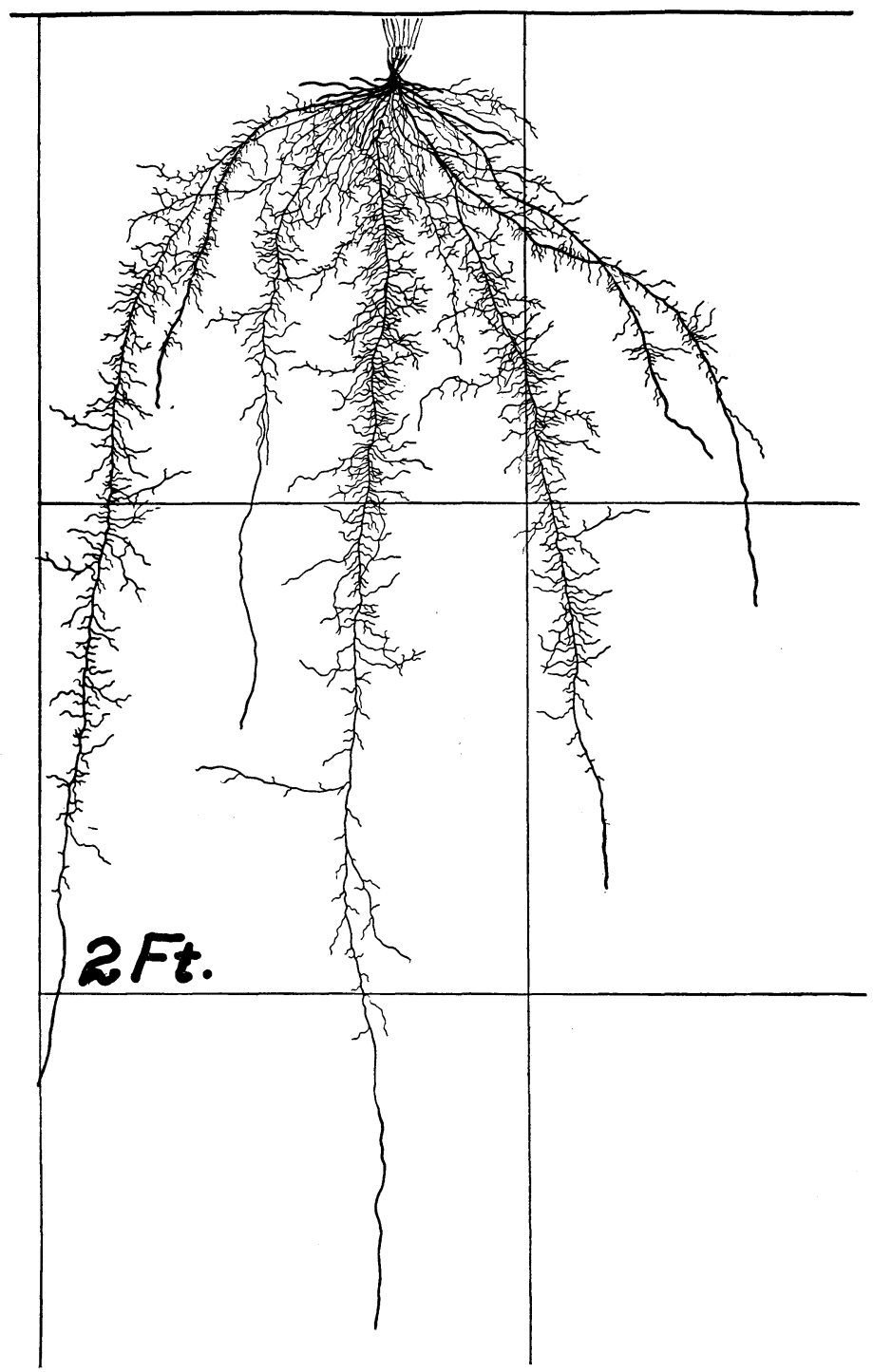

FIG. 6.--Root system of a single plant of winter wheat 40 days old 
of tops was $21 \mathrm{gm}$; likewise, the young tender bases and root systems in the first four inches of soil gave a dry weight of only $15 \mathrm{gm}$.

The first samples in spring were taken on April 12, when the plants were 3 inches high and had a total spread of leaves of 6.5 inches. The foliage covered approximately one-third of the soil. Upon the application of water, the loose surface soil to a depth of 1 to 1.5 inches was rapidly eroded. The rows of wheat, with and without tops intact, offered considerable resistance thereafter and the plants remained upright, just as when the subsoil held the deeper roots, until all but the last half-inch of soil had been washed away. The rows were thus plainly demarked and even a single plant missing in the row made a noticeable difference in the rate of soil removal. The dry weight of the root-crowns and roots was now increased to only $21.6 \mathrm{gm}$; the tops weighed nearly the same, 23.5 gm. To erode the soil from the clipped plants required 7 minutes; from the unclipped, 11.

The third pair of samples was secured on April 29, when the rapidly growing, erect plants were heavily tillered. The height was 7 inches. In addition to the 82 parent plants in the sample with tops removed there was an average of 7.5 tillers per plant. The foliage cover was approximately 40 per cent and its dry weight had increased to $88 \mathrm{gm}$. The old roots now interlaced fully between the rows in the surface 4 inches and new roots were abundant. Their dry weight, including stem-bases below ground, was $38 \mathrm{gm}$.

The sample with tops removed was completely eroded in 11 minutes, although the crowns stood firmly in the rows until almost all of the soil was gone. The soil between the rows was eroded much more rapidly, and after it was removed the sides of the three ridges of soil held by the roots were then exposed to erosion as well as the tops. Where the tops were left intact, they stood entirely erect until the first inch of soil was removed. The stems and leaves then began to flatten against the soil, taking on somewhat the old rosette position, and furnishing much protection. The rows stood firmly even after the soil between them was entirely removed. In places the leaves were so thick that they broke the impact of the water and shed it like a thatched roof, thus diverting it away from the soil beneath. Erosion time was consequently increased about 73 per centto 19 minutes.

The young spikes were plainly visible in the swollen sheath-early "boot" stage-on May 17, when samples were again taken. The plants gave a uniform stand about 20 inches tall, and the foliage cover ( 60 per cent) obscured more than half of the soil. Very few weeds were present, and these were mere seedlings only one-half inch or less in height. The 75 parent stalks with an average of 5.4 tillers gave a total dry weight of 
$247 \mathrm{gm}$. The parts underground weighed $70 \mathrm{gm}$. Thus both tops and roots had undergone much development since the preceding sampling.

Dry weight of roots and tops of the undisturbed sample was also determined. It had only 65 plants, but there were 5.8 tillers per plant. The dry weight of tops exceeded that of the denuded sample by only $3.9 \mathrm{gm}$. and that of the underground parts by about $1 \mathrm{gm}$. Although these weights were unusually similar (a third lot weighing $204 \mathrm{gm}$.) yet no extreme differences were found in any of the pairs of samples of various plants selected for study.

The soil in which the clipped plants grew was eroded in only 13 minutes, just 2 minutes more time being required than in the preceding denuded sample, although the weight of underground parts had increased 84 per cent. Erosion time for the undisturbed sample, however, was somewhat more than doubled, i.e. increased from 19 to 40 minutes. This was in accord with the greater development of tops.

After 2 minutes of watering, the tops spread widely, a few stems were lodged but most stood erect. After 10 minutes, about one-half were lodged, and all had fallen after 20 minutes when nearly two-thirds of the soil had been washed away. The bases of the stems were rigid and held firmly long after all the soil between the rows had been removed.

When the wheat was flowering, on June 5, a fifth pair of samples was secured. The plants were 3 feet tall and afforded a foliage cover estimated at 75 per cent. There were no weeds. The 60 plants in the sample with tops removed had an average of 8.5 tillers each. When the 417 $\mathrm{gm}$. of tops were clipped the soil was eroded in 17 minutes. This was 4 minutes longer than was required on May 17. The stream of water, directed vertically against the plants, caused them to lodge down the $10^{\circ}$ slope after about an inch of the surface soil was washed away. This occurred after a period of 8 minutes. Adjustment was then made so that the lodged cover was distributed uniformly, as has been described under methods. The stems and leaves formed an effective thatch against the force of the water, and the time for complete erosion was increased to 59 minutes.

The heads were rapidly filling and most kernels were in the early "dough" stage on June 19. The crop stood erect at a height of 45 inches (Fig. 7). The stems were of greater diameter and much heavier than on June 5. The basal leaves were mostly dead to a height of 12 inches but still clung to the stems. The foliage cover had now attained 100 per cent, no soil being visible when the crop was observed from above. The 523 stems of the denuded sample weighed $520 \mathrm{gm}$., and the underground parts $74 \mathrm{gm}$. Thus while the tops had increased one-fourth in weight, the roots had made no gain.

The bared sample was eroded in 16 minutes. The unclipped wheat began to lodge at once under the impact of the water. This also occurred 


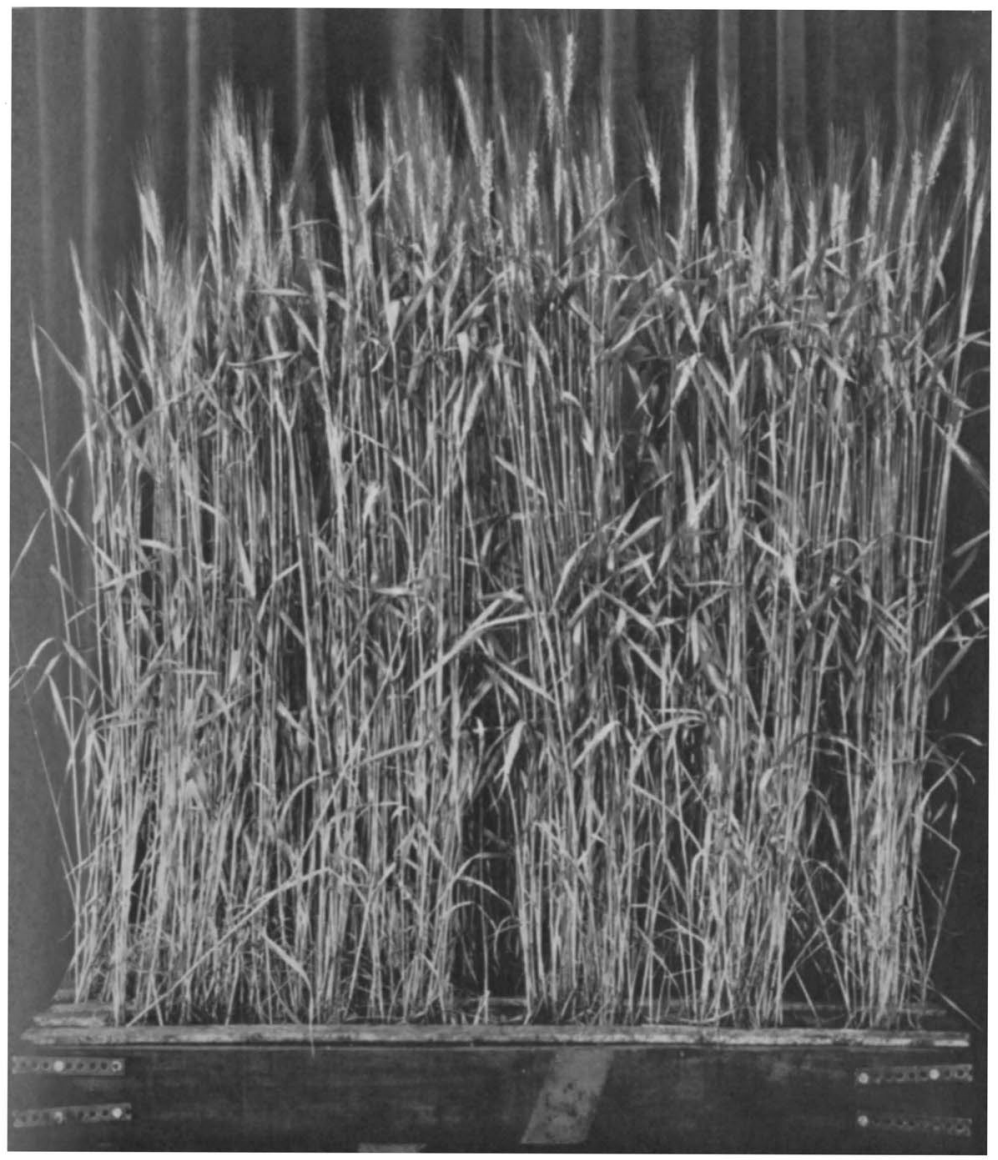

FIG. 7.-Sample of lowland soil with wheat 45 inches tall, taken on June 19.

in the field the day after the samples were taken when a .91-inch rain fell during a period of 35 minutes. For a time the layer of broken leafy stems of the experimental sample was 6 to 12 inches from the soil. It formed such an efficient screen that after 5 minutes the runoff water was almost clear. Gradually the cover settled closer to the earth as the hold of the roots was slowly weakened, but the process was indeed slow. The great mass of roots held firmly, since the impact of the water was broken, and erosion proceeded slowly. By the end of the hour soil had been removed to the bottom of the box in only a very few of the least protected places. Finally, the soil between the rows gave way but the 
rows themselves held, each as a separate unit, and only after one hour and 53 minutes was all of the soil removed.

The last sample before harvest was secured on July 2 when the grain was rapidly ripening. It was harvested four days later. The heavy ears caused the stalks to lean somewhat so that they were now only 42 inches instead of 45 inches tall. The crop had suffered from an epidemic of rust. All of the leaves had withered, shriveled, and dried; the stems alone were green. The foliage cover was still approximately 100 per cent. No increase in dry weight of tops (521 gm.) had occurred since the previous sampling, although the number of plants remained the same. The underground parts showed a slight decrease, from 74 to 65 gm. (cf. Fig. 8).

Soil from the denuded sample was eroded in 15 minutes. The unclipped plants lodged almost at once under the impact of the stream of water. One hour and 39 minutes was required for complete erosion. This decrease in efficiency in the ripening stage resulted from the shriveling of the leaves.

Final samples from the stubble field were taken on August 5. Owing to dry weather, the usual growth

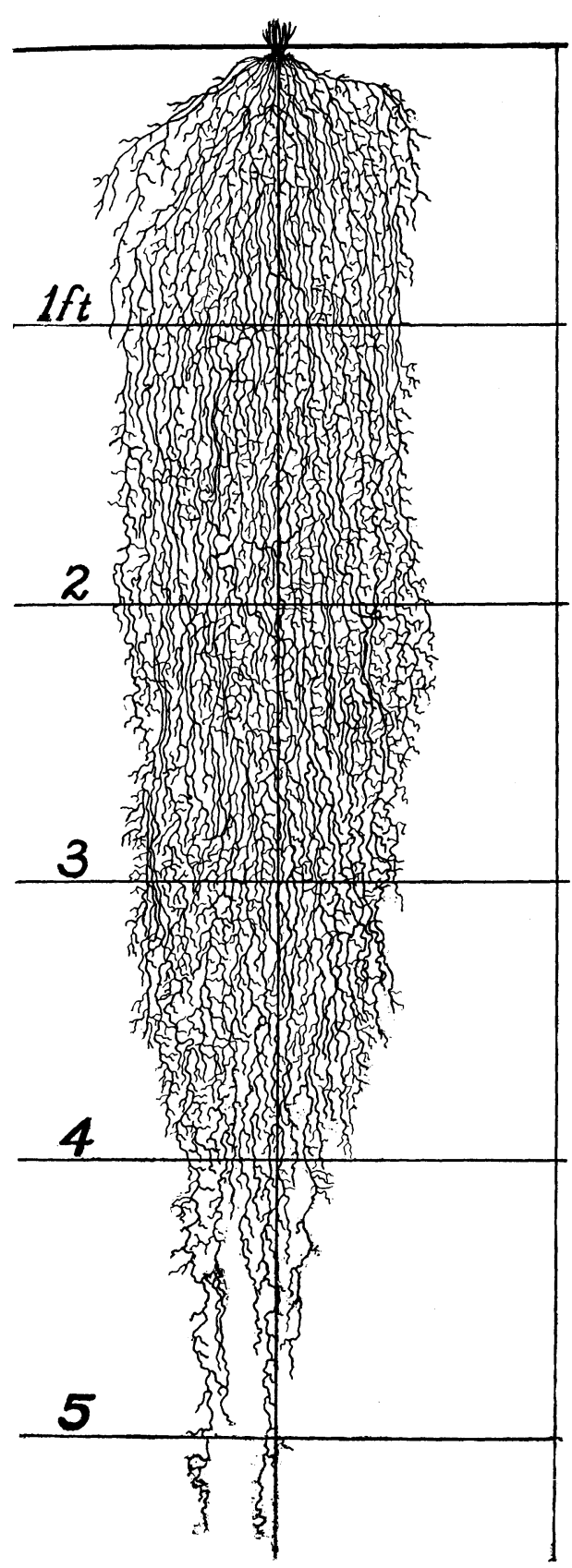

FIG. 8.-Mature root system of a winter wheat plant from a lowland field. Few roots occurred in the surface inch or two of soil. 
of weeds did not appear. The stubble, about 8 inches high, together with the fallen debris protected the soil. The inefficiency of this protection was revealed upon the application of water. Only 3 minutes longer (18 min.) were required to erode the sample with stubble than a similar sample from which the stubble and debris had been removed.

\section{DISCUSSION}

The preceding data are summarized in Table 4, and the relative periods required for complete erosion are shown in Figure 9. Even casual study of these data shows clearly the great importance of plant cover in protecting the soil. While the underground parts alone more than doubled the efficiency of the soil in resisting water erosion, protection afforded by maturing tops increased it 9 to 10 fold. The slender, elongated stems and the elongated narrow leaves, common to the grass family, are highly efficient in protecting the soil. When the plants lodge, as they frequently do during severe storms when forces of erosion are especially active, they form a thatched cover which breaks the force of the water, spreads it more or less evenly, and conducts it away gently with little loss of surface soil.

TABLE 4.-Turkey red winter wheat grown on lowland soil.

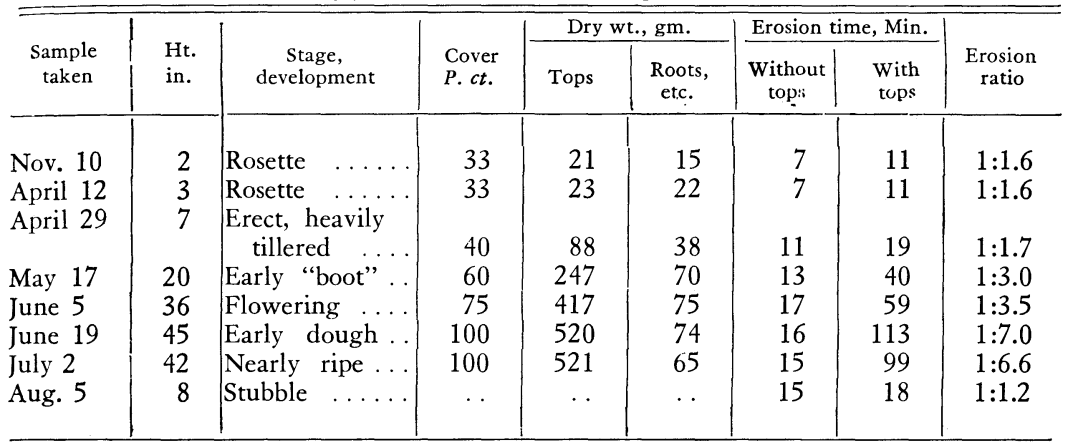

Little relation was shown between the amount of underground parts and resistance to erosion, an increase from 15 to $75 \mathrm{gm}$. dry weight increasing the erosion time only 10 minutes. Much of the entire dry weight and, consequently, its increase was not due to the thread-like roots but to the bases of the stems in the surface 2 inches of soil (Fig. 6). That the dry weight of tops increased much more rapidly than the erosion time is also apparent. This may be accounted for by the fact that much of the dry weight material was used in building stems and heads rather than foliage. The erosion ratio of roots to tops increased rapidly with the growth of the plants until it reached a maximum of $1: 7$, thus revealing the great efficiency of the aboveground parts. 


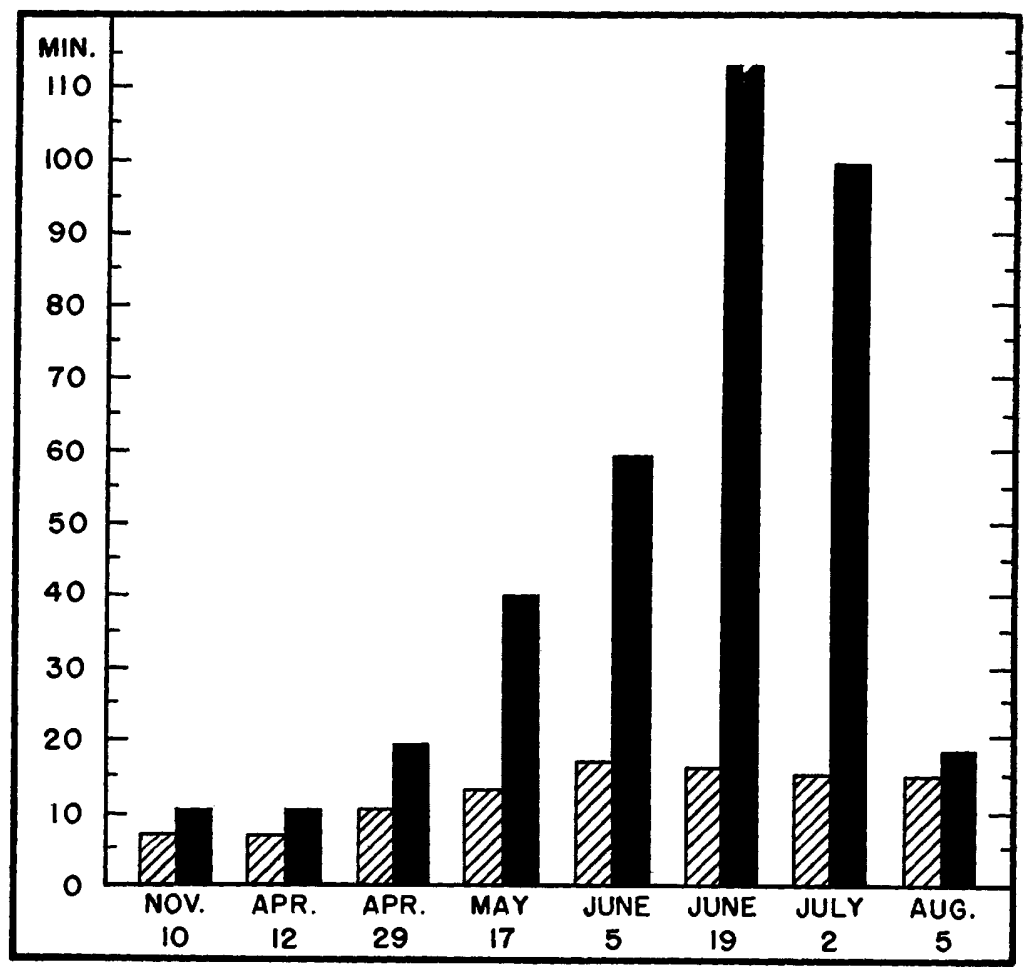

FIG. 9.-Relative efficiency of underground parts of lowland winter wheat without tops (hatched) and with tops (black) in preventing erosion.

\section{WHEAT ON UPLAND SOIL}

A second series of 7 pairs of samples of winter wheat was secured from a field on a level hilltop. There was enough clay to make the soil somewhat sticky when wet.

The first samples were taken on April 5, when the wheat was only three inches tall. The plants were mostly in the "rosette" condition, characteristic of winter. The total spread of the tops was 4 inches and the foliage cover did not exceed 20 per cent. Upon applying water, the loose one-half inch of topsoil of both samples was quickly removed, after which erosion proceeded more slowly. The plants remained erect and alined in the rows until erosion was practically completed. It required 12 minutes to remove the soil where the tops had been clipped, and 15 where they partially protected the soil. The dry weight of tops was $18 \mathrm{gm}$. and that of underground parts $17 \mathrm{gm}$. There were 130 plants with an average per plant of 6 tillers. 
One month later, on May 6, a second pair of samples was taken. As a result of dry weather the soil was of low water content and hard. The wheat was partially wilted. The plants were 7 inches tall and the foliage cover was approximately 45 per cent. Tillering was marked. The 120 plants in the one sample had an average of 6 tillers. Dry weight of tops had increased to $81 \mathrm{gm}$., and that of parts underground to $35 \mathrm{gm}$. The time for eroding the soil where it was held by the roots alone was 18 minutes, an increase of 50 per cent over the previous sample. Plants of the second sample flattened to the ground after 4 minutes and afforded sufficient protection to delay complete erosion for a total period of 25 minutes.

A third pair of samples was secured on May 25, after long continued rains, and when the plants had reached a height of 15 inches and presented a foliage cover of about 60 per cent. One sample had 85 plants and 515 tillers, the other one 80 parent stalks and 540 offshoots. The tops, in the same order, weighed 123 and $122 \mathrm{gm}$., and the underground parts 41 and $47 \mathrm{gm}$. Thus they had made good gains both above and below ground. The denuded sample was eroded in 17 minutes but erosion time under the plant cover was increased to 29 minutes. After only 3 minutes two-thirds of the stems had lodged, and soon all were prostrate on the soil.

As a result of dry weather the wheat grew slowly. When the crop had reached a height of 25 inches and was beginning to head, on June 7, samples were again secured. Good rains had thoroughly moistened the soil, and the foliage cover had increased to 70 per cent. The 90 plants with 550 tillers of one sample gave a dry weight of tops of $203 \mathrm{gm}$. The underground parts weighed only $39 \mathrm{gm}$.

The soil sample from which the tops had been removed eroded in only 17 minutes; that with tops intact required 63 minutes. Upon the application of water, enough soil was soon eroded from the bases of the plants to cause the tops to lodge down the slope. After readjustment of the lodged plants so as to make a more uniform cover (p. 11) they formed an efficient protection in breaking the force of the water and conducted much of it down the slope before it reached the soil. The damming effect was also considerable.

A fifth sampling was made on June 22. The plants were still half green, 36 inches tall, and presented a foliage cover of 75 per cent. The tops gave a dry weight of $354 \mathrm{gm}$. which was an increase of 74 per cent over the samples taken two weeks earlier. The underground parts weighed $42 \mathrm{gm}$. The compacted soil was eroded from the roots of the clipped plants in 20 minutes, but the tops formed such an effective thatch for the soil of the second sample that the time was prolonged to 84 minutes. The plants had lodged within the first 5 minutes, after which there were periods when the runoff water was clear. 
Just before harvest, on July 5 , additional samples were taken. The leaves were no longer green, but remained intact upon the yellow stems, hence the foliage cover remained unchanged. The plants had increased slightly in height and were now 38 inches tall. There were no weeds on the dry, compact soil. Dry weight of tops had increased with the filling of the grain to $408 \mathrm{gm}$. Weight of underground parts remained practically unchanged, $43 \mathrm{gm}$. The sample unprotected by tops eroded in 18 minutes; the one with the protecting plant cover intact was entirely washed away only after 87 minutes.

The seventh and last pair of samples was secured three weeks later on July 25. The stubble had been cut at a height of 12 inches. Because of continued dry weather there were practically no weeds. The compact soil with stubble removed was eroded in 18 minutes. At first the stubble stood rigidly upright breaking the force of the water on the second soil sample. But after 1 to 1.5 inches of the loose soil had eroded from its base during the first 3 minutes, it lodged on the soil surface. The straw was far too limited in quantity to give efficient protection, and only a very few withered leaves remained. The soil was first removed between the rows, the dried base of each plant furnishing temporary protection to the mound of earth held beneath. The roots were still undecayed and showed great tensile strength. The total time for erosion was only 21 minutes.

\section{DISCUSSION}

The preceding data are summarized in Table 5, and the relative periods required for complete erosion are shown in Figure 10. The rapid development of resistance to erosion with the growth of a cover of plants paralleled in general that on lowland. The much greater importance of tops reinforced by roots than roots alone in stabilizing soil is again clearly apparent. The longer periods required for erosion where roots alone protected the soil as compared with similar periods on lowland soil, are due not to the greater efficiency of the roots of the upland wheat but to the greater clay content of the soil. The shorter periods for erosion with tops intact re-

TABLE 5.-Turkey red winter wheat grown on upland soil.

\begin{tabular}{|c|c|c|c|c|c|c|c|c|}
\hline \multirow[b]{2}{*}{$\begin{array}{r}\text { Sample } \\
\text { taken }\end{array}$} & \multirow[b]{2}{*}{$\begin{array}{l}\text { Ht. } \\
\text { in. }\end{array}$} & \multirow[b]{2}{*}{$\begin{array}{c}\text { Stage, } \\
\text { development }\end{array}$} & \multirow[b]{2}{*}{$\begin{array}{l}\text { Cover } \\
\text { P. ct. }\end{array}$} & \multicolumn{2}{|c|}{ Dry wt., gm. } & \multicolumn{2}{|c|}{ Erosion time, Min. } & \multirow[b]{2}{*}{$\begin{array}{c}\text { Erosion } \\
\text { ratio }\end{array}$} \\
\hline & & & & Tops & $\begin{array}{l}\text { Roots, } \\
\text { etc. }\end{array}$ & $\begin{array}{c}\text { Without } \\
\text { tops }\end{array}$ & $\begin{array}{l}\text { With } \\
\text { tops }\end{array}$ & \\
\hline April 5 & 3 & Rosette & 20 & 18 & 17 & 12 & 15 & $1: 1.2$ \\
\hline May 6 & 7 & Erect, tillering & 45 & 81 & 35 & 18 & 25 & $1: 1.4$ \\
\hline May 25 & 15 & Early "boot". & 60 & 123 & 41 & 17 & 29 & $1: 1.7$ \\
\hline June 7 & 25 & Flowering .. & 70 & 203 & 39 & 17 & 63 & $1: 3.7$ \\
\hline June 22 & 36 & Early dough. & 75 & 354 & 42 & 20 & 84 & $1: 4.2$ \\
\hline July 5 & 38 & Ripe & 75 & 408 & 43 & 18 & 87 & $1: 4.8$ \\
\hline July 25 & 12 & Stubble & & & 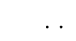 & 18 & 21 & $1: 1.2$ \\
\hline
\end{tabular}




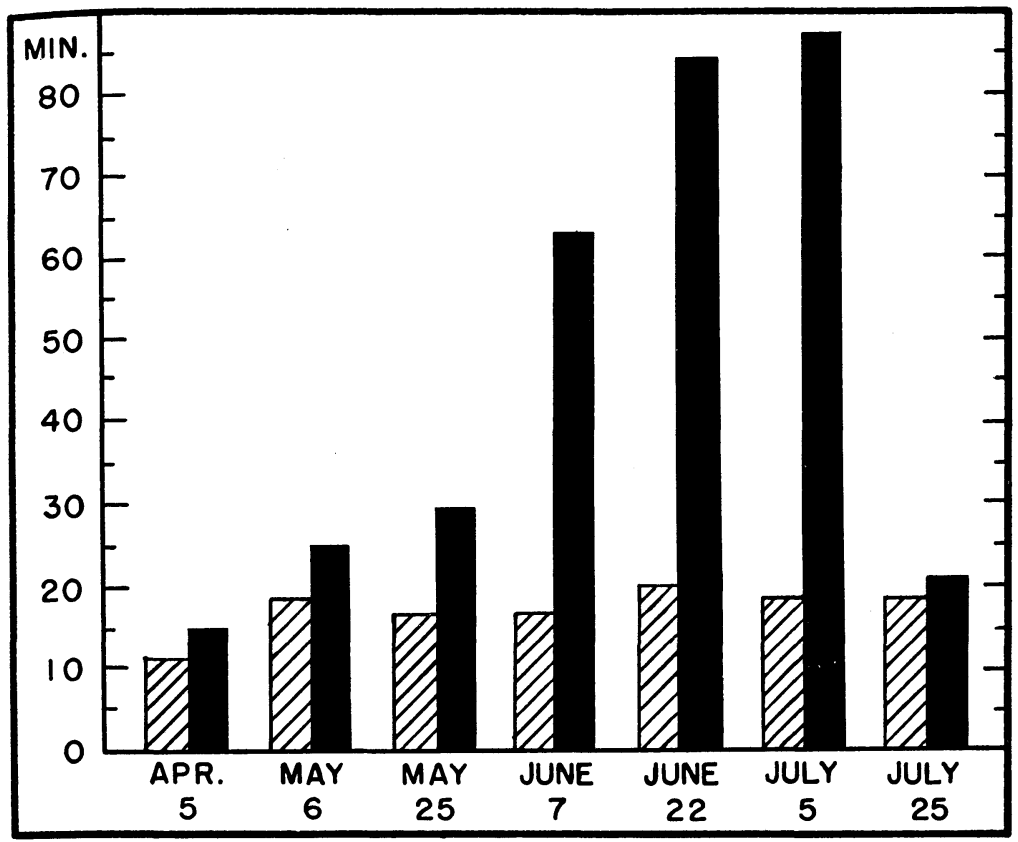

FIG. 10.-Relative efficiency of underground parts of upland winter wheat without tops (hatched) and with tops (black) in holding the soil against erosion.

sulted from the poorer cover developed on the dry upland. Here the highest erosion ratio attained was 1:4.8 compared with 1:7 on lowland.

A crop of winter wheat furnishes some protection against soil erosion during fall, winter, and early spring. But ordinarily much more than half of the soil surface between the rows is unprotected. From the viewpoint of soil stabilization alone, broadcasting the seed would result in greater protection than drilling in rows, which practice leaves much soil exposed at all times. This conclusion results from the fact that effective resistance to erosion by wheat is not so much a factor of a thick cover as a cover widely spread and continuous. As shown in previous experiments, a single leaf is effective as regards protecting the soil directly beneath it. With renewal of growth in spring the protecting cover rapidly increases. Although growth was retarded by drought in this experiment, the increase from May 25 to June 7 was 66 per cent.

\section{OATS ON LOWLAND SOIL}

Three pairs of samples of White Kherson Oats (Avena sativa L.) were taken from a level lowland field between June 8 and July 10, 1935. The crop had been drilled at the rate of 2 bushels per acre. The frames were placed lengthwise across the drill rows. 
The first sampling oczurred on June 8 when the crop was 17 inches tall and had a foliage cover of 50 per cent. The root system of a single young oat plant reveals the fact that even after 60 days of growth the soil is fairly well threaded with fine rootlets (Fig. 11). The 67 plants of the sample where tops were removed had 315 tillers, a dry weight of tops of $107 \mathrm{gm}$. and a root weight of $28 \mathrm{gm}$. The denuded soil was eroded in 10 minutes, that with tops intact, which soon lodged upon the surface, in 19 minutes.

The crop developed so rapidly during the following 10 days that the height reached 27 inches, the foliage cover 80 per cent, and the dry weight of tops (229 gm.) was more than twice that 10 days earlier. The grain was in the early dough stage of development. The dry weight of the underground parts had increased ( 75 per cent) to $49 \mathrm{gm}$. The 69 broadleaved plants were weighted down under the impact of the water and flattened against the surface of the soil. They offered a formidable barrier between water and soil, breaking the force of the stream and causing the water to run

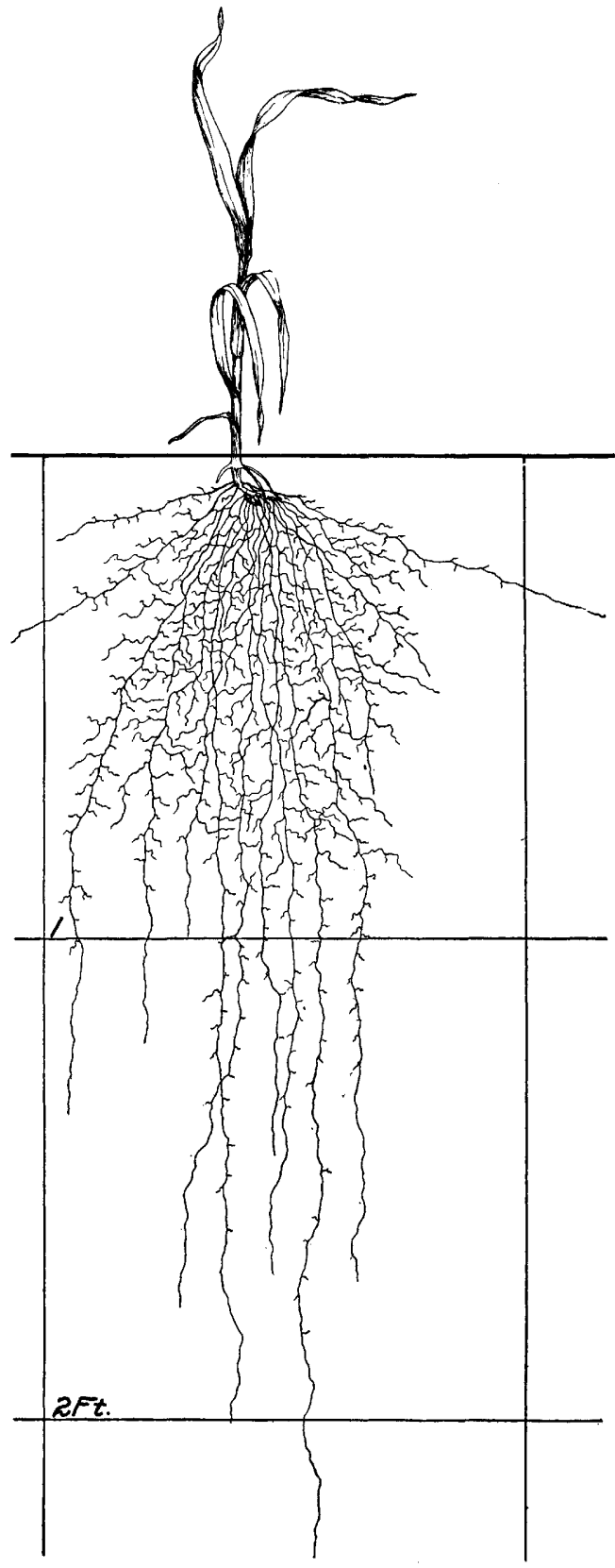

FIG. 11.- Roots and tops of a single oat plant 60 days old. 
gently over the thatch of foliage. Many lower leaves formed series of dams which checked the rate of runoff and temporarily held the loosened soil. The soil between the rows was always the first to be removed. Erosion time was increased to 45 minutes under the cover, but only 12 minutes were required to wash away the soil when the cover was removed.

The last samples were dug on July 10 , a few days before harvest. Rain had caused some plants heavy with grain to lodge but most stood erect, reaching a height of 34 inches. The drying leaves were still intact upon the stems. The cover had increased to 85 per cent, the dry weight of tops to $312 \mathrm{gm}$., but the roots $(43 \mathrm{gm}$.) weighed somewhat less than at the previous sampling. Erosion time of bared soil was again 12 minutes but that of the sample with tops intact increased to 63 minutes. This lengthening of the time by 40 per cent may be attributed in part to the greater mass of plant materials protecting the soil and in part to its firmer texture as the straw matured.

\section{DISCUSSION}

Although the oats were grown adjacent to the lowland wheat, they failed to produce as heavy a cover, $229 \mathrm{gm}$. as compared with $520 \mathrm{gm}$. of wheat, when both were in the early dough stage (Table 6). The erosion time for the soil protected by the oats was, consequently, only 45 minutes

TABLE 6.-Oats grown on lowland soil.

\begin{tabular}{|c|c|c|c|c|c|c|c|}
\hline \multirow{2}{*}{$\begin{array}{c}\text { Sample } \\
\text { taken }\end{array}$} & \multirow{2}{*}{$\begin{array}{l}\text { Height } \\
\text { in. }\end{array}$} & \multirow{2}{*}{$\begin{array}{l}\text { Cover } \\
\text { P. ct. }\end{array}$} & \multicolumn{2}{|c|}{ Dry wt., gm. } & \multicolumn{2}{|c|}{ Erosion time, Min. } & \multirow{2}{*}{$\begin{array}{l}\text { Erosion } \\
\text { ratio }\end{array}$} \\
\hline & & & Tops & $\begin{array}{l}\text { Roots, } \\
\text { etc. }\end{array}$ & $\begin{array}{c}\text { Without } \\
\text { tops }\end{array}$ & $\begin{array}{l}\text { With } \\
\text { tops }\end{array}$ & \\
\hline June 8 . & 17 & 60 & 107 & 28 & 10 & 19 & $1: 1.9$ \\
\hline June 18. & 27 & 80 & 229 & 49 & 12 & 45 & $1: 3.8$ \\
\hline July 10 & 34 & 85 & 312 & 43 & 12 & 63 & $1: 5.3$ \\
\hline
\end{tabular}

as compared with 113 minutes for the wheat. Thus at this time the dry weight of the tops of wheat was about 2.3 times as great and the resistance to the forces of erosion was 2.5 times as great as that of the oats. Moreover, while the wheat samples were taken parallel with the rows, those of oats were taken at right angles to the rows. With the development of the crop during a period of 32 days, erosion resistance was increased 3.3 times.

\section{YOUNG ALFALFA ON UPLAND SOIL}

A series of 5 pairs of samples of common alfalfa (Medicago sativa L.) was secured during the growing season from upland soil. The crop had been sown on September 8, 1934, and owing to very favorable conditions of moisture had made a good initial growth. The field had produced crops for many years, the preceding one being winter wheat.

Initial samples were taken on April 19, when the plants were 2 inches tall (Fig. 12). A sample included 5 rows one meter long, the outer rows 


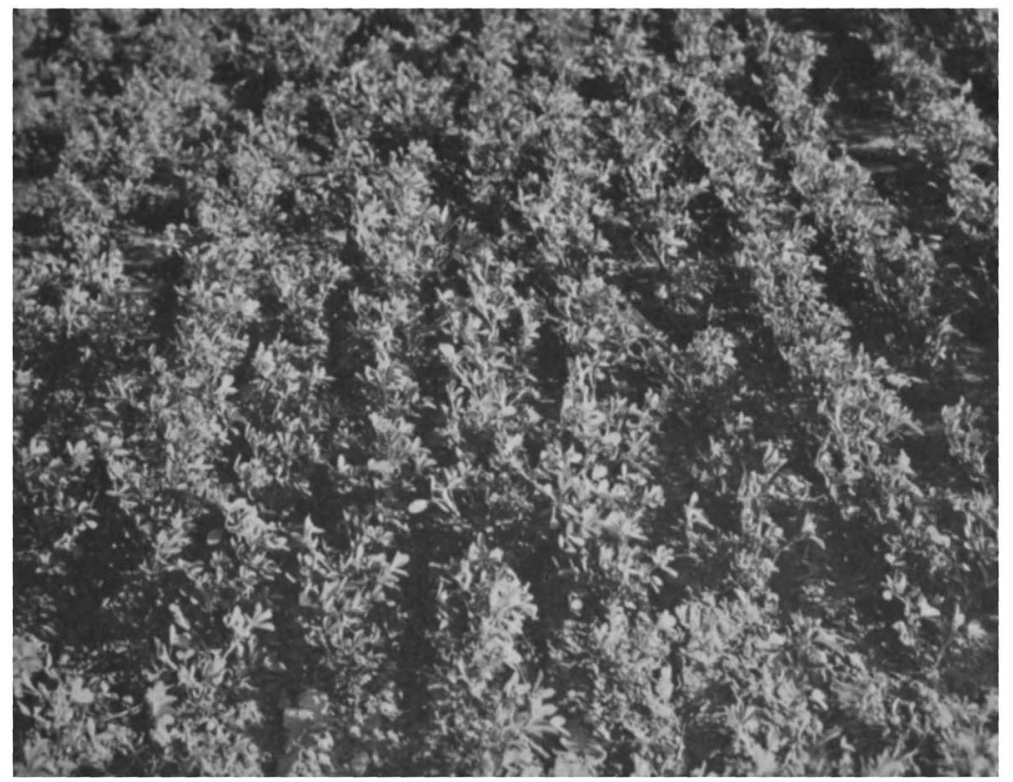

FIG. 12.-Young alfalfa about 2.5 inches high on April 27. The seed had been drilled early in September of the preceding autumn.

being about 2 inches from the sides of the frame. The young plants covered only about 25 per cent of the soil surface. The taproots of young alfalfa produce few rootlets in the surface 1 to 1.5 inches of soil nor do the deeper laterals extend widely (Fig. 13). The entire underground parts of the 166 plants in one sample weighed only $19 \mathrm{gm}$., and the tops but 20 $\mathrm{gm}$. The taproots were $2.5 \mathrm{~mm}$. or less in diameter; the base of the crowns spread about $5 / 8$ inch at the soil surface. Hence, the crop furnished scant protection to the soil. The soil of the denuded sample washed away in 7 minutes and the unclipped one in 8 minutes. ${ }^{1}$

Five weeks later, on May 24, a second pair of samples was secured. The plants had grown rapidly and were 9 inches tall. They covered approximately half of the soil surface. The dry weight of tops (176 plants) had increased to $95 \mathrm{gm}$., and that of underground parts to $50 \mathrm{gm}$. The increase of more than 2.5 fold of underground parts was due almost entirely to the growth of the taproots and crowns. The fibrous roots had apparently grown but little, although the clusters of nodules were now prominent. Erosion time with tops removed was increased to 9 minutes, a gain of 29 per cent. With tops intact the erosion time $(15 \mathrm{~min}$.) was 88 per cent longer than for the preceding sample.

\footnotetext{
${ }^{1}$ A duplicate set of samples taken three days later yielded very similar data.
} 
Another pair of samples was taken just before the first cutting of the crop on June 14. Conditions for growth had been unfavorable because of too much cold, cloudy weather. The height had increased to 13 inches and the foliage cover to 60 per cent, but there was little increase in amount of branching or foliage. Many of the lower leaves were yellowing and falling. The dry weight of tops of the 165 plants in one sample was $116 \mathrm{gm}$. The sample from which the plants had been clipped eroded in 10 minutes; the cover of the other sample delayed complete erosion for 19.5 minutes.

On July 26, samples of the second growth were taken. The rains of early July had insured good development. The plants were 16 inches tall, widely branched, and the foliage cover was 85 per cent. Blossoming was just beginning. The dry weight of tops was $203 \mathrm{gm}$. and that of roots $91 \mathrm{gm}$. Where the cover was removed the time of erosion was 14.5 minutes, as compared to the previous 10 minutes.

The stream of water was prevented from coming into direct contact with the soil of the second sample because of the thick cover. The plants lodged under the force of the water as frequently occurs in fields during heavy rains accompanied by strong winds. In places the tent-like cover of green stems, standing 5 to 8 inches above the surface, protected the soil more efficiently than where the lodged branches were so few that the bare soil was partly exposed. Little ero-

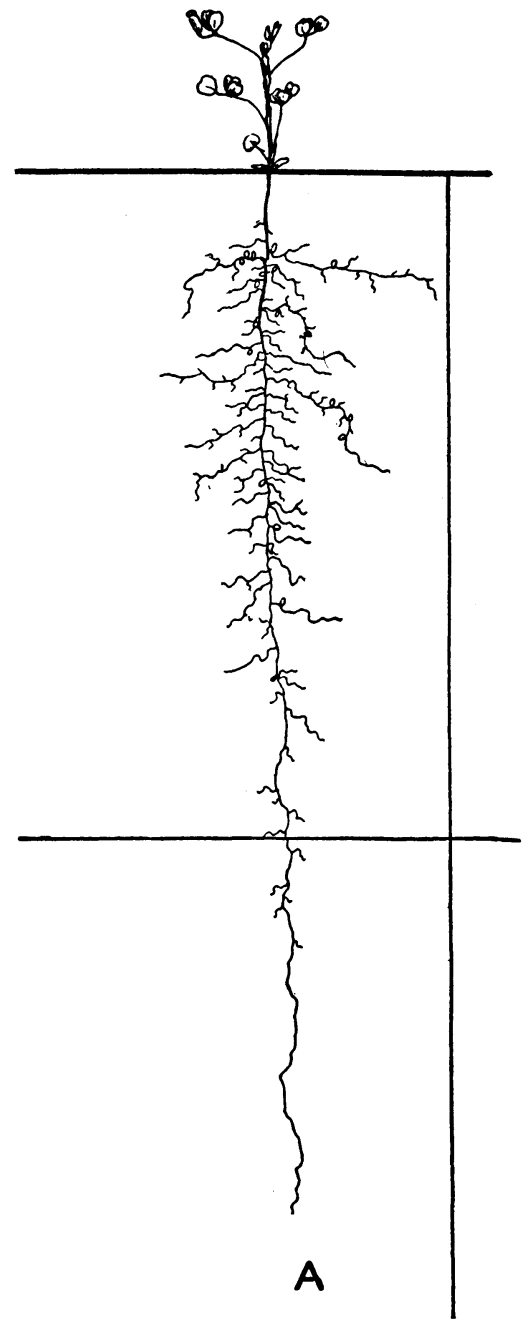

FIG. 13.-Alfalfa plant 63 days old and nearly two feet deep. sion occurred under the former condition but the soil washed away rapidly where it was unprotected. Where the root-crowns were reinforced by overlapping of neighboring tops, the cover was most effective. As the 
soil was eroded elsewhere, these places remained as columns which resisted soil removal until the last. Thus 39 minutes were required to entirely erode the soil. This was twice the time recorded for the preceding sample.

Because of the late summer drought and consequent poor development of the crop, final samples were not taken until October 25. The plants were 16 inches tall, had a foliage cover of 90 per cent, and had made some gains in both tops and roots. Their dry weights were $211 \mathrm{gm}$. and 117 gm., respectively. Erosion time for the bared soil increased to 18 minutes and that with a plant cover to 48 minutes.

\section{DISCUSSION}

The results of this series of experiments are given in Table 7 and Figure 14. It is obvious that as the young plants became established and developed a vigorous top and a good root system the resistance to erosion

TABLE 7.-Alfalfa planted in September, 1934, on upland soil, and samples taken during 1935.

\begin{tabular}{|c|c|c|c|c|c|c|c|c|}
\hline \multirow{2}{*}{$\begin{array}{c}\text { Sample } \\
\text { taken }\end{array}$} & \multirow{2}{*}{$\begin{array}{l}\text { Height } \\
\text { in. }\end{array}$} & \multirow{2}{*}{$\begin{array}{l}\text { Cover } \\
P . c t \text {. }\end{array}$} & \multicolumn{3}{|c|}{ Dry weight, grams } & \multicolumn{2}{|c|}{ Erosion time, Min. } & \multirow{2}{*}{$\begin{array}{l}\text { Erosion } \\
\text { ratio }\end{array}$} \\
\hline & & & Tons & $\begin{array}{l}\text { Tap- } \\
\text { roots }\end{array}$ & $\begin{array}{l}\text { Fibrous } \\
\text { roots }\end{array}$ & $\begin{array}{l}\text { Without } \\
\text { tops }\end{array}$ & $\begin{array}{l}\text { With } \\
\text { tops }\end{array}$ & \\
\hline April 19. & 2 & 25 & 20 & . & $19^{1}$ & 7.0 & 8.0 & $1: 1.1$ \\
\hline May 24 & 9 & 50 & 95 & 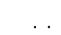 & $50^{1}$ & 9.0 & 15.0 & $1: 1.7$ \\
\hline June 13 & 13 & 60 & 116 & 43 & 14 & 10.0 & 19.5 & $1: 2.0$ \\
\hline July 26. & 16 & 85 & 203 & 81 & 10 & 14.5 & 39.0 & $1: 2.7$ \\
\hline Oct. 25 . & 16 & 90 & 211 & 102 & 15 & 18.0 & 48.0 & $1: 2.7$ \\
\hline
\end{tabular}

1 The taproots were not separated from their fibrous branches in the early sampling.

rapidly increased. The erosion ratio of 1:1.1 of April, increased to 1:2 in June and 1:2.7 in late summer. A part of the resistance resulted from the compacting of the soil by rains and was not due to the plants, but this was probably a small part. In Table 7 it may be seen that the greatest portion of the increasing weight was due to taproots and not to their fibrous branches. The 165 or more roots per sample compacted the soil about them as they pressed it aside in enlarging, and furnished centers of stabilization as well as anchorage for the root fibers radiating outward. Effective protection above ground was apparently proportional to the extent of the branches and foliage. As in the case of wheat, the aboveground parts were by far the more important in controlling erosion. The long period of growth of alfalfa, once it is established, is distinctly favorable to its usefulness in erosion control. Its maximum capacity to resist erosion seems to be attained nearly or entirely by the end of the first full season of growth, at least if the first season is favorable, as is indicated by the following experiments. 


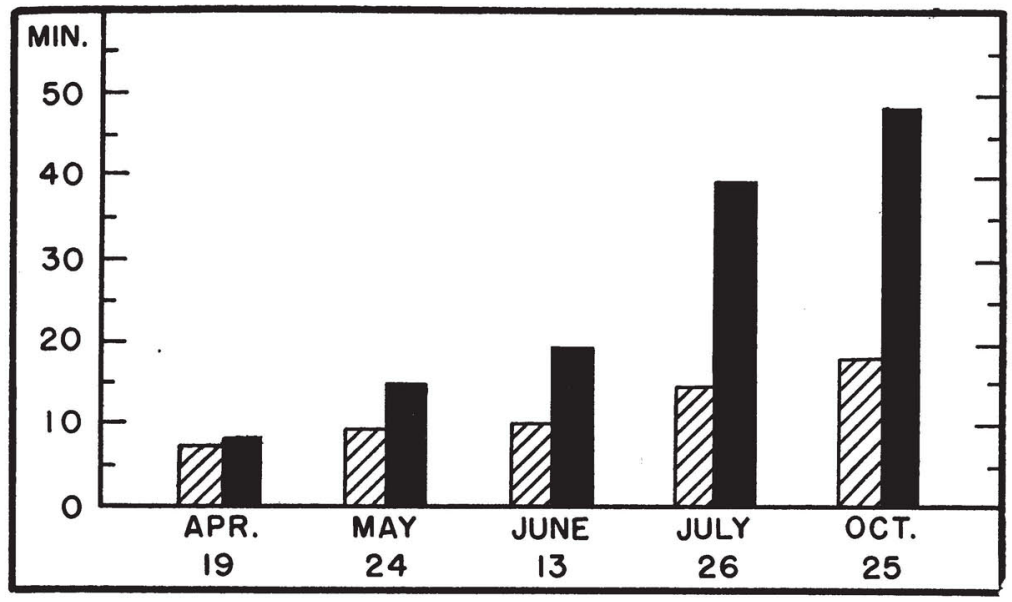

FIg. 14.- Relative efficiency of underground parts of young alfalfa without tops (hatched) and with tops (black) in preventing erosion.

\section{OLD ALFALFA ON LOWLAND SOIL}

A series of 5 pairs of samples of common alfalfa was used. They were taken at intervals between April 20 and July 10 from a 4-year-old stand on nearly level lowland soil.

The first samples were secured on April 20. The new growth averaged 8 inches in height and although the stand was thick the plants were leafy to the base (Fig. 15). The dense foliage afforded a cover of 95 per cent.

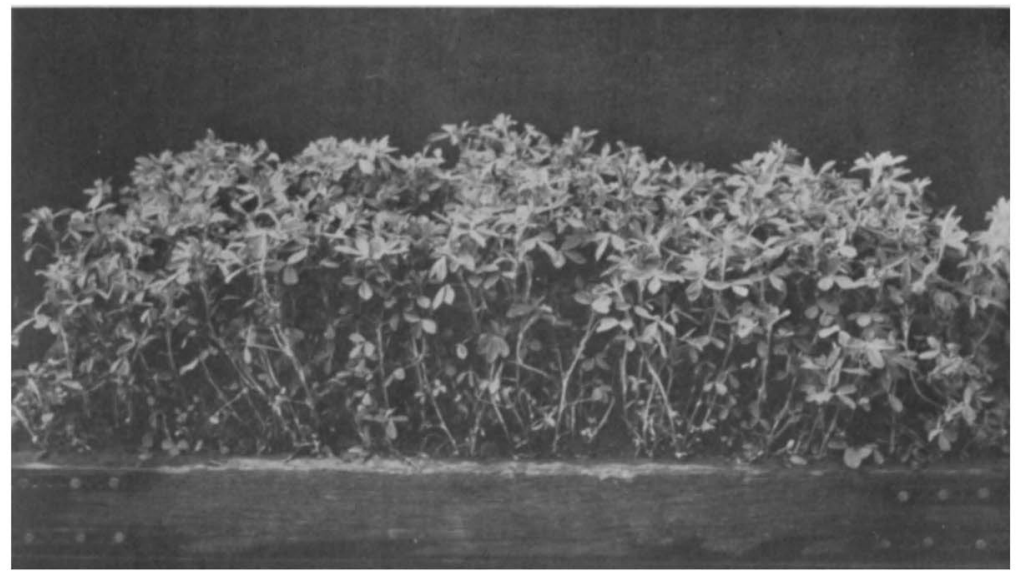

Fig. 15.-Alfalfa 8 inches tall taken from lowland on April 20. Note the dense cover. 
The 108 plants of the denuded sample yielded a dry weight of $116 \mathrm{gm}$. When the tops were removed the soil eroded in only 11.5 minutes, despite the presence of the numerous taproots and widely spreading crowns. These coarser underground parts weighed $133 \mathrm{gm}$. when dried, and the abundant fibrous roots $25 \mathrm{gm}$. The largest of the taproots were 8 to 13 $\mathrm{mm}$. in diameter. No lateral branches were found in the surface 2 inches of soil. The soil between the crowns, held only by the fibrous roots, was first to wash away. Each crown acted as a center of soil stabilization for a short time. The crown, supported by its taproot, was not overturned until the last inch of soil was partly eroded.

The plant cover to which water was applied lodged at once, forming a close network of leaves and branches over the surface and breaking the force of the water. Plants lodged on neighboring crowns constituted a fairly rigid, immobile network. Some of the stems that were in closest contact with the soil served as miniature dams and temporarily held the loosened soil. Total time for erosion was 32 minutes.

A second pair of samples, taken 26 days later on May 16, contained plants of 16 inches average height and a foliage cover of 100 per cent. Blossoming was beginning. The tops yielded a dry weight of $174 \mathrm{gm} .{ }^{1}$ The dry weight of taproots and crowns had also increased to $167 \mathrm{gm}$. The fibrous roots were about as before, $29 \mathrm{gm}$.

After 8 minutes of erosion most of the soil had been removed from the clipped lot, revealing the underground part (Fig. 16). The remainder of it was removed in 6 minutes. The tops stood erect until water was applied. Then they lodged, as before, within the space of one-half square meter delimited by the upper, 12-inch frame, adjustments by clipping having been made as described on page 11 . After 28 minutes all of the soil was washed away.

Samples were again taken on June 5. As the result of a period of cool, rainy weather, the basal leaves had blackened and died and the stems also were discolored to a height of several inches. The plants, moreover, were somewhat lodged, although the general height was 28 inches, and the mass of the plant cover seemed less than previously, although it still completely obscured the soil. The increase of 15 per cent in dry weight was due to increase in size and woodiness of the stems, rather than to growth of foliage. Roots had not increased in dry weight, and the erosion time without tops was the same as for the sample on April 20-11.5 minutes. With the cover intact, the soil was eroded in 31 minutes, which was about the same period as for the two preceding samples.

Upon the return of sunny weather the crop was mowed at a height of 3.5 inches. A few lodged stems were not cut by the mower. Two samples from this stubble were secured on June 7. All of the aboveground parts

\footnotetext{
${ }^{1}$ The tops of a second sample weighed $177 \mathrm{gm}$.
} 


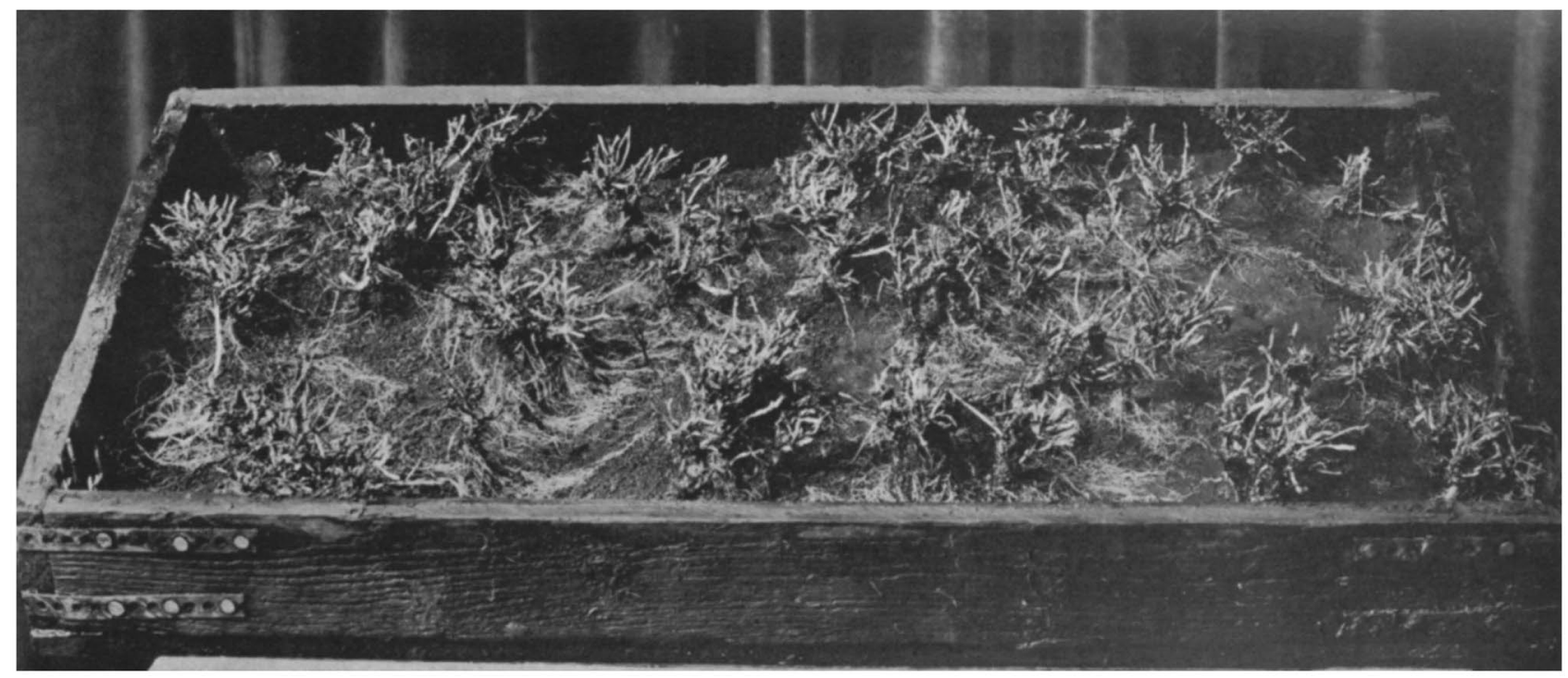

Fig. 16.-Alfalfa on may 16 atter the tops had been removed and most of the soil eroded, showing the underground parts. 
were removed from one, the other was left undisturbed. The denuded sample eroded in 10 minutes, the one with stubble intact in 13 minutes.

The fourth regular pair of samples was taken on July 8 . Since the usual area for sampling was flooded, they were secured 40 feet distant. In digging the samples the heavier nature of the soil was at once apparent. The plants were 28 inches tall and blooming. Figure 17 shows that lower portions of the stems were not leafy nor were the stems much branched. There was a complete cover of foliage. Dry weight of tops $(253 \mathrm{gm}$.) was 26 per cent greater than that of the preceding sample; weight of roots (138 gm.) was 21 per cent less. The bared soil completely eroded only after 21 minutes; that with a plant cover resisted erosion for 43 minutes. The ratio of erosion time of samples with roots only, to those with roots and tops was the same $(1: 2)$ as on May 16 , but less than that $(1: 2.7)$ of June 5.

The last pair of samples was also taken from a 4-year-old stand on alluvial soil but from a field in which considerable silt had been deposited. Judging from the depth of the burial of the crowns, about 1.5 inches of soil had been washed in within a period of 2 or 3 years. Consequently there were few fibrous roots $(17 \mathrm{gm}$.) in the surface 4 inches of soil, although the dried taproots and crowns weighed $107 \mathrm{gm}$. The open stand furnished a foliage cover of only 85 per cent, notwithstanding the plants were 18 inches tall. Dry weight of tops was only $151 \mathrm{gm}$. As a result, the rate of erosion was greatly increased. The bared soil was washed away within 9 minutes, that protected by the incomplete cover in 24 minutes.

\section{DISCUSSION}

Examination of Table 8, where the results with lowland alfalfa have been summarized, shows the resistance to erosion varied but little in the same area when the tops were removed. This is in accordance with the fact that few or no new roots were produced in the surface soil after the first sampling. Variations in the effect of tops are readily accounted for

TABLE 8.-Alfalfa from a four-year-old stand on lowland soil.

\begin{tabular}{|c|c|c|c|c|c|c|c|c|}
\hline \multirow{2}{*}{$\begin{array}{c}\text { Sample } \\
\text { taken }\end{array}$} & \multirow{2}{*}{$\begin{array}{c}\text { Height } \\
\text { in. }\end{array}$} & \multirow{2}{*}{$\begin{array}{l}\text { Cover } \\
\text { P. ct. }\end{array}$} & \multicolumn{3}{|c|}{ Dry weight, grams } & \multicolumn{2}{|c|}{ Erosion time, Min. } & \multirow{2}{*}{$\begin{array}{r}\text { Erosion } \\
\text { ratio }\end{array}$} \\
\hline & & & Tops & $\begin{array}{l}\text { Tap- } \\
\text { roots }\end{array}$ & $\begin{array}{c}\begin{array}{c}\text { Fibrous } \\
\text { roots }\end{array} \\
\end{array}$ & $\begin{array}{c}\text { Without } \\
\text { tops }\end{array}$ & $\begin{array}{l}\text { With } \\
\text { tops }\end{array}$ & \\
\hline April 20 & 8 & 95 & 116 & 133 & 25 & 11.5 & 32 & $1: 2.8$ \\
\hline May 16 & 16 & 100 & 174 & 167 & 29 & 14.0 & 28 & $1: 2.0$ \\
\hline June 5 . & 28 & 100 & 201 & 149 & 26 & 11.5 & 31 & $1: 2.7$ \\
\hline July $8^{1}$ & 28 & 100 & 253 & 117 & 21 & 21.0 & 43 & $1: 2.0$ \\
\hline July $10^{2}$ & 18 & 85 & 151 & 107 & 17 & 9.0 & 24 & $1: 2.7$ \\
\hline
\end{tabular}

\footnotetext{
${ }^{1}$ A denuded sample on June 7 was eroded in 10 minutes; one with stubble 3.5 inches high and accumclated litter, in 13 minutes.

${ }^{2}$ From another lowland field where topsoil had been deposited about the crowns of the 4-year-old plants.
} 


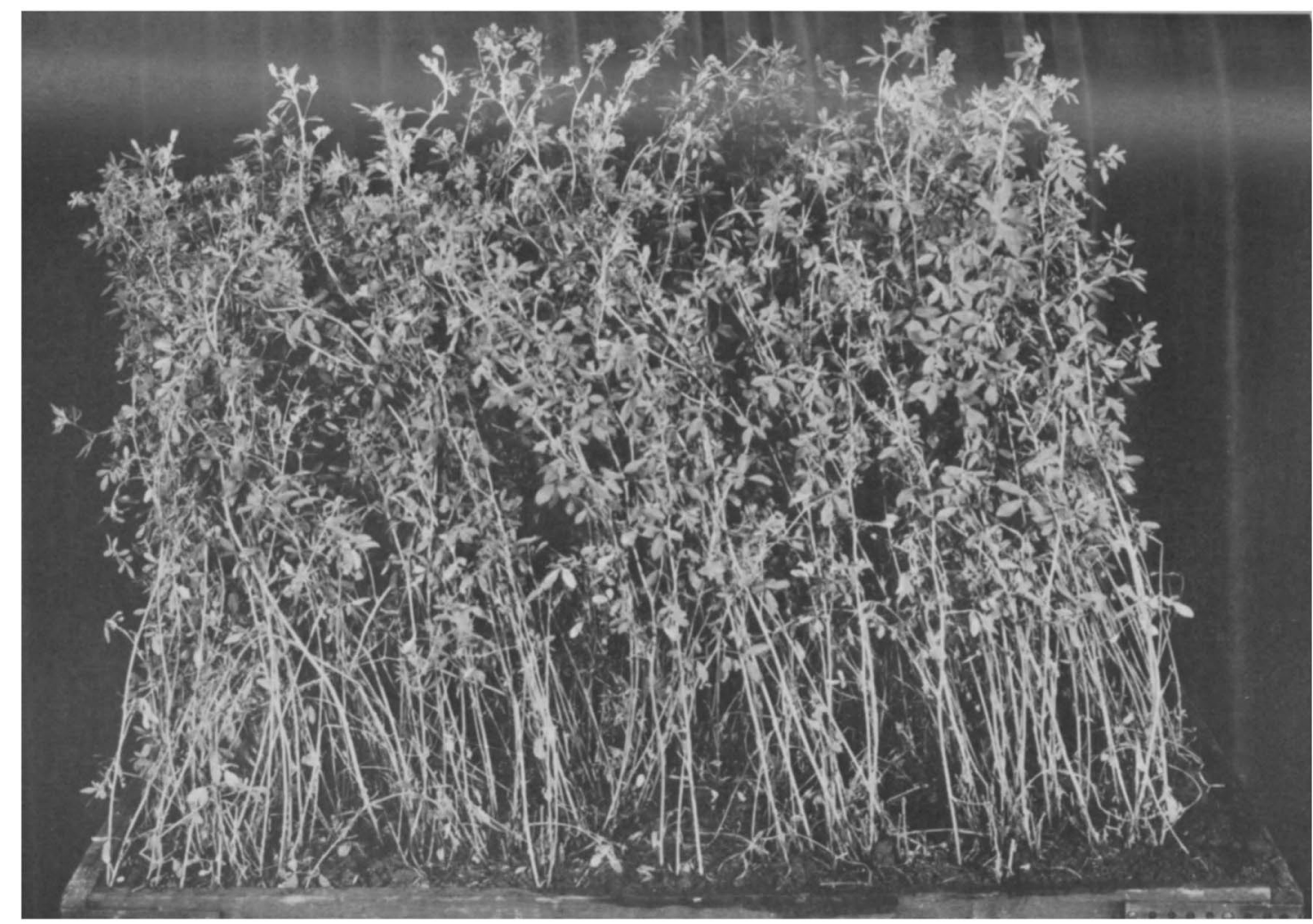

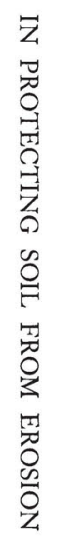

Fig. 17.-Alfalfa 28 inches tall taken from lowland on July 8 when the plants were blossoming. 
by a study of the leafiness of the foliage cover although the correspondence with dry weight (sometimes consisting materially of partially defoliated stems) is not so close. The average erosion time with roots intact was practically the same (11 minutes) as that on the upland, and that with the cover intact did not exceed that of the upland after midsummer. Consequently the erosion ratios of samples from both fields are the same, from $1: 2$ to $1: 2.7$.

The yield of a cutting of a good even stand of alfalfa, measured by dry weight, was much less than that of a field of unripe wheat growing on similar lowland soil. Nor was the alfalfa as efficient in protecting the soil as was the wheat during its period of maximum development. While protection afforded by the shorter upland wheat was less, yet the cover was more uniform and probably equally efficient or more efficient than upland stands of 2- to 4-year-old alfalfa. Unlike the dense, continuous cover found on lowlands, the upland fields usually present many open spaces where plants are missing and the soil is protected only by weeds.

The permanency of cover throughout a period of years, both summer and winter, is distinctly in favor of the alfalfa in its general relation to soil stabilization. Cover to be effective need not be living, frozen tops of alfalfa, fallen debris from former cuttings, weeds, etc., all furnish cover, and any kind of cover protects the soil.

\section{SORGHUM ON LOWLAND AND UPLAND SOILS}

Two pairs of samples of Hegari sorgo (Sorghum vulgare var. saccharatum (L.) Boerl.) were secured and the relative resistance offered by roots alone and roots with tops was determined. One lot was obtained from lowland and the second from upland soil. In both cases the crop was well advanced in its development. A single row of plants one meter in length was obtained in each sample.

The samples from lowland were taken on July 29. The plants were about 3.5 feet tall, and each had 8 to 10 leaves. The leaves averaged about 2 feet in length and 2 to 4 inches in greatest width. The bases of the 21 to 23 stems that occurred in each sample were 0.5 to 1.0 inch in diameter. The tops of the closely spaced plants spread so widely that they completely concealed the soil between the rows which were 38 inches apart. They had a dry weight of $388 \mathrm{gm}$.

The only resistance offered to erosion, after the tops were removed, was that of the narrow row of stem-bases and their widely spreading roots. In this experiment the water was applied at a height of 4 feet. Most of the roots extended laterally, if at all, in the third and fourth inch, thus furnishing little anchorage to the surface soil, nor were they able to stabilize the soil except near the base of the plant. Plants missing in the row also furnished vulnerable places, as well as the loss of soil from the sides. The 
whole sample was eroded in 8 minutes. Underground parts, when dried, weighed $46 \mathrm{gm}$.

As the water struck the leaves of the plants growing in the second sample, its force was effectively broken except near the edges where leafends alone afforded protection. Here it beat upon the soil, although with force much diminished. The plants stood 10 minutes as a unit, after which enough soil had been eroded from their bases to weaken their hold. Gradually they lodged down the slope. The abundant foliage furnished much protection to the middle of the sample but relatively little elsewhere. Consequently the soil from the sides of the sample eroded and then that in the ridge under the row of stems was undermined and washed away. The whole process required 25 minutes.

The second pair of samples was taken two weeks later on August 13. The crop was in a much more advanced stage of development. The samples contained 39 to 41 plants uniformly distributed in the single dense row. They were only slightly taller than plants of the preceding lot but the leaves were larger and more abundant (Fig. 1). Some older leaves were drying. The tops yielded a dry weight of $515 \mathrm{gm}$.

With tops removed, the bulk of the sample was eroded in 10 minutes, but the ridge of soil held by the stem-bases and fibrous roots was still firm (Fig. 2). This single row of closely knit underground parts afforded so much protection that 8 more minutes were required to wash away the remaining soil. So firmly did the cord-like roots anchor the crowns in place that they still maintained their position after all the soil had eroded. The mass of underground parts weighed, when dried, $74 \mathrm{gm}$.

Where the cover was left intact, resistance to erosion was greatly prolonged. A central strip about 10 inches in width was best protected. Here the broad, drooping leaves shed most of the water. A few were broken and fell to the ground. After 30 minutes the plants still stood firmly in the row, although the soil was rapidly removed from both sides. Ten minutes later the central strip of 8 to 10 inches in width alone remained, almost intact. Thereafter the stream of water was concentrated on this area. The water was first retarded or deflected by the erect stems and their drooping leaves, which formed a dense cover. The older, deteriorated leaves had fallen and now protected the soil surface. Finally, the thick mat of coarser brace roots interwoven with the finer one of fibrous threads efficiently held the soil.

A period of 58 minutes was required to erode the soil from this living barrier. Thus the total time with cover intact was one hour and 38 minutes. This was 5.5 times as long as when protection from erosion was due to underground parts alone. 


\section{DISCUSSION}

The resistance offered by sorgo to soil erosion results from the large amount and wide distribution of a type of foliage which readily breaks the force of the water and conducts much of it to the ends of the long, broad leaves. When the water reaches the ground, the soil is still held by the strong stem-bases and abundant coarse roots. This latter type of resistance is greatly localized near the base of the plants as is clearly shown when a few plants are missing in a row. Effectiveness of this crop as a soil stabilizer would be greatly increased by distributing the same amount of seed in closer rows or spreading it more uniformly over the entire area and not concentrating the plants in rows.

In the sorghum growing regions of the Southwest it has been found that "there is also much evidence that the milo plant, acting as a cover crop while growing and later furnishing large plant litter, is far superior to cotton in preventing runoff. . . . Next to grass, milo has been the most efficient crop in prevention of soil wastage by erosion" (Dickson, '29).

\section{MAIZE ON LOWLAND SOIL}

Hogue's yellow dent corn (Zea mays L. var. indentata Bailey) was planted on June 6 , in a plot of lowland soil. The rows were 42 inches apart and the plants spaced 13 inches distant. The weeds were kept down by scraping the soil with a hoe, thus the surface remained level. One side of the plot was unplanted but kept free of weeds. When a sample of corn, which included three stalks in a row, was taken, a second sample from the bare area was secured as a control. No samples with tops intact were dug, the purpose of this experiment being to determine the effectiveness of the root system and stem-bases of corn in various stages of development in holding the soil against the forces of erosion.

The first comparison was made on June 30, when the corn was 9 inches high and in the sixth-leaf stage. The root system of young plants is not very extensive in the surface 4 inches of soil (Fig. 18). The dry weight was only $3 \mathrm{gm}$. Consequently, difference in erosion time of the two samples was practically negligible, the soil being washed away in 7.5 and 8 minutes, respectively.

The corn was 30 inches tall at the second sampling on July 12, and the plants had an average of 10 large leaves. Underground parts had increased to $15 \mathrm{gm}$. in dry weight. Erosion time of the control sample remained 7.5 minutes, that with the roots of corn eroded in 9.5 minutes. These results were practically duplicated with an extra pair of samples secured a day later.

The third pair of samples was excavated 12 days later, on July 24. An average stalk, clothed with 14 large leaves, had attained a height of nearly 5 feet. The underground parts had nearly tripled in weight (41 gm.). 


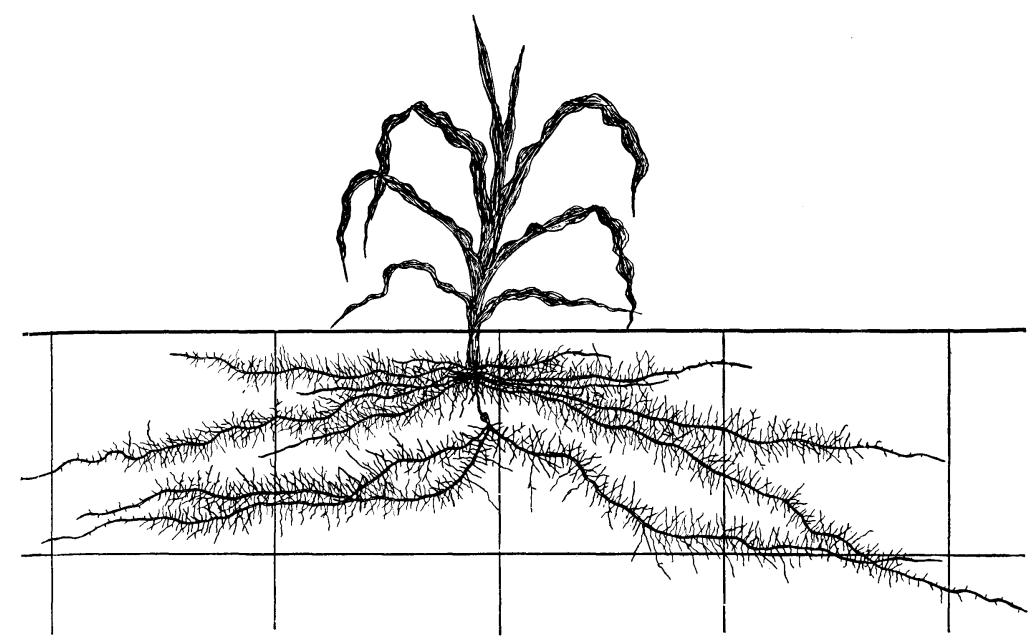

FIG. 18.- Iowa Silver Mine corn 36 days o!d and about one foot deep showing limited extent of root materials in the surface 4 inches of soil.

The great bulk of the roots was concentrated near the base of the crown and it was there almost entirely that resistance to erosion was encountered. Even this was only enough to extend the erosion time from 8 minutes (control) to 11 minutes.

The final samples from the experimental field were taken on August 9, about 2 weeks later. The plants were over 6 feet tall and vegetative development was nearing completion. Much growth had also occurred in the surface 4 inches of soil, especially the enlargement of the stem-bases and the addition of many brace roots. The latter would have been more plentiful had not the drought hindered their development. Fibrous roots had also made a good growth. The weight had increased from 41 to $65 \mathrm{gm}$.

The bare soil was now somewhat more compact than in June, which accounts for a slightly longer time for erosion. This, however, required only 9 minutes. When water was applied to the sample with corn roots, it became evident that the soil in the row in the middle of the box was being firmly held in place for a distance of 6 to 8 inches about each stalk. These columns of root-bound soil stood firmly at the end of the 9 minutes necessary to remove the remainder. In fact this soil was almost hidden by the abundant roots (Fig. 19). With continued erosion the soil of these three strongholds was removed. This required 10 minutes, making the total erosion time 19 minutes, more than half of which may be attributed to the presence of the living underground parts. 


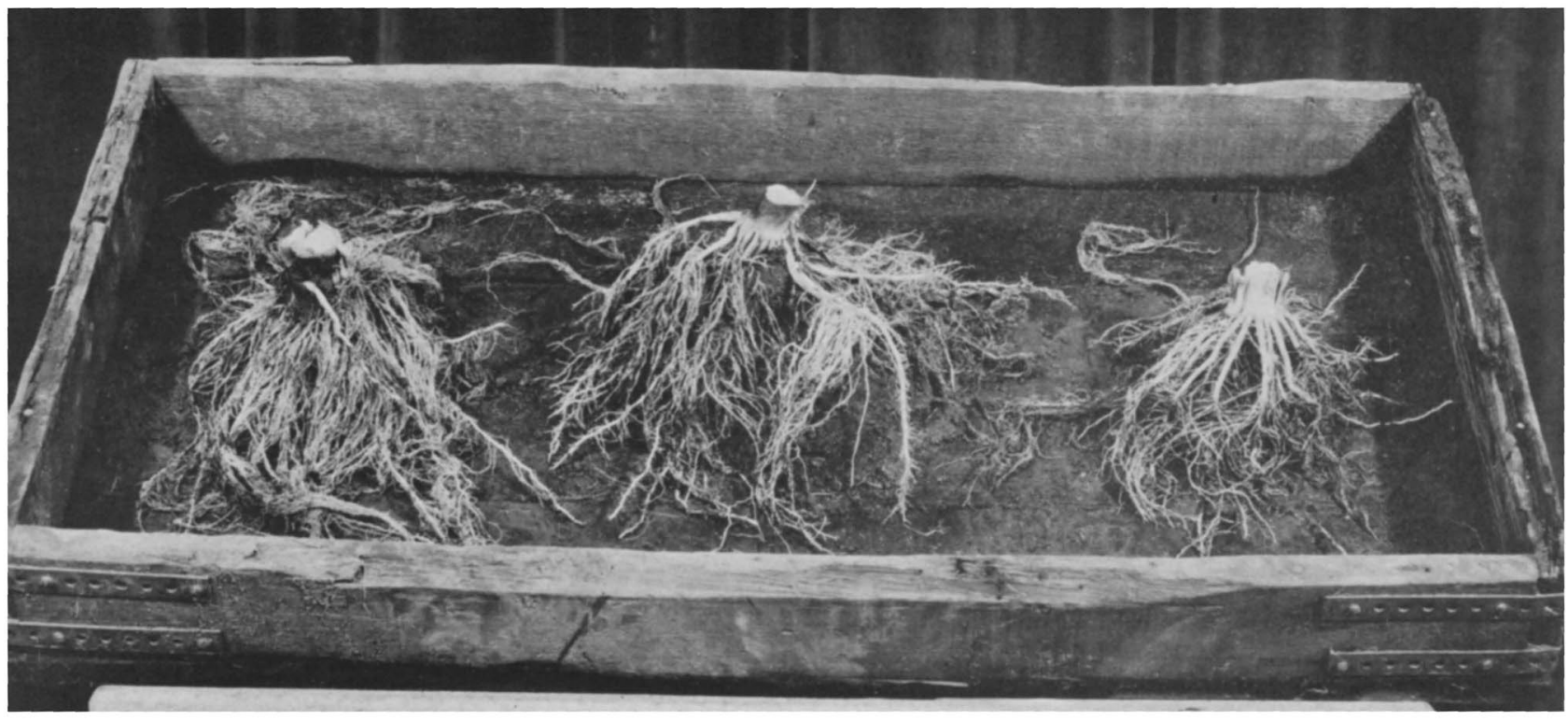

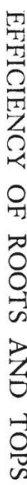

FIG. 19.-Columns ot soll neld by the roots of corn after the rest of the sample had been washed away. 
Similar samples from another field, taken in September, gave results which were lower than those just described. The bare soil eroded in 10 minutes, and the one with corn roots in 15 minutes.

\section{DISCUSSION}

Examination of Table 9 shows plainly that the root system of corn gave practically no resistance to erosion until brace roots began to develop after midsummer. Hence during May and June when the plants are small and the soil kept loose by tillage operations, the heavy seasonal rains cause much damage. Frequently more than half of the total seasonal erosion occurs in June alone (Bartel, '25). Even after brace roots are formed the sphere of influence is greatly localized. The total effectiveness is probably decreased where the crop is grown in hills rather than in drilled rows.

TABLE 9.-Hogue's yellow dent corn grown on lowland soil.

\begin{tabular}{|c|c|c|c|c|c|c|}
\hline \multirow{2}{*}{$\begin{array}{l}\text { Sample } \\
\text { taken }\end{array}$} & \multirow{2}{*}{$\begin{array}{l}\text { Height, } \\
\text { inches }\end{array}$} & \multicolumn{2}{|c|}{ Dry weight, grams } & \multicolumn{2}{|c|}{ Erosion time, Min. } & \multirow{2}{*}{$\begin{array}{c}\text { Erosior } \\
\text { ratio }\end{array}$} \\
\hline & & Tops & $\begin{array}{l}\text { Roots, } \\
\text { etc. }\end{array}$ & Bare soil & With roots & \\
\hline June 30. & 9 & 4 & 3 & 7.5 & 8.0 & $1: 1.0$ \\
\hline July 12 . & 30 & 70 & 15 & 7.5 & 9.5 & $1: 1.3$ \\
\hline July 24 & 58 & 312 & 41 & 8.0 & 11.0 & $1: 1.4$ \\
\hline Aug. 9 & 75 & 430 & 65 & 9.0 & 19.0 & $1: 2.1$ \\
\hline
\end{tabular}

Although missing plants or hills are of little or no significance in reducing crop yields, as has been shown by Kiesselbach ('18), yet they might well act as a contributing factor in increasing soil erosion, since the bare spaces serve as foci for the process of undercutting. In experiments with certain other similarly widely spaced plants, much variation in erosion rate resulted from uneven number of fully grown plants (Holland, '26).

\section{CONCLUSIONS}

These experiments confirm the results of other workers that the character of the vegetation covering the soil is the principal factor in controlling erosion. They also show that the effect when the plant cover is intact exceeds that of underground parts alone 3 to 7 times.

Maximum protection offered by each crop is shown in Table 10. Here it may be seen that winter wheat ranks highest and sorgo second. Alfalfa, because of its smaller leaves, smaller total foliage, and branched habit, proved to be less effective even when in a dense stand. Because of the permanency of protection both summer and winter and the rapid growth in spring and after each cutting, alfalfa clearly outranks wheat as a soil protector.

The amount of living underground material is far less than that of the original grassland. Weaver and Harmon ('35) report 3.3 tons per acre in the surface 4 inches of upland soil and 4.1 tons on lowland. The 
$T_{A B L E}$ 10.- Relative maximum protection against erosion afforded by field crops. Time in minutes.

\begin{tabular}{c|c|c|c|c|c|c|c}
\hline Crop & $\begin{array}{c}\text { Wheat } \\
\text { on } \\
\text { lowland }\end{array}$ & $\begin{array}{c}\text { Wheat } \\
\text { on } \\
\text { upland }\end{array}$ & $\begin{array}{c}\text { Oats } \\
\text { on } \\
\text { onland }\end{array}$ & $\begin{array}{c}\text { Alfalfa } \\
\text { on } \\
\text { upland }\end{array}$ & $\begin{array}{c}\text { Alfalfa } \\
\text { on } \\
\text { lowland }\end{array}$ & $\begin{array}{c}\text { Sorgo } \\
\text { on } \\
\text { upland }\end{array}$ & $\begin{array}{c}\text { Corn } \\
\text { on } \\
\text { lowland }\end{array}$ \\
\hline With tops .... & 113 & 87 & 63 & 48 & 43 & 98 & $\ldots$ \\
Without tops... & 17 & 20 & 12 & 18 & 21 & 18 & 19 \\
\hline
\end{tabular}

maximum amount of wheat roots in the same layer per acre was .67 ton, that of sorgo .66 ton, and that of old alfalfa was only 1.7 tons.

Any factor that prevents the development of a full stand diminishes the value of a crop as a protection to the soil against erosion. Careful study should be given to the handling of row crops so as to maintain the bare surface soil in the best condition to prevent runoff water losses and accompanying loss of soil. Row planting and clean cultivation are ideals of man, not of nature.

The destructive action wrought upon the experimental samples of row crops when water was applied recalled vividly to mind similar devastation on hilly lands of the corn belt witnessed by the writers. Heavy rains of early summer sometimes removed all of the 3 or more inches of soil loosened in cultivation and deposited it on the portions of the field at the base of the slope. The crop was washed out on the hillsides and buried under several inches of soil in the valley. Bennett ('31) reports 5 inches of rain falling on May 10, mostly in 4 hours, on fields planted to cotton in Houston black clay soil at Temple, Texas. The loss was 96 per cent of the rain. The water in running off carried with it 23 tons of soil per acre. This torrential rain was general, falling over approximately 3 million acres of Black Belt land with similar harmful results. A rainfall of 12 inches in 36 hours has recently been reported in California.

On steep slopes and highly erosive lands that are too valuable to abandon crop production, closer spacing of rows or broadcasting the same amount of seed, where feasible, would result in greatly increasing soil protection. In Missouri, for example, soy beans were drilled solid, since when drilled in rows they permitted almost as much erosion as corn (Miller and Krusekopf, '30). Since some crops are more valuable but afford less soil protection than others, strip cropping is desirable.

Any practice which removes plant cover or plant debris from the land is undesirable from the viewpoint of soil conservation. Thus heading the grain is preferable to binding the crop and, after threshing, stacking the straw. Letting the stubble stand hinders erosion; burning aids it. Letting the cornstalks remain in place and the fallen leaves, etc., accumulate as litter is preferable to cutting and shocking the corn and thus exposing bare soil. 
Since any plant cover is better than none, on rolling land especially it is advisable to adjust the rotation so that the land will be covered by a crop practically all of the time.

\section{EXPERIMENTS WITH PASTURE CROPS}

\section{SUDAN GRASS}

Sudan grass (Sorghum vulgare var. sudanense (Piper) Hitchc.) is an annual pasture grass which makes a rapid growth even under a low rainfall. The seed was broadcast at the rate of $22 \mathrm{lbs}$. per acre on June 6 . The rich, alluvial soil had been under cultivation for many years, recently planted to truck crops, and previous plowing and harrowing had produced an excellent condition of tilth.

Initial samples were secured on July 1 when the plants had attained a height of 10 inches and produced a foliage cover of approximately 85 per cent. Rough pigweed (Amaranthus retroflexus L.) and green foxtail (Setaria viridis (L.) Beauv.) were present in small numbers. The sample with plant cover removed eroded in 8 minutes. The living underground parts, when dried, weighed $20 \mathrm{gm}$. They were so fragile that they had little effect in retarding soil erosion when water was applied through the open hose.

When the numerous leafy plants were left intact, erosion time was extended to 13 minutes. The plants lodged immediately under the force of the water, but there was not enough material (58 gm.) to cover completely the whole area. Water striking the bare soil between the rows quickly washed it away and this resulted in rapid undercutting beneath the plants in the rows.

The following 12 days were very favorable to growth and the plants attained a height of 29 inches. The long, broad leaves with the smaller ones of the numerous tillers, produced a foliage cover of 95 per cent (cf. Fig. 20). The dry weight of tops (191 gm.) was 3.3 times that 12 days earlier. Underground parts had more than doubled in weight (44 gm.). Three additional minutes ( 11 in all) were required to erode the bared sample, which was now threaded with roots. The one with cover intact increased from the former 13 to 67 minutes.

The protection furnished by the leaves and stems lodged down the slope was remarkable. In places the cover was an inch thick. For many minutes the runoff water was clear, very little coming in contact with the soil. The water gradually forced its way into the most poorly protected soil, entry usually occurring where plants were thinnest. Areas about the bases of the plants held out longest. The damming effect of the cover. once erosion began, was marked. 


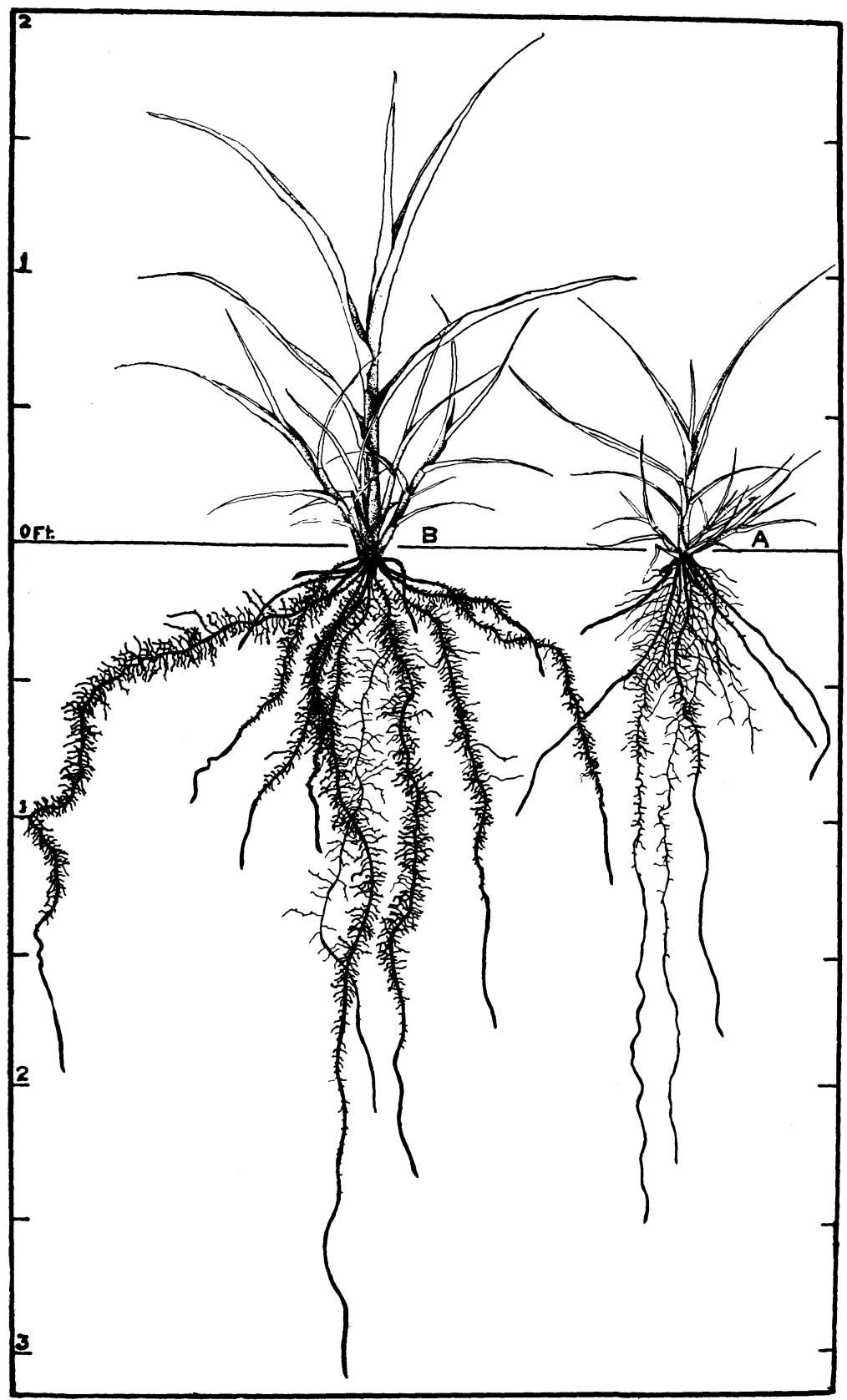

FIG. 20.-Development of Sudan grass 26 and 30 days after planting. (After Peralta) 
Twelve days later, July 24, a third pair of samples was excavated. Very hot, dry weather made it imperative to water the experimental plants, and rapid growth continued. The plants were 40 inches high; the thick stems with their broad leaves and a rather distinct understory of tillers nearly obscured the soil. In a few places only was the cover sufficiently open to permit the growth of weeds, a few green foxtail still persisting. From the clipped material a dry weight of $346 \mathrm{gm}$. was determined. The root system and other underground parts had increased less rapidly in the 4 inches of soil, the dry weight being $53 \mathrm{gm}$. This was largely due to growth of the stem-bases and of rather numerous new lateral roots.

Erosion time of the denuded sample $(12 \mathrm{~min}$.) remained almost as before, but with cover intact the time was greatly prolonged $(95 \mathrm{~min}$.). Under the force of the water the plants were bent over but did not at once flatten upon the surface of the ground, the lodged cover being 5 to 7 inches high. While the loose surface soil was being removed, runoff water was muddy, but after a few minutes it became clear and remained clear for about 40 minutes.

The tangled mass of stems and leaves effectively broke the force of the water for a long time. Finally openings began to develop and erosion followed with increasing intensity. The moving soil was retarded by the check dams formed by the plant materials now closely compacted to the surface. The cover during 24 days of growth had become more than 7 times as effective as on July 1.

The final samples were secured on August 5. Repeated watering had permitted continuous growth. The plants had headed at a height of about 4.5 feet. The dry, basal leaves were still clinging to the stems, the upper green leaves were 15 to 25 inches long. Width varied from one-half to nearly one inch. The thick stems were well anchored by many brace roots. The numerous tillers had also made considerable growth and the understory was well developed. The total dry weight of tops was $489 \mathrm{gm}$. and that of underground parts $77 \mathrm{gm}$. (cf. Fig. 21).

The denuded sample had over 200 crowns and root-bases to anchor the soil. The mass of fibrous roots was found to be much greater than before. Each stem-base served as a center of resistance against soil erosion. After 6 minutes the soil around them had been removed to such a degree that they appeared as small isolated columns. Some remained intact after 13 minutes. The massed network of roots, now much more intricate and stronger than before, delayed soil movement. Total erosion time was 20 minutes, an increase of 67 per cent over that of July 24.

The plant cover protected the soil so thoroughly that during the first 1.5 hours only $3 / 8$ inch was removed. Thereafter the water entered more readily through the battered cover but not until the expiration of 2 hours and 42 minutes was all the soil removed. 


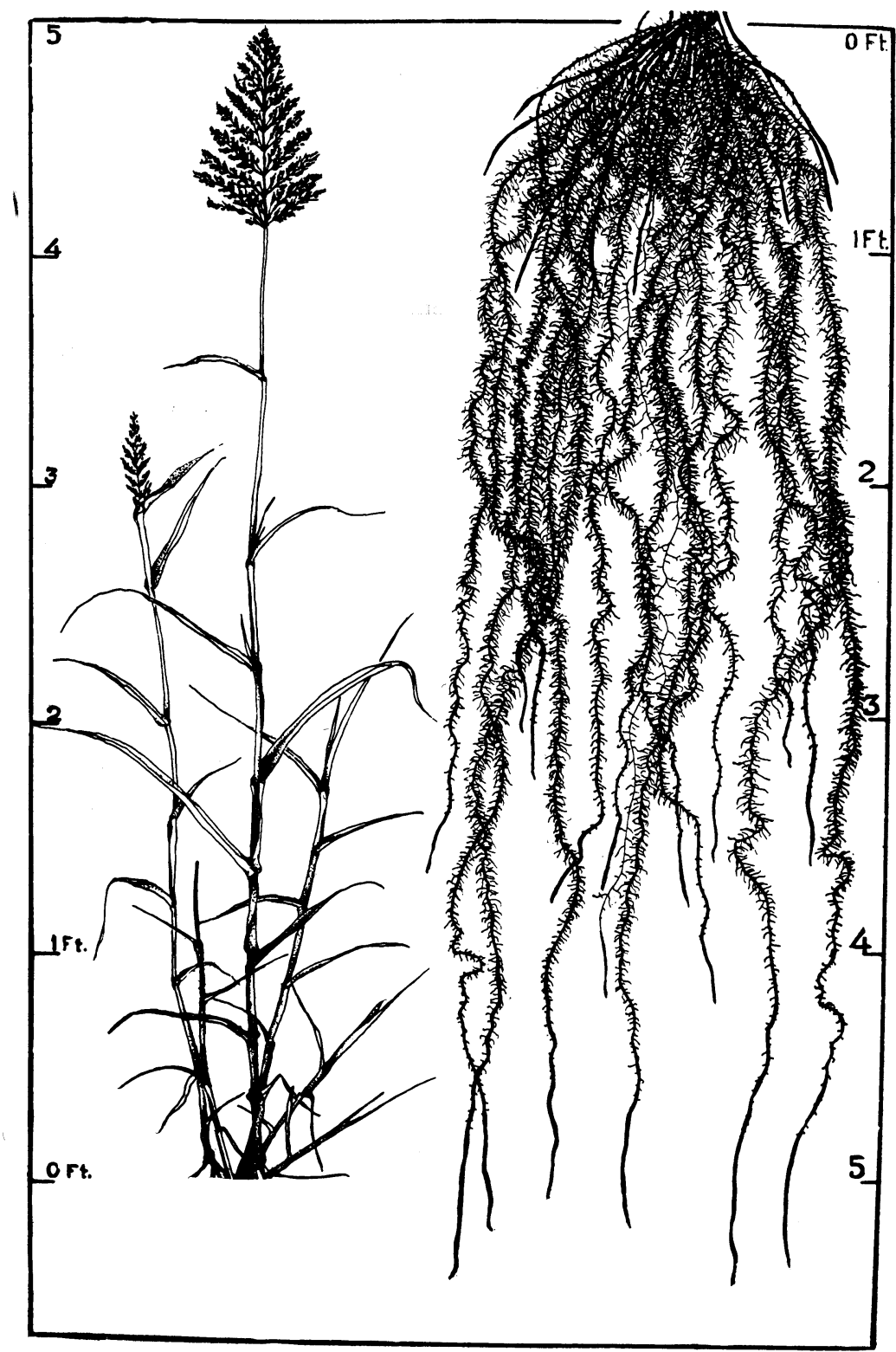

FIG. 21.-Development of Sudan grass when blossomıng, 56 days after planting. Neither tops nor roots have attained their maximum size. (After Peralta) 
Two additional pairs of samples were secured from another field 10 days later. The soil was also alluvial in origin and very similar in texture. The smaller number of parent plants per sample was compensated by the greater number and better development of tillers. The tops weighed slightly more (ave. $501 \mathrm{gm}$.) and the roots (ave. $61 \mathrm{gm}$.) somewhat less than those of the preceding sample. Erosion time for the denuded samples was 17 minutes and that of the control 181 minutes. These results are in general agreement with those of August 5.

\section{DISCUSSION}

The results of this series of experiments are given in Table 11 and Figure 22. The efficiency of the rapidly growing roots is shown by the steady increase in erosion time from 8 minutes, when the crop was 10 inches tall on July 1, to 20 minutes, when it had reached a height of 56 inches on August 5. The effectiveness of the tops increased much more rapidly, the erosion ratio increasing from 1:1.6 to $1: 8.1$ during this 34 -day period of growth.

TABLE 11.-Sudan grass grown on lowland soil.

\begin{tabular}{|c|c|c|c|c|c|c|c|}
\hline \multirow{2}{*}{$\begin{array}{c}\text { Sample } \\
\text { taken }\end{array}$} & \multirow[b]{2}{*}{$\begin{array}{l}\text { Height } \\
\text { in. }\end{array}$} & \multirow{2}{*}{$\begin{array}{l}\text { Cover } \\
\text { P.ct. }\end{array}$} & \multicolumn{2}{|c|}{ Dry wt., gm. } & \multicolumn{2}{|c|}{ Erosion time, Min. } & \multirow{2}{*}{$\begin{array}{l}\text { Erosion } \\
\text { ratio }\end{array}$} \\
\hline & & & Tops & $\begin{array}{c}\text { Roots, } \\
\text { etc. }\end{array}$ & $\begin{array}{c}\text { Without } \\
\text { tops }\end{array}$ & $\begin{array}{l}\text { With } \\
\text { tops }\end{array}$ & \\
\hline July 1 & 10 & 85 & 58 & 20 & 8 & 13 & $1: 1.6$ \\
\hline July 12 & 29 & 95 & 191 & 44 & 11 & 67 & $1: 6.0$ \\
\hline July 24 & 40 & 100 & 346 & 53 & 12 & 95 & $1: 7.9$ \\
\hline Aug. 5. & 56 & 100 & 489 & 77 & 20 & 162 & $1: 8.1$ \\
\hline
\end{tabular}

A good stand of Sudan grass is more efficient in preventing soil erosion than any of the field crops investigated. Its high efficiency results from a combination of abundant, long leaves, close spacing of plants, and the strong fibrous root system. The dry weight of tops was less and that of underground parts about equal to winter wheat grown in similar soil. Although it is a short-lived crop, once the seedlings are established they soon develop an efficient protective cover. Too thin seeding is compensated by abundant tillering. The roots elongate at the rate of .75 to 1 inch per day; a height of 13 inches is reached in 20 days and over 4 feet in 40 days, and tillering is profuse (Peralta, '35). Its rapid development of resistance to erosion, its ability to grow on many types of soil, its resistance to drought, and later the production of abundant litter, together make it a valuable crop for use in strip cropping, etc. Moderate pasturing leaves much cover to protect the soil during winter.

\section{४ง $\Lambda$ ОТО Іа马MS}

A single pair of samples of yellow sweet clover (Melilotus officinalis (L.) Lam.) was secured from a lowland field. The two-year-old plants were 


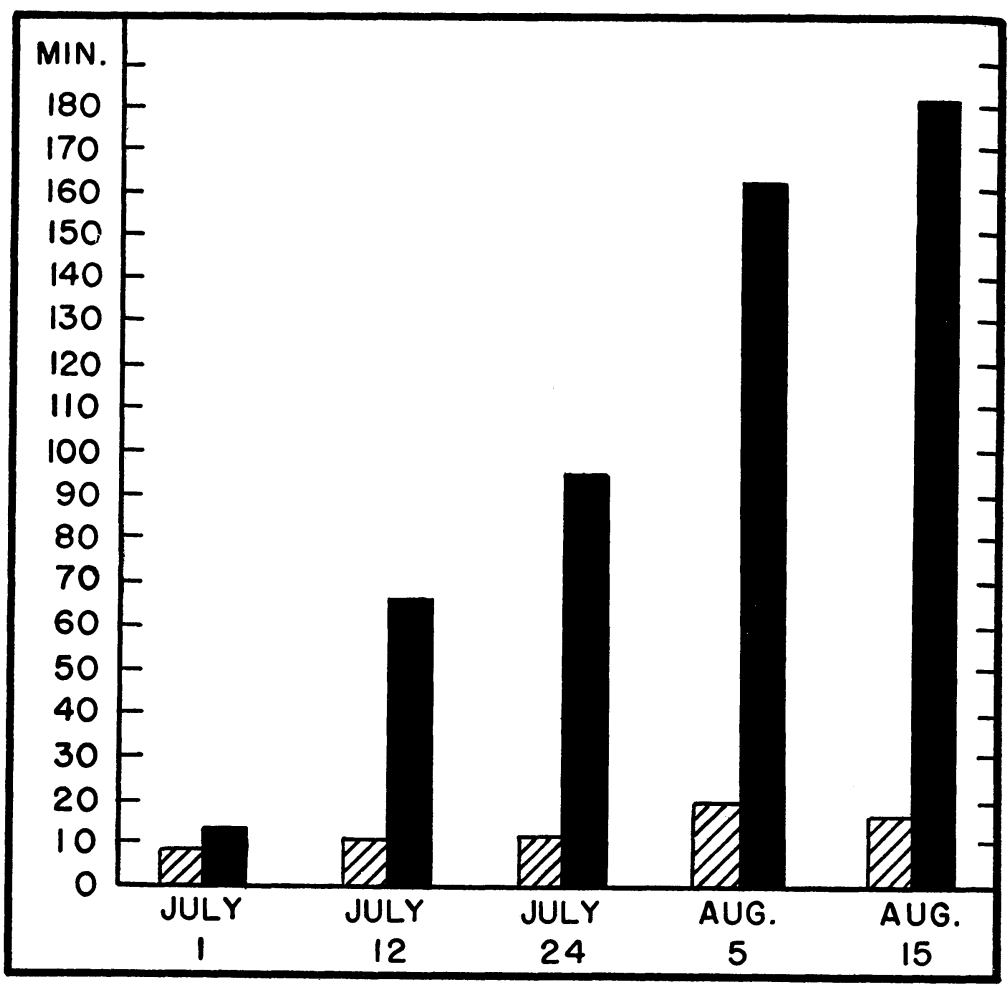

FIG. 22.- Relative efficiency of underground parts of Sudan grass without tops (hatched) and with tops (black) in preventing erosion.

about 28 inches tall and in full bloom on June 20. The tops were much branched and the foliage was so dense as to obscure completely the soil beneath. There were, in addition, numerous young plants in the undergrowth.

The tops of the plants bent downward under the force of the water and formed a tangled mass which was held a long time several inches above the soil surface by the coarse main stems and larger branches. This tangle of stems, foliage, and racemes of flowers broke the force of the water which was then conducted more gently to the surface of the soil. Exceptions were areas where only a few stems occurred and the foliage was correspondingly sparse. Here the water struck with much force and resulted in the loosening of the soil. Notwithstanding the rather large dry weight of the foliage $(233 \mathrm{gm}$.), the coarse stems and small leaves did not form a thatch as do the grass crops and the protection was less efficient. First removing the soil beneath the thinnest cover and then washing away 
the rest of the sample, the runoff water was muddy during the entire 64 minutes the open hose was employed.

The strong taproot system, like that of alfalfa, is only moderately supplied with fibrous rootlets in the surface soil. In the denuded sample, the taproots furnished $39 \mathrm{gm}$. dry weight, the fibrous branches only $27 \mathrm{gm}$. This included a few living roots of weeds. The firmly anchored taproots afforded some resistance to soil removal when water was applied, but the rather small network of fibrous roots was not very effective in retarding erosion. Hence the whole sample was washed away in only 15 minutes.

\section{RAPE}

Rape (Brassica napus L.) is frequently used in eastern Nebraska for pasturing swine. Samples were secured from such a pasture on June 23. Each contained about 120 plants. The stand of these broad-leaved plants, which were two feet tall, was excellent. Viewed from above practically no soil was visible. Between some plants, however, the protection afforded was often that of only the thickness of a single leaf. The succulent tops from a half-meter area weighed $222 \mathrm{gm}$. when dried.

When water was applied, the plants bent over and became tangled in such a manner as to form a series of ridges which broke the force of the stream. During the first half hour this jumbled mass of tops stood 10 to 15 inches above the soil surface. The broad, glaucous, turgid leaves were very effective in soil protection. Even an isolated leaf was remarkably efficient. But in the more open places, water found its way to the soil which was then slowly removed. With the undermining of the individuals, the plants lodged on the soil surface and in so doing left new openings for further erosion. After 1 hour and 6 minutes erosion was complete.

Underground parts of the denuded sample had a dry weight of $44 \mathrm{gm}$. Of this only $9 \mathrm{gm}$. were fine branches, the remainder was taproots. Erosion was completed in only 10 minutes.

\section{DISCUSSION}

These two unrelated types of dicotyledonous plants, because of their structural characteristics, both offered remarkable resistance to water erosion. In both the resistance was due overwhelmingly to tops and not to underground parts, although those of sweet clover were at least onethird more efficient than roots of rape. Fortunately both are valuable as temporary pasture crops. Resistance offered by the mustard was due almost entirely to the broad, glaucous leaves. The branched stems of the legume together with the small compound leaves resulted in an erosion ratio of 1:4.3 as compared with 1:6.6 for rape. An example of the efficiency of sweet clover may be harl from Guthrie, Oklahoma. Soil planted to cotton without a winter cover crop lost, from January to June, 15.9 tons per acre by erosion. Oats reduced the loss to 3.9 tons, and sweet clover to 0.5 ton per acre (Winters, '30). 


\section{HUNGARIAN BROME GRASS}

Samples of Hungarian brome grass (Bromus inermis Leyss.) were secured from a 4-year-old pasture on lowland soil. The field had been sown to a pasture mixture of several grasses and legumes in 1931, but, with rare exceptions, only a stand of brome grass remained in 1935. The area had been mowed annually for hay, and light pasturing was also practiced. The stand was rather thin over most of the field, the foliage cover rarely exceeding 40 to 50 per cent, but on the lowest ground it was dense. Here the foliage cover varied between 85 and 100 per cent. Pasturing, especially when the soil was wet, had compacted the surface.

Samples from the low ground were secured on June 26. The grass was in full bloom, the widely spread panicles forming a layer at a height

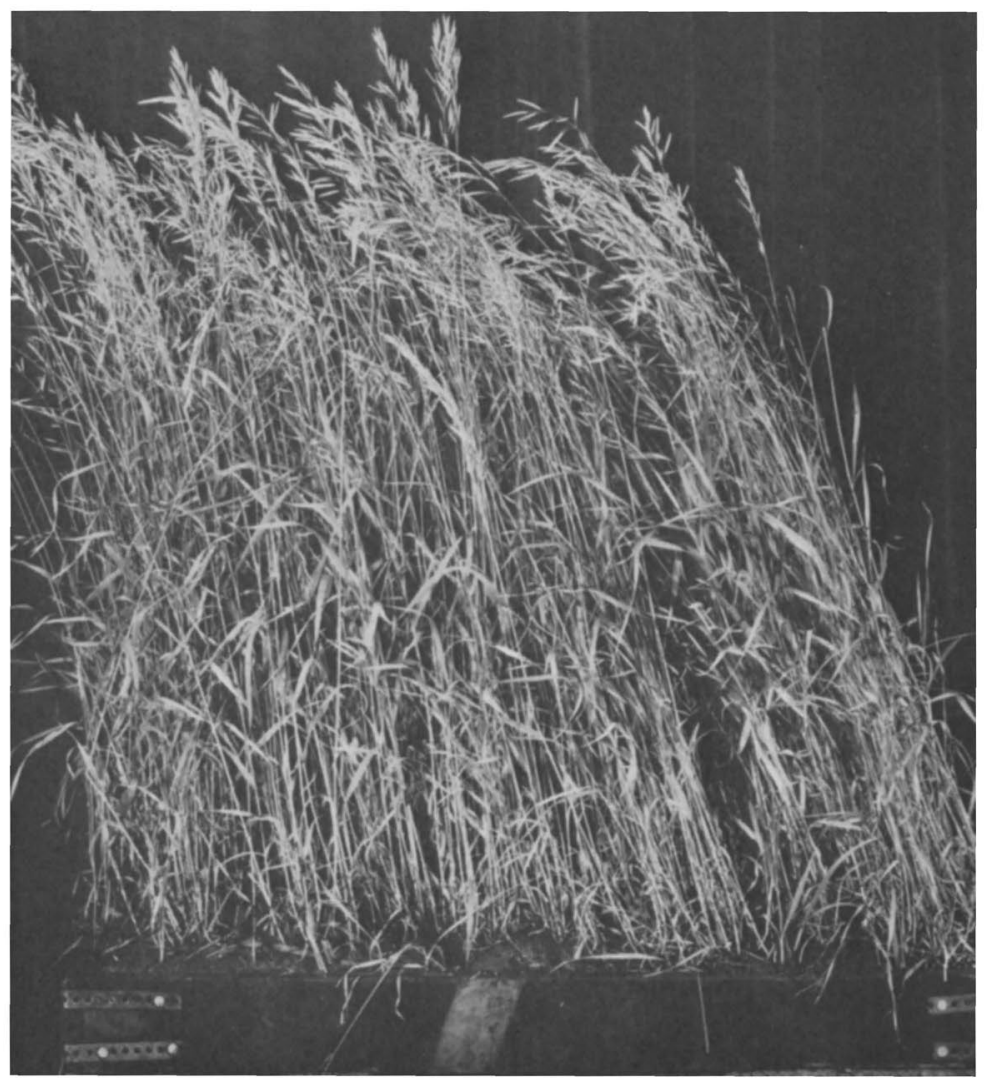

Fig. 23.--Sample of Hungarian brome grass secured from an old pasture on July 1 when the plants were in bioom. 
of 36 inches. The bulk of the foliage did not attain a height beyond 20 to 24 inches. A third layer, 3 to 6 inches high, was composed of the dead basal foliage which still clung to the stems. The mass of plant materials, $357 \mathrm{gm}$. in dry weight, completely obscured the soil (Fig. 23).

Lodging under the impact of the water, this mass of plants served as a barrier through which water scarcely penetrated. Instead it ran from the surface as clear water. After two hours with the open hose, the smaller stream of greater force was applied. For about an hour the water still remained almost free of sediment. The continued impact of the water, however, finally forced an opening in the much compacted cover and erosion began. It continued during a period extending over two hours before all of the soil was removed. Thus 2 hours with the open house and 3 hours and 5 minutes with the nozzle attached were required to erode the single one-half square meter.

When the cover was removed, runoff water was muddy from the beginning. After the surface inch was eroded, the numerous stem-bases and the great mass of rhizomes and fibrous roots were exposed.

These underground parts, with a dry weight of $220 \mathrm{gm}$., formed an excellent protection against further erosion. The thread-like rhizomes were 8 to 15 inches long, and with the interwoven mass of tough, brownish roots formed an unbroken mat which was 0.5 to 1 inch thick after all of the soil had been removed (Fig. 24). When dried, the mat was similar to a fiber rug.

With the gradual removal of the soil, the thickness of the root-rhizome mat protecting the soil surface increased. Two hours with the open hose and 25 minutes with nozzle attached were required to complete the process of erosion.

Two days later' a second pair of samples was dug from the higher ground. Here the flower stalks were only 28 inches tall and the general level of the foliage 15 inches. The layer of dead basal leaves was far less pronounced. The cover afforded was only 45 per cent, and its dry weight $158 \mathrm{gm}$.

Not enough plants were present, even when lodged, to completely cover the soil. Hence erosion began simultaneously with the application of water, and it seemed that the time interval might be short. With the exposure of the underground parts, however, the rate was so much diminished that even after 2 hours erosion was far from complete. In fact, the soil had been removed to about an inch only in average depth. After the nozzle was attached the process was greatly accelerated, although 1 hour and 7 minutes passed before erosion was complete.

The protecting and binding action of the mass of underground parts was again exhibited when the sample with tops removed was eroded. The mat was only about two-thirds as great (150 gm.) as that of the previously 


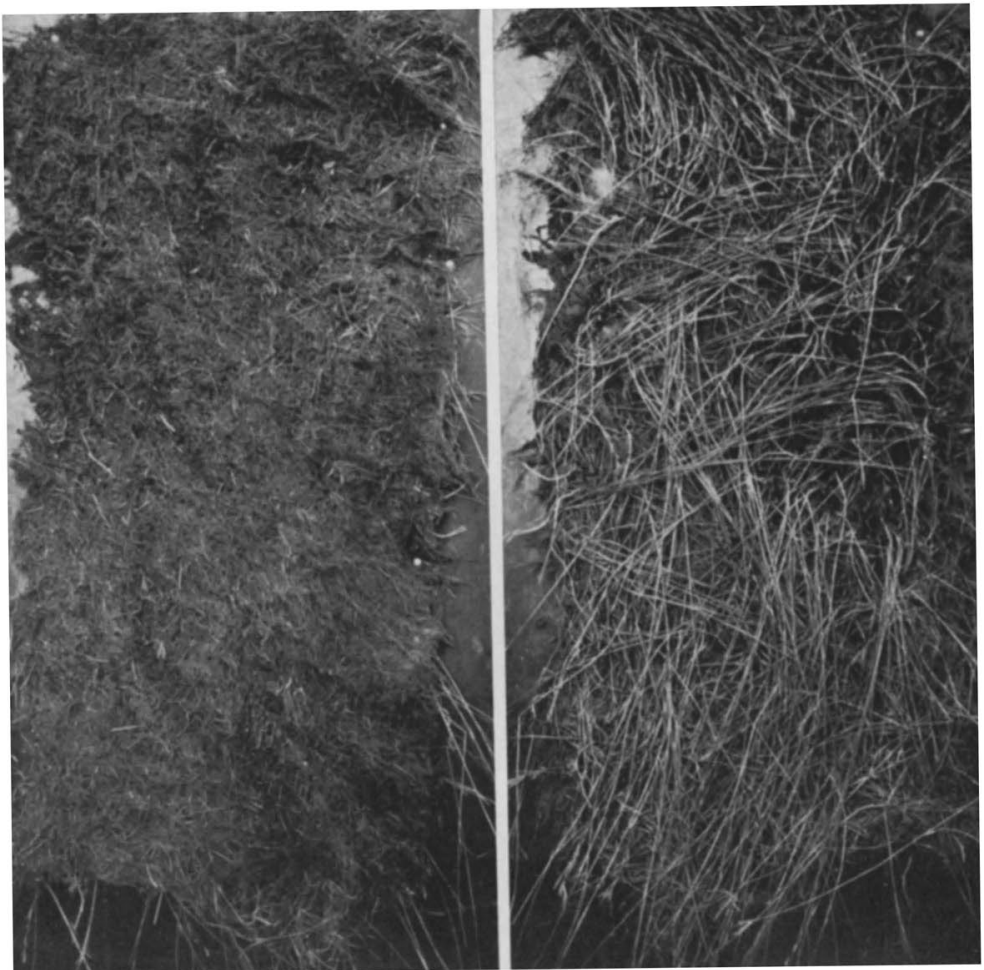

Fig. 24.-Two views of the dense mat formed by the underground parts of Hungarian brome grass in the surface 4 inches of soil.

clipped plants, hence its resistance to erosion was proportionately less. Erosion time was 2 hours with the open hose and 10 minutes with nozzle attached.

\section{DISCUSSION}

The difference between the two samples of brome grass was mainly a difference in the thickness of stand. Allowing for the compactness of the soil, the resistance of this 4-year-old grass crop is outstanding. The tops broke the force of the water and conducted much of the water away while the roots firmly bound the soil. The root-mat closely resembled that of bluegrass, only that of brome grass was thicker. The denser the plant cover, the more effective was the power of the crop to check soil erosion. Thus the thicker stand (357 gm. dry wt.) resisted soil removal 1.6 times as long as the thinner one (158 gm.). Difference in time of erosion of soil held by roots alone was much less (Table 12). 
TABLE 12.-Results of erosion of various pasture crops with and without tops.

\begin{tabular}{|c|c|c|c|c|c|c|c|c|}
\hline \multirow[b]{2}{*}{$\begin{array}{l}\text { Kind } \\
\text { of crop }\end{array}$} & \multirow[b]{2}{*}{$\begin{array}{l}\text { Sample } \\
\text { taken }\end{array}$} & \multirow[b]{2}{*}{$\begin{array}{l}\text { Height } \\
\text { in. }\end{array}$} & \multirow[b]{2}{*}{$\begin{array}{l}\text { Cover } \\
\text { P. ct. }\end{array}$} & \multicolumn{2}{|c|}{ Dry wt., gm. } & \multicolumn{2}{|c|}{ Erosion time, Min. } & \multirow[b]{2}{*}{$\begin{array}{c}\text { Erosion } \\
\text { ratio }\end{array}$} \\
\hline & & & & Tops & $\begin{array}{l}\text { Roots, } \\
\text { etc. }\end{array}$ & $\begin{array}{c}\text { Without } \\
\text { tops }\end{array}$ & $\begin{array}{l}\text { With } \\
\text { tops }\end{array}$ & \\
\hline Sweet clover & June 20 & 28 & 100 & 233 & 66 & 15 & 64 & $1: 4.3$ \\
\hline Rape & June 23 & 25 & 95 & 222 & 44 & 10 & 66 & $1: 6.6$ \\
\hline Brome grass & June 26 & 36 & 98 & 357 & 220 & $120+^{1}$ & $120 t^{2}$ & $1: 7.4$ \\
\hline Brome grass & June 28 & 28 & 45 & 158 & 150 & $120-^{3}$ & $120-4$ & $1: 6.7$ \\
\hline Rye & Oct. 25 & 4 & 98 & 69 & 37 & 10 & 19 & $1: 1.9$ \\
\hline
\end{tabular}

1 Plus 25 minutes with nozzle attached.

2 Plus 3 hours and 5 minutes with nozzle attached.

3 plus 10 minutes with nozzle attached.

4 Plus 1 hour and 7 minutes with nozzle attached.

The more nearly a crop approaches the native prairie grasses in its form, manner of growth, and length of life, the greater is its efficiency in resisting the forces of erosion. Hence the excellent manner in which brome grass binds and holds the soil in hilly pastures and especially on recently graded roadsides is readily understandable.

RYE

A sample of Rosen rye (Secale cereale L.) was taken on October 25 from a lowland field where the crop had been thickly drilled for late fall pasture. The field had also grown rye the preceding year. The plants were 4 inches tall and formed a thick mat of vegetation. The overlapping leaves afforded an almost complete cover of foliage (Fig. 25). The three rows of the denuded sample, each one meter long, contained nearly 1,000 plants and tillers. The dry weight was $69 \mathrm{gm}$.

The rows of plants presented such dense foliage that it served effectively in preventing erosion, since the water could scarcely penetrate the cover. The less protected areas between the rows were the first to erode. After this soil was removed, the rows themselves were undermined, the whole process being accomplished in 19 minutes.

Without tops the soil sample was completely eroded in 10 minutes. Underground parts, when dried, weighed $37 \mathrm{gm}$.

\section{DISCUSSION}

Winter rye, like winter wheat, is a cover crop for the soil during a season when most crops do not thrive. Rye drilled thickly for pasture offers more protection than does wheat which is sown later in the fall. In these experiments the two crops grew on similar soils. Tops of the rye weighed more than three times as much as those of the wheat and roots were nearly 2.5 times as abundant. Wheat was secured 15 days later. Without tops, erosion time was 43 per cent greater in rye and 73 per cent greater where the plant cover was intact. 


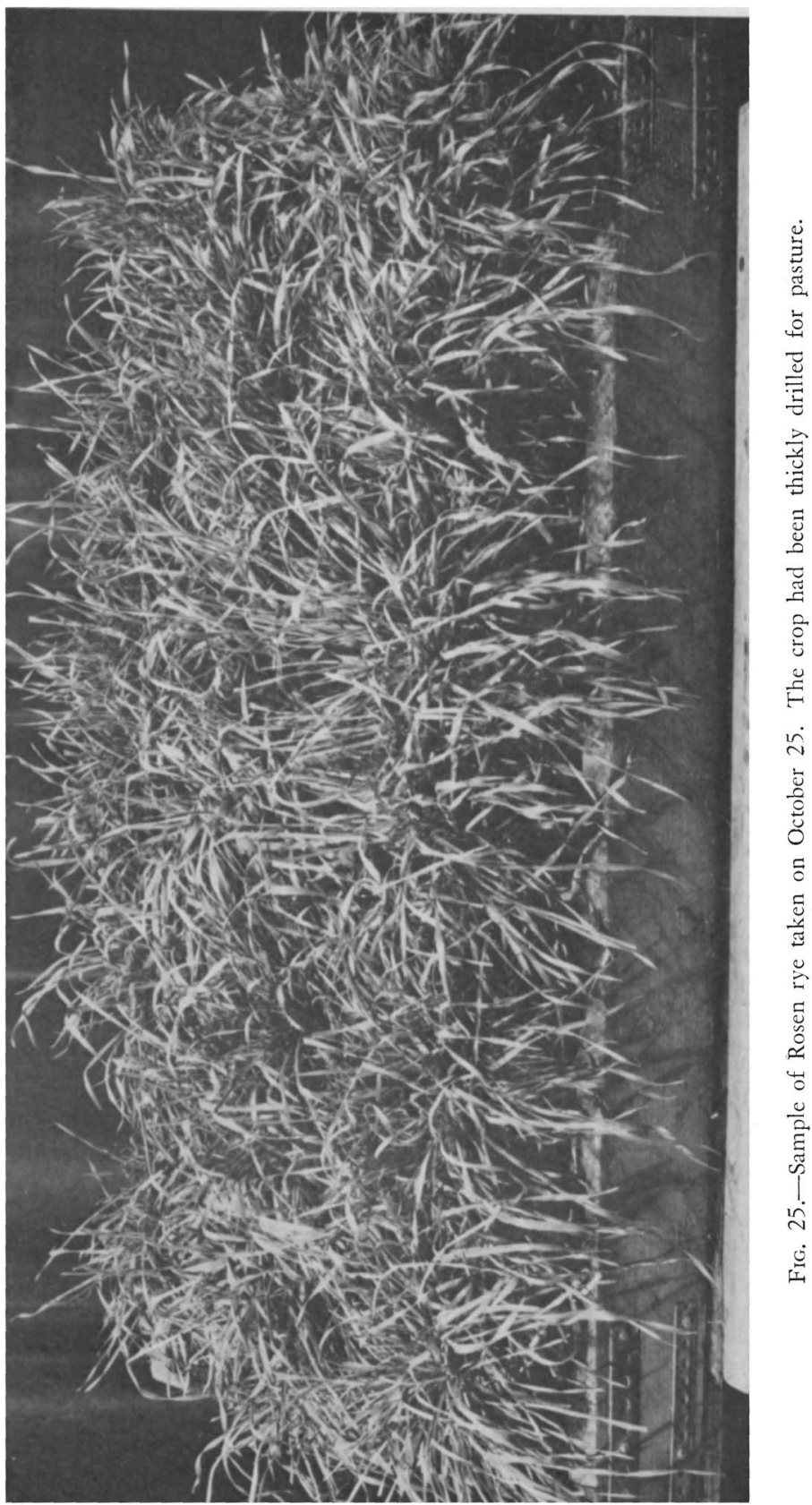




\section{CONCLUSIONS}

From the data summarized in Table 13 it may be seen that there is a wide variation in the effectiveness of different pasture crops in retarding erosion. In general, crops with the longer life span are the more effective, and among these, sod-forming grasses are best. In fact, Hungarian brome grass approaches native prairie grasses in its efficiency as a soil binder. The advantages of pasture crops over those of tilled fields in preventing erosion are very great. The plants, not being confined to rows, may exert a direct and continuous influence over the whole area. The undisturbed soil becomes consolidated, partly by roots spreading through it to near the surface. Any fallen litter is held in place and further protects the soil. Moderate

TABLE 13.- Relative maximum protection against erosion afforded by pasture crops. Time in minutes.

\begin{tabular}{c|c|c|c|c|c|c}
\hline Kind of crop & $\begin{array}{c}\text { Sudan } \\
\text { grass }\end{array}$ & $\begin{array}{c}\text { Sweet } \\
\text { clover }\end{array}$ & Rape & $\begin{array}{c}\text { Brome } \\
\text { grass, } \\
\text { thick }\end{array}$ & $\begin{array}{c}\text { Brome } \\
\text { grass, } \\
\text { thin }\end{array}$ & Rye \\
\hline Without tops ... & 20 & 15 & 10 & $120^{1}$ & $120^{3}$ & 10 \\
With tops .... & 162 & 64 & 66 & $120^{2}$ & $120^{4}$ & 19 \\
\hline
\end{tabular}

1 Plus 25 minutes with nozzle attached.

2 Plus 3 hours and 5 minutes with nozzle attached.

3 Plus 10 minutes with notzle attached.

Plus 1 hour and 7 minutes with nozzle attached.

pasturing, as in Sudan grass, rye, and other grasses, promotes tillering, and the low cover increases considerably in basal area and surface root materials. Early spring growth of perennials and the rapid reestablishment of a new plant cover, reinforced in its efficiency by the remains of the old one, afford much protection during heavy, early seasonal rains.

The forester secures maximum benefit in protecting eroding soil by selecting trees of rapid growth and dense crowns that furnish abundant litter. Permanency of growth is a chief consideration. If they seed early, produce suckers or root sprouts freely, or layer as do willows, poplars, and red maples, so much the better. The object is to produce quickly a complete cover (McIntyre, '35). Similar objectives-density and permanency of cover-are to be sought in maintaining or reclaiming highly erosive soils, and in holding soils on steep slopes and elsewhere. Extending pasture acreage, maintaining a plant cover at all times, and pasture improvement on overgrazed areas are chief weapons against wastage of soil fertility or the soil itself through erosion.

\section{EXPERIMENTS WITH GARDEN CROPS}

\section{POTATOES}

Three pairs of samples of potatoes (Solanum tuberosum L.) were secured, two from lowland and one from upland, on July 15-23. The plants 
had completed their growth above ground but were still in excellent condition. Those of the first lowland samples were 18 inches tall. A sample included 3 hills, each containing 2 main stalks. The bushy plants had a spread of about 2 feet and the $249 \mathrm{gm}$. of tops covered approximately 90 per cent of the soil. The prominent, coarse branches, 0.5 to 0.8 inch in diameter, formed a conspicuous part of the cover.

The soil denuded of plant cover was readily washed away. The mass of coarse roots in the surface 4 inches was not extensive nor were fibrous roots abundant (Fig. 26). The coarse fibrous roots, of $17.5 \mathrm{gm}$. dry weight, did not spread throughout the entire sample nor lend firm anchorage to the soil. The soil around the numerous tubers was also readily washed away, the entire process of erosion requiring only 9 minutes.

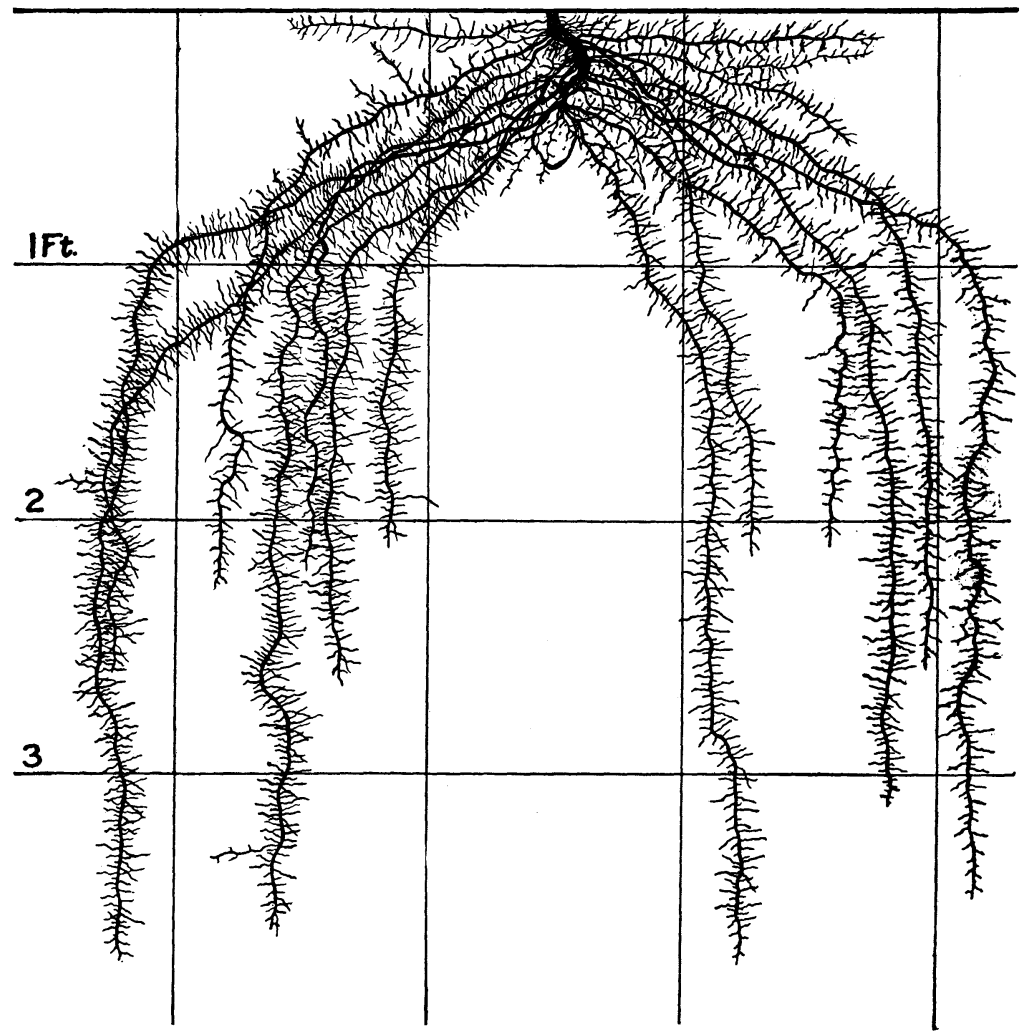

Fig. 26.-One-half of the root system of a mature potato plant showing limited extent of roots in the surface 4 inches of soil. 
Water striking against the foliage caused the plants to lodge closely to the soil. The force of the water was broken and the stream deflected rather unevenly. The younger branches with their abundance of leaves offered the greatest resistance. Between the poorly foliated, coarser stems the water found ready access to the soil. Since there was not enough plant material for a complete cover over the whole surface, the soil was entirely removed in 25 minutes.

Plants of a second sample from another lowland field were also 18 inches tall. The branches spread widely, and there were 2 to 3 main stalks in each hill. Although the dry weight of the tops (259 gm.) was only 10 grams more than that of the preceding sample, the tops consisted of a greater number of slender vines and a larger number of more evenly distributed leaves. In fact, it seemed to be a case where the "plants had all gone to vines," for while the soil was completely obscured the tubers were few and small.

Under the impact of the water, the plants quickly lodged, covering the soil with a thick layer of stems and leaves. So dense was the cover that for a time the force of the water was effectively broken; consequently there was little erosion. The rather stiff, coarse stems held most of the foliage away from the soil and no thatched canopy could be formed. Neither was there much damming of the soil. After 25 minutes the surface was irregularly and deeply eroded. Once this was accomplished, the process was completed after an additional period of 10 minutes. Without the protection of tops, erosion of the second sample was completed in 10 minutes. Dry weight of the fibrous roots was again small, only $16.1 \mathrm{gm}$.

The upland field, from which the final samples were secured, had previously been used for temporary pasture. The plants were only 15 inches tall and a total spread of 18 inches had been attained. The coarse branches and sparse foliage covered only about 60 per cent of the soil. The dry weight of tops was $166 \mathrm{gm}$. The compact soil of the denuded sample required 10 minutes for its removal. The underground parts exclusive of tubers weighed $11.5 \mathrm{gm}$. The very open, inadequate cover of the second sample permitted erosion to begin almost at once. First the unprotected soil was removed and next the remaining portion was undermined, the whole process requiring only 18 minutes.

\section{SWEET POTATOES}

Samples of sweet potatoes (Ipomoea batatas Lam.) were obtained from two separate gardens in upland soil. The soil samples, dug on August 11, were completely obscured by the dense, widely spreading vines, which formed a loose cover 8 to 10 inches thick. When dried, that over one-half square meter weighed $238 \mathrm{gm}$.

When water was applied the mass of vines and leaves flattened to the ground and broke the force of the stream. The strongest barrier was 
formed by the crowns of the two plants in the sample where the numerous stems originated. Since the broad leaves did not form a complete thatch, as do the leaves of many monocotyledons, the water gradually forced openings through the weakest points in the cover. Erosion of the loose soil once begun, became accelerated and in 37 minutes all of the soil had washed away.

The usual development of an abundance of fine fibrous roots in the surface soil had been hindered by deep cultivation (cf. Fig. 27). Those present $(11.9 \mathrm{gm}$.) offered so little resistance to soil movement that the denuded sample was eroded in 8 minutes. The few coarser roots added only $18.3 \mathrm{gm}$. to the weight of underground parts.

A second pair of samples, taken on August 16, had somewhat more foliage (251 gm.) and grew in a more compacted soil. The fibrous roots were, however, practically the same, $11.5 \mathrm{gm}$. Erosion time for the sample protected by tops was 43 minutes. To erode the denuded one required only 10 minutes.

PEAS

Samples of garden peas (Pisum sativum L.) were taken from an upland garden on August 12. Each sample contained 9 plants distributed in three hills. The plants were 22 inches tall and had sufficient foliage to cover 85 per cent of the soil. The dry weight of tops was $157 \mathrm{gm}$. and that of roots $13.9 \mathrm{gm}$. Although the long, coarse roots spread throughout the sample they offered little resistance to erosion. The fourth inch of soil was sufficiently compacted to extend the erosion time of the denuded sample to 12 minutes.

After a single minute under the stream of water, the plants lodged forming a cover only 4 to 8 inches tall. It was especially efficient in shedding water near the middle of the box where the leaves were most concentrated. The overlapping leaves, supported beneath by numerous stems, not only broke the force of the water but also conducted it gently to the sides or lower end of the sample. Weak places in the discontinuous cover permitted erosion to begin, and once started it became continuously accelerated so that within 30 minutes it had removed the last of the soil from the taproots.

CARROTS

The sample of carrots (Daucus carota L. var. sativa DC.) consisted of 33 large and 15 small plants in a one-meter row (Fig. 28). They were 14 inches tall and the mass of foliage furnished a cover of approximately 95 per cent. The tops gave a dry weight of $240 \mathrm{gm}$. The force of the water caused the plants to lodge at once forming a ridge-like mass which was particularly efficient in protecting the middle of the sample. The ends of the leaves touching the soil near the sides of the box caused considerable damming effect as the loose soil slowly moved to the lower end and was 


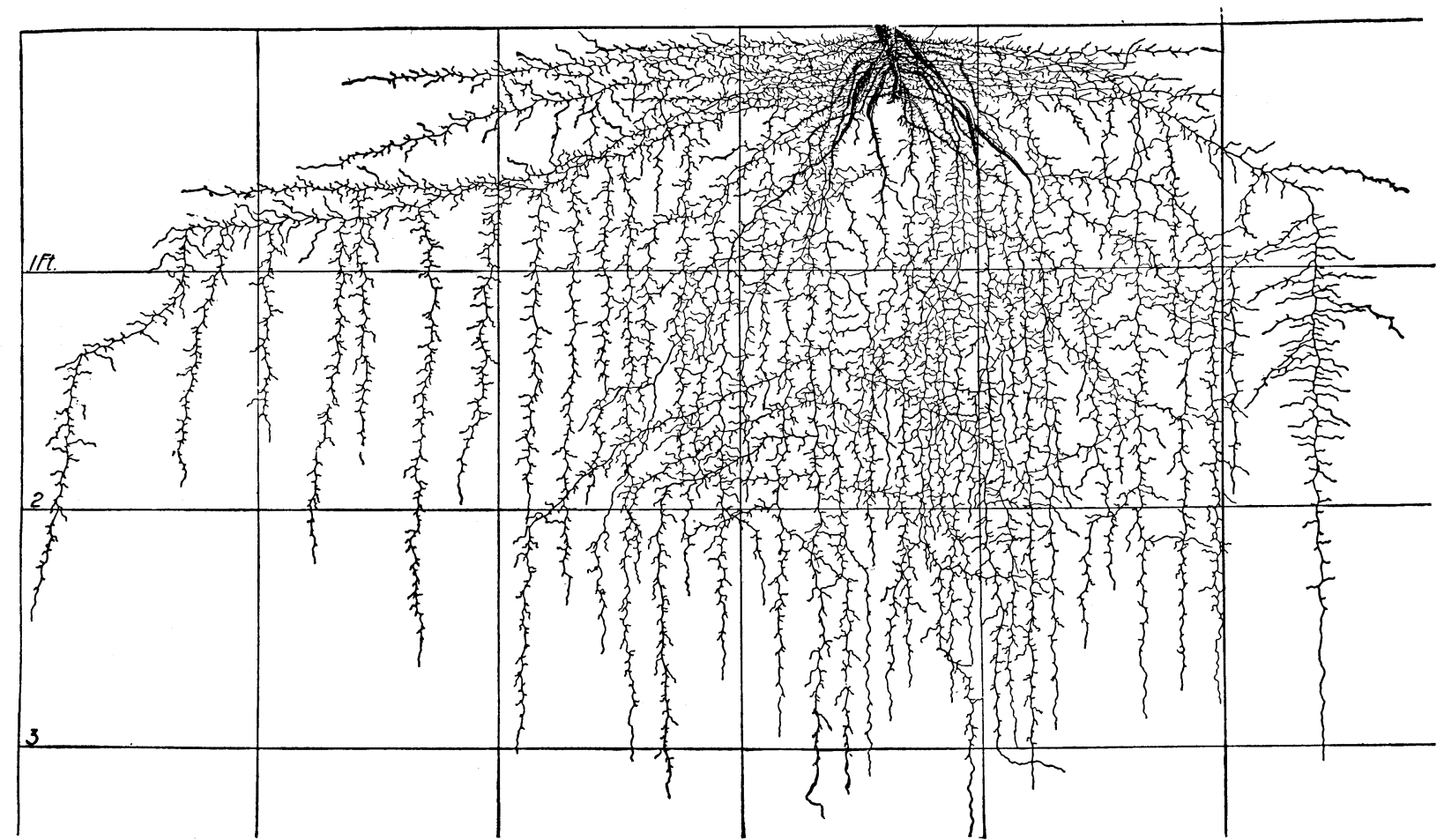

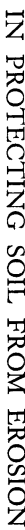

FIG. 27.-Development of the root system of sweet potato on July 25. (After Weaver and Bruner, Root Development of Vegetable Crops. McGraw-Hill Book Co.) 


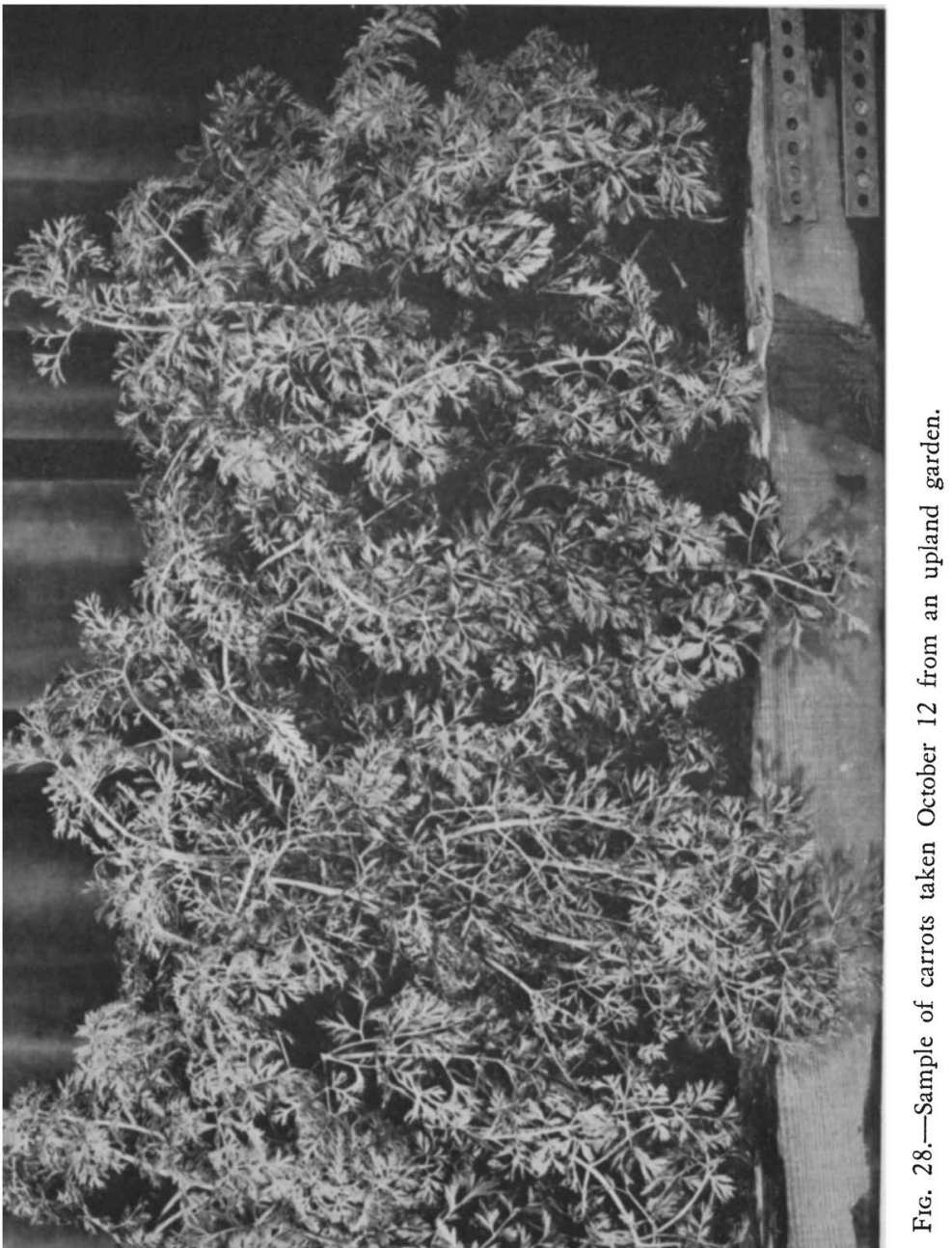


washed through the openings. Undercutting from the sides of the row, the water removed the soil from about the fleshy taproots, and erosion was complete after 49 minutes.

The fleshy taproots of the carrots were poorly branched in the surface 4 inches (Fig. 29). The laterals yielded only 5 gm. dry weight. Since all were in one row, resistance to erosion was greatly localized and the whole sample washed away in 11 minutes.

\section{PARSNIPS}

A single pair of samples of parsnips (Pastinaca sativa L.) was taken from an upland garden on October 4. Each sample consisted of a single row one meter long. The late summer had been one of drought and the plants were not large. The rounded tops were 12 inches tall and spread only widely enough to cover three-fourths of the soil. The dried tops weighed $140 \mathrm{gm}$. The centers of the crowns alone fully broke the force of the water. The much dissected leaves of the fallen plants spread widely over the soil, but near the periphery of the plant mass offered little resistance to erosion. After only 23 minutes the entire sample had been washed away.

As the bared sample quickly eroded it was evident that the taproots offered little resistance. The meager growth of fibrous roots weighed only $4.1 \mathrm{gm}$. So little resistance to soil movement occurred that erosion was completed in 10 minutes.

\section{TOMATOES}

A single pair of samples of common tomato (Lycopersicon esculentum Mill. var. commune Bailey) was excavated on September 28 from a rather compact upland soil. The two large plants of each sample entirely covered the soil. The heavy branches were spread widely over the surface; the more erect ones reached a height of 25 to 30 inches. Foliage was well developed (Fig. 30). The coarse stem-bases did not begin to branch until a depth of 2 to 3 inches was attained, nor were the $12.5 \mathrm{gm}$. of coarse fibrous roots sufficient to offer a substantial barrier to erosion. The compactness of the soil seemed to be the most important factor in prolonging erosion of the bared sample to 13 minutes.

Plants of the second sample at first withstood the water in an erect position. Only after about 12 minutes were they lodged into a loose, tangled mass of coarse stems and foliage extending to a height of 10 to 15 inches. The stream was deflected and its force broken by the numerous stems. The large leaves also were efficient barriers between water and soil. Where several occurred together the soil remained intact to near the end of the experiment. So efficient was the protection that slow undermining of the soil was not very apparent until the expiration of one-half hour. 


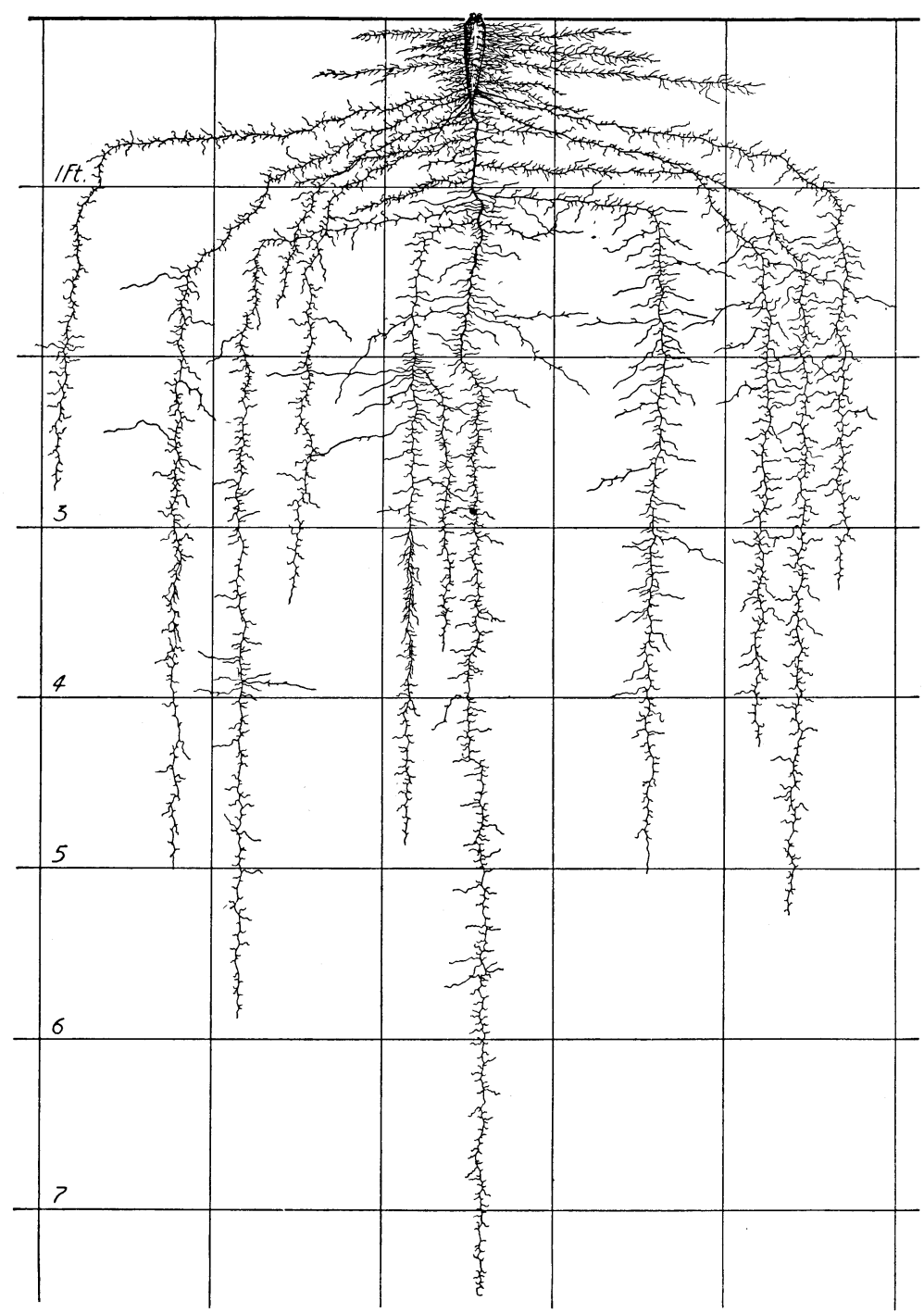

Fig. 29.-Root system of carrot when still growing vigorously on August 12 . (After Weaver and Bruner, Root Development of Vegetable Crops. McGraw-Hill Book Co.) 


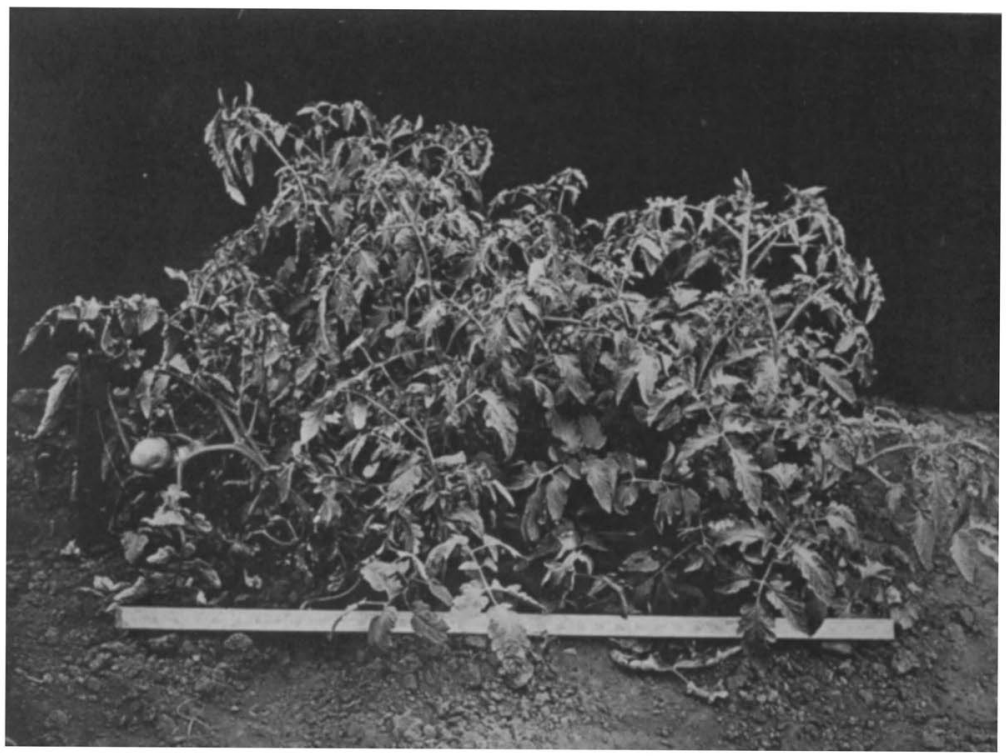

FIG. 30.-Fine growth of tomato plants in late summer covering a half square meter of soil.

Erosion, once under way, was not hindered by the damming effect often furnished by a plant cover, since the leaves were in the main held above the eroding soil by attachment to the coarse, still partly erect stems. Only after 66 minutes of continuous washing was erosion complete.

\section{DISCUSSION AND CONCLUSIONS}

In Table 14 the data on garden crops have been tabulated for purposes of comparison. The very bushy tops of tomatoes afforded the greatest protection, carrots ranked second, and were followed closely by sweet potatoes

TABLE 14.-Various garden crops grown in upland soil. ${ }^{1}$

\begin{tabular}{|c|c|c|c|c|c|c|c|}
\hline \multirow{2}{*}{$\begin{array}{l}\text { Kind } \\
\text { of crop }\end{array}$} & \multirow{2}{*}{$\begin{array}{c}\text { Sample } \\
\text { taken }\end{array}$} & \multirow{2}{*}{$\begin{array}{l}\text { Cover } \\
\text { P. ct. }\end{array}$} & \multicolumn{2}{|c|}{ Dry weight, gm. } & \multicolumn{2}{|c|}{ Erosion time, Min. } & \multirow{2}{*}{$\begin{array}{c}\text { Erosion } \\
\text { ratio }\end{array}$} \\
\hline & & & Tops & $\begin{array}{c}\text { Fibrous } \\
\text { roots }\end{array}$ & $\begin{array}{c}\text { Without } \\
\text { tops }\end{array}$ & $\begin{array}{l}\text { With } \\
\text { tops }\end{array}$ & \\
\hline Potatoes & July 15 & 90 & 249 & 17.5 & 9 & 25 & $1: 2.8$ \\
\hline Potatoes & July 21 & 99 & 259 & 16.1 & 10 & 35 & $1: 3.5$ \\
\hline Potatoes & July 23 & 60 & 166 & 11.5 & 10 & 18 & $1: 1.8$ \\
\hline Sweet potatoes & Aug. 11. & 100 & 238 & 11.9 & 8 & 37 & $1: 4.6$ \\
\hline Sweet potatoes & Aug. 16. & 100 & 251 & 11.5 & 10 & 43 & $1: 4.3$ \\
\hline Peas & Aug. 12 . & 85 & 157 & 13.9 & 12 & 30 & $1: 2.5$ \\
\hline Parsnips & Oct. 4 & 75 & 140 & 4.1 & 10 & 23 & $1: 2.3$ \\
\hline Carrots & Oct. 12 & 95 & 240 & 5.0 & 11 & 49 & $1: 4.5$ \\
\hline Tomatoes & Sept. 28. & 100 & 535 & 12.5 & 13 & 66 & $1: 5.0$ \\
\hline
\end{tabular}

${ }^{1}$ The first two samples were from lowland soil. 
and potatoes in efficiency of tops. Peas and parsnips ranked lowest. This sequence probably varies somewhat from year to year depending upon conditions for growth, and especially with the stage of plant development. Only small differences in erosion time were found where the tops were removed.

Compared with field crops, mature plants of gardens usually held the soil much less firmly, even similar row crops as sorgo and corn were more effective. The average difference in erosion time between the two groups of mature plants with tops removed was 8 minutes, an increased efficiency of 80 per cent in favor of field crops. This was probably due in part to more frequent and perhaps deep cultivation in the garden which decreased the efficiency of the shallower portions of the root systems. With tops intact, tomatoes and carrots were as efficient as oats and alfalfa but less so than wheat and sorgo. Sweet potatoes ranked with alfalfa in preventing erosion but the other garden crops were less effective than were those of the field.

Most garden crops will satisfactorily control erosion, once they cover the ground. Soy beans planted in strips on a 10 per cent slope at Auburn, Alabama, reduced erosion 50 per cent (Sexton and Diseker, '33). Unless soy beans are drilled solid in Missouri they allow almost as much erosion as corn (Miller and Krusekopf, '30). Thus the power of plants to resist erosion results from the combined action of tops and roots; underground parts alone are much less efficient. The short life span and late growth in spring are decidedly disadvantageous to garden crops in preventing soil loss.

Although fertility of gardens is more easily maintained than that of more extensive tracts, yet it should be kept in mind that "In nearly every section, water or soil fertility, or both, are limiting factors in crop production. . . . It is now being recognized more and more that the losses of soil fertility taking place through erosion are many times greater than the losses by even the poorest cropping system. . . Water is the vehicle by which soil fertility is transported from the land" (Dickson, '29).

If the remains of dead vines and tops are left upon the ground throughout the winter they effectively protect the soil. The large raindrops are broken into smaller ones, which reach the earth deprived of their original velocity and mass.

\section{EXPERIMENTS WITH WEEDS}

The efficiency of weeds in preventing soil erosion was determined by using pairs of samples of various species at different times, and often from different fields, during the growing season. Species used were rough pigweed, field bindweed, knotweed, little barley, tumbleweed, yellow foxtail, spotted spurge, crab grass, and dandelion. 


\section{ROUGH PIGWEED}

Two samples of rough pigweed (Amaranthus retroflexus L.) were taken from an unplanted portion of a lowland cornfield plowed and disked in May. The field adjoined that from which wheat was secured. The thick stand of weeds had attained a height of 9 inches and afforded a foliage cover of 98 per cent when the samples were taken on June 21 (Fig. 31). The one-half square meter sample of soil bore 275 plants. The tops had a dry weight of $67 \mathrm{gm}$. and the roots $12 \mathrm{gm}$. Abundant rains had wet the soil and the plants were turgid and tender. Consequently they lodged almost immediately upon the application of water and were

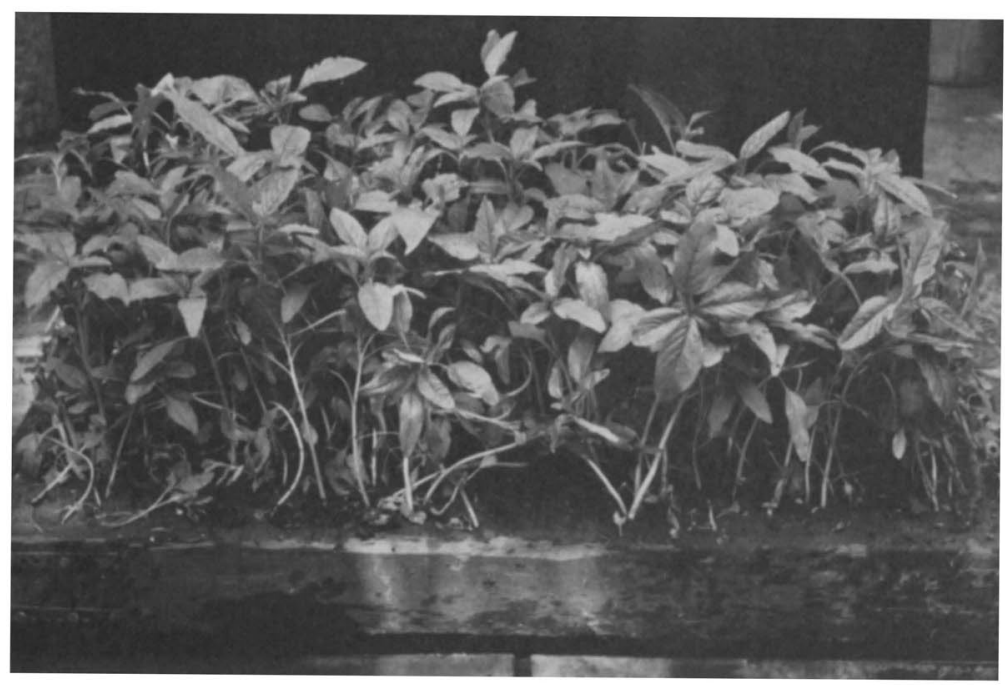

FIG. 31.--Thick stand of young pigweed secured in a soil sample on June 21. It offered relatively little resistance to erosion.

all prostrate at the end of 1 minute. The foliage was inadequate to cover the soil completely and numerous bare spaces were left with little or no protection. Moreover, the soil was unconsolidated. The sample from which the plants were clipped was eroded in 5.5 minutes, the one with a plant cover in 11.5 minutes.

A second pair of samples was secured from another field of similar but more compacted lowland soil on July 6 . The rough pigweeds composed about 95 per cent of the cover and green foxtail the remainder. The general height of the dominant plants was 18 inches, but many of the suppressed plants as well as the foxtail did not exceed 8 inches. The group of weeds furnished a foliage cover of about 90 per cent. Although the soil from which the tops of the weeds were removed contained $23 \mathrm{gm}$. of tap- 
roots and crowns, and $27 \mathrm{gm}$. of fibrous roots, yet it was completely washed away in 7.5 minutes. Where the plants were unclipped, the smaller, weaker weeds fell prostrate at once upon the application of water. Some of the large ones stood erect until nearly all the soil had been washed away. Movement of the plant cover under the force of the stream of water exposed the soil in such a manner that it was eroded irregularly rather than uniformly. Total time for erosion was only 14 minutes. Dry weight of tops was $192 \mathrm{gm}$.

A third pair of samples from the same place as the second was taken on July 26. The general height of the rough pigweeds was now 45 inches. The lower leaves had dried and fallen leaving the stems bare to a height of about 18 inches. Of a total of 50 plants, only 15 were of large size, with taproots 0.5 to 0.75 inch in diameter. A thin understory of green foxtail, about 12 inches tall and drying, further protected the soil. The plant cover completely obscured the soil. When the tops were removed it was found that the roots offered little resistance to erosion notwithstanding their increased dry weight. This was $37 \mathrm{gm}$. for taproots and $27 \mathrm{gm}$. for fibrous branches and underground parts of the foxtail. Only 8 minutes were required to wash away the soil.

The plants in the second sample at first stood erect despite the stream of water. Soon they began to bend over and in so doing became intermixed in such a manner as to form a tangled mass such as one sees in fields following a heavy rain. After 5 minutes the entire cover was lodged so that the tops were only 10 to 15 inches above the soil. The leafless bases of the stems alone protected the soil in places, while elsewhere there was a good cover of foliage. The dead grass lying close to the soil produced a damming effect, while the coarse stems of the pigweeds and their bedraggled foliage broke the force of the water. After 15 minutes of soil erosion the hold of the roots was weakened and the plant cover flattened more closely to the soil surface. The cover was too open for maximum stability and was moved about by the force of the water. Consequently erosion continued and all of the soil was removed after 27 minutes. Thus the cover of weeds, with a dry weight of 433 gm., mostly distributed in stems, had more than tripled the time for erosion.

\section{FIELD BINDWEED}

The field bindweed (Convolvulus arvensis L.) is one of the most persistent weeds of cultivated land. It. spreads by slender creeping roots mostly within the upper four inches of soil. In cultivated fields and in old, well established areas of bindweed, these creeping roots are often inconspicuous (Fig. 32).

Samples were taken on July 17 from a well developed patch in a field of corn. The upland soil had been plowed in early spring, but otherwise the land was undisturbed. The growth of weeds was 3 to 5 inches tall and 


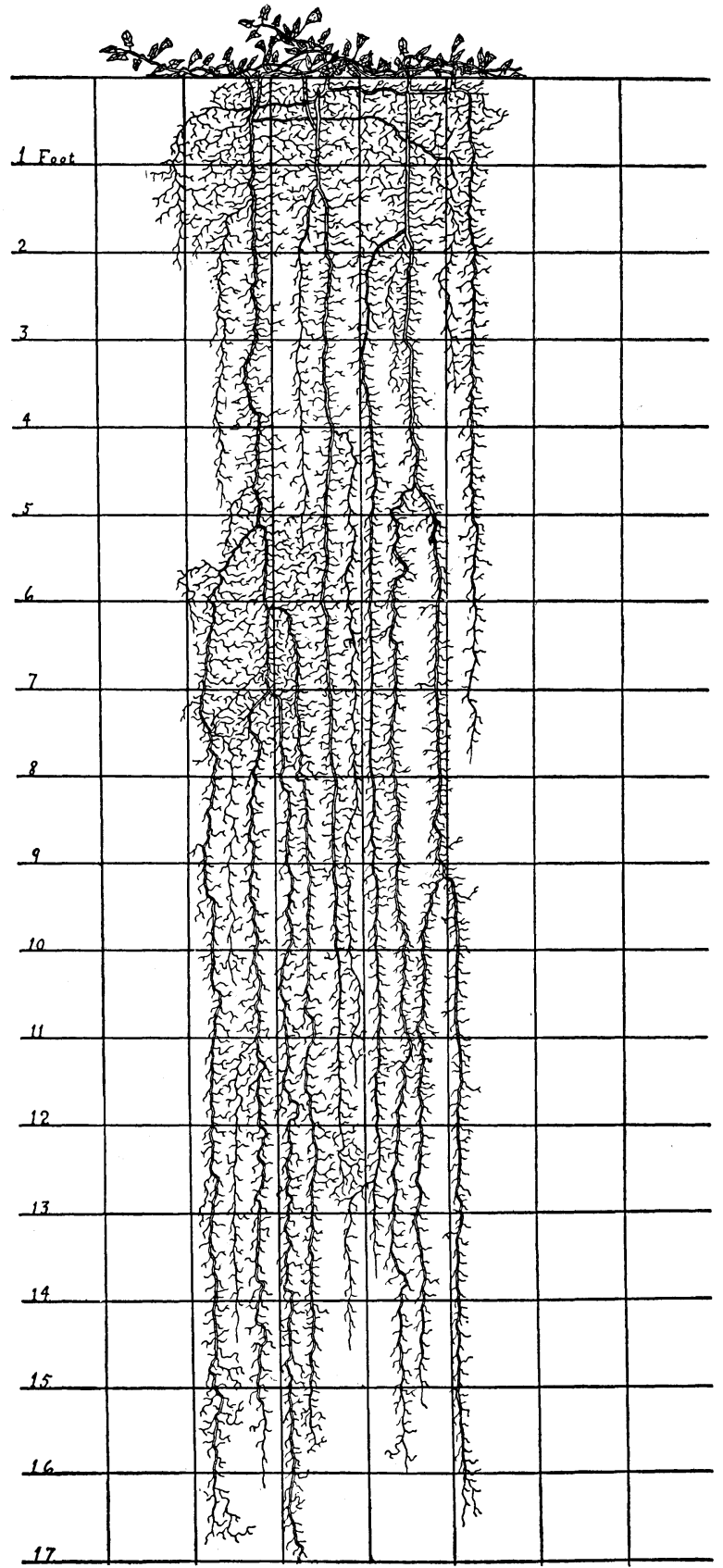

FIG. 32.--Roots and tops of field bindweed showing great depth of root penetration. (After Kiltz) 
completely obscured the soil. When the tops were removed by clipping, the underground parts, which weighed only $11 \mathrm{gm}$., offered so little resistance that the somewhat compacted soil was entirely eroded at the end of 14 minutes. Upon the application of water to the sample with a plant cover, the plants flattened out over the surface to a height of only 0.5 inch where the cover was thinnest to 1.5 inches where thickest. After 10 minutes, soil erosion under the thinner portions of the cover was marked. Once depressions were formed, erosion was hastened by the undercutting of the better protected places. Total time for complete erosion was extended to nearly three times that required for the bared soil, i.e., 38 minutes. The dry weight of tops totaled $169 \mathrm{gm}$.

Another pair of samples of bindweed was secured on August 3, from an upland cornfield. The weed was well established and the soil was entirely obscured by the dense tangle of wiry stems and numerous leaves, the living mat extending 1.5 to 6 inches above the surface. The tops when dried weighed $122 \mathrm{gm}$. and the roots $23 \mathrm{gm}$. Where the tops were removed, the somewhat compacted, bared soil withstood the stream of water from the open hose for a period of 18 minutes. After 5 minutes, the plant materials flattened to a height of about 2 inches, revealing the soil in several spots. These areas were conspicuous among the green stems and leaves. Following the continued application of water, holes began to develop as the less protected soil was washed away from under the thinnest parts of the cover. In other places, the tangle of leaves and twine-like stems offered continuous resistance to erosion for 45 minutes, when the soil was completely removed.

\section{KNOTWEED}

Knotweed (Polygonum aviculare L.) is an indicator of hard, trampled or compacted soil. The samples of this wiry stemmed and very leafy species were secured on September 25 and consisted of a pure growth about 1.5 inches high. Notwithstanding the small size of the leaves, they and the branches were so numerous as to completely obscure the soil. The lowland soil was much compacted by trampling of farm animals. Indeed it was so well interlaced with roots and so firmly compacted that 60 minutes were required to wash away the sample after the cover of vegetation had been clipped and removed.

The mat-like cover afforded much resistance to soil erosion by effectively breaking the force of the water. In most compacted portions of the well moistened samples little erosive action was visible for a long time. After 120 minutes of continuous washing with the open hose only thirtyeight per cent of the soil mass had been removed. To conserve time, the nozzle was then attached to the hose and thus the force of the water striking the soil greatly increased (p. 10). Even under this severe test, 18 minutes were required to erode completely the soil. 


\section{LITTLE BARLEY}

This weed (Hordeum pusillum Nutt.) makes a rapid growth from seed which germinates in late summer. The seedlings are usually so dense that a carpet of vegetation results. The samples were taken from lowland along a roadside. The Wabash silt loam was fairly compact. The seedlings had grown after the rains of early September and were 3 to 4 inches tall when the samples were secured on September 30. After preliminary counting, it was calculated that a sample contained approximately 10,000 plants. As a result of the severe competition, the plants had lodged and the height was thus reduced to only 3 to 4 inches.

In clipping the tops it was found that the caryopses of the seedlings were near the soil surface along with many others, the seeds of which failed to germinate. These, together with some debris and the many fibrous roots of the seedlings, gave sufficient protection against erosion so that the sample without a cover was washed away only after 17 minutes. The dried tops weighed 123 gm., the underground parts, including numerous older roots from which the tangled roots of the seedlings could not be separated, $63 \mathrm{gm}$.

The thick mat of seedlings broke the force of the water and also served to dam back the eroding soil, once the weaker places in the cover had given way. After a time numerous holes were formed by the loosened soil washing out, but great masses of tops and an abundance of fibrous roots still held the loose soil. Thus 61 minutes were required for the completion of erosion.

TUMBLEWEED

This tumbleweed (Amaranthus graecizans L.) is a close relative of the rough pigweed but takes on the form of a more or less spherical topped, much branched, bushy plant not unlike the Russian thistle. A sample of bare lowland soil was secured from the field without disturbing its structure. The top frame was then put in place, and a single large plant was selected to furnish a protecting cover. The taproot was cut at the ground line and the weed placed within the frame. It was found to be just large enough to completely occupy it without crowding of the branches. This was done early in September while the plant was still green and in full foliage. The plant was 18 inches high and afforded a cover of approximately 90 per cent. Although many rigid stems intervened between the hose and the soil, they were clothed only with the rather small, narrow, oblong leaves. The main stem and the bases of the larger branches had few leaves and it was here especially that the force of the water was broken by the network of branches alone. After 30 minutes the plant had settled to within about 12 inches of the soil surface, but because of the rigidity of the stems few came in contact with the soil surface, and these exerted no damming effect. While a sample of similar bare soil was eroded 
in 8 minutes, that under the protection of the tumbleweed, with $512 \mathrm{gm}$. of dry matter (distributed mostly in the branches), resisted erosion for 46 minutes.

YELLOW FOXTAIL

Two experiments were performed in which a cover of dead plants was employed. A fairly rank growth of mature, dried plants of yellow foxtail (Setaria lutescens (Weigel) F. T. Hubb), covering a half square meter of lowland soil, was transferred to an erosion box. The box contained a sample of bare soil obtained without disturbance of structure from a field on the upland. The large bunches of plants were about 20 inches tall and afforded a nearly complete cover.

After 10 minutes the grasses lodged and were compacted to within a few inches of the soil surface. The thatch of dead leaves and stems proved very efficient both in breaking the force of the water and in damming back the soil after it had been loosened. Complete washing away of the soil occurred only after 65 minutes. The tops were then recovered. They yielded a dry weight of $263 \mathrm{gm}$.

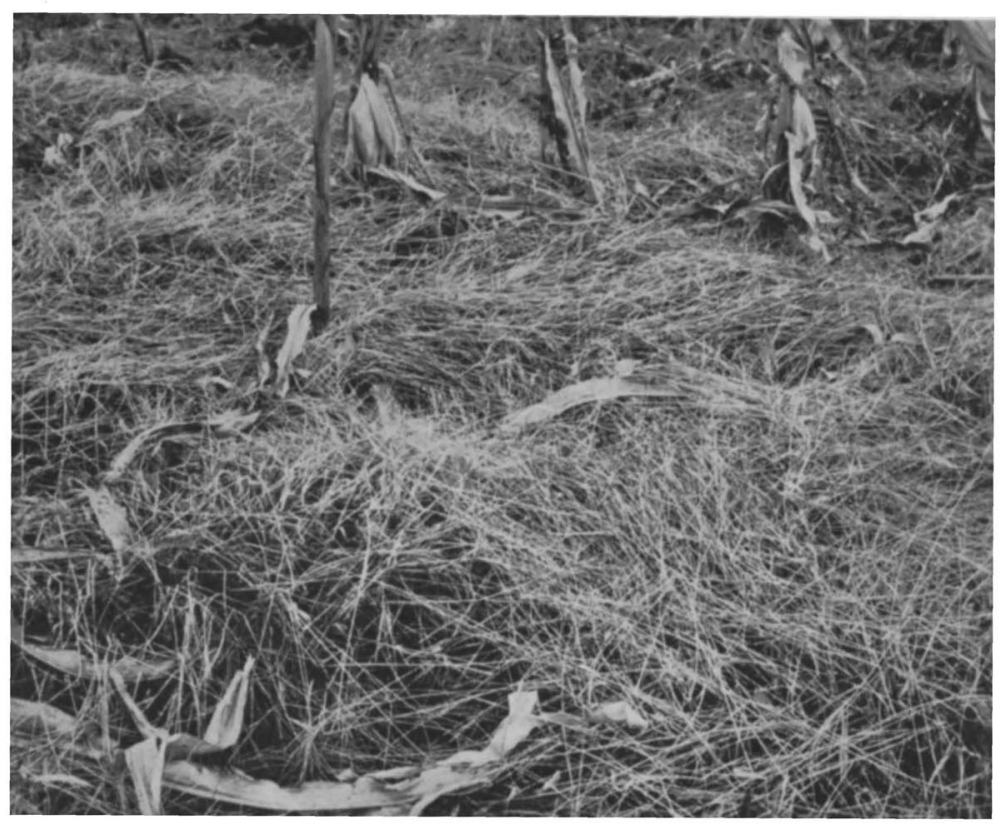

Fig. 33.-Dead crab grass covering the soil in a nearly bare spot in an upland cornfield. It furnished considerable protection against erosion. 
The dried remains of plants of crab grass (Syntherisma sanguinale (L.) Dulac) growing on one-half square meter of upland soil were secured from a cornfield on October 15 (Fig. 33). They were uniformly distributed over the surface of loose soil placed in the frame and thoroughly watered only 4 days earlier. Water was then applied as rain through the shower-bath nozzle. The mat of tangled stems and withered leaves, although only about 2 to 3 inches thick, furnished excellent protection to the loose bare soil. After an hour, when the soil had been washed away beneath the thinner portions of the cover, the plants settled over the sides of the remaining hummocks and columns, protecting them a long time. Not until the expiration of 3 hours and 25 minutes under the artificial rain did the $167 \mathrm{gm}$. of protecting plant remains permit of complete erosion. A similar sample without protection was eroded in 13 minutes.

\section{SPOTTED SPURGE}

The spotted spurge (Chamaesyce maculata (L.) Small) is an entirely prostrate plant which arises from a small taproot and spreads widely over the bare soil. The small leaves grow so thickly on the numerous wiry stems that at least the center of the mat, which alone may cover 25 to over 100 square inches, forms a complete cover. Only where the radiating stems separate at the edges of the mat is the cover incomplete, unless other spurges overlap to fill the interspaces. The vertical thickness of the mat is usually one-half inch or less. This species is common in summer and fall on otherwise bare soil of well tilled cornfields, gardens, yards, and waste areas. By cutting the taproot at the ground line the whole mat may be lifted from the soil and spread out naturally elsewhere.

The boxes were filled as before with loose soil which was first screened and well mixed as in the experiments with artificial rain (p. 12). The first sample of bare soil eroded in 12.5 minutes. The second was protected by a single layer of the mats of the spotted spurge. Care was taken to avoid overlapping and the mats were trimmed at the edges of the frame.

The cover of living, unattached plants protected the soil from the water in a remarkable manner, nor was there any shifting of the mats. After a time the loose soil beneath the weakest places in the cover began to erode. These areas slowly multiplied until channels began to form in many places. Beneath the more protective centers of the mats little erosion occurred from above, so that after two or more hours the sample of soil had been separated by erosion into a number of vertical columns, varying in size with the extent of the mats. But as erosion continued the uncompacted soil was washed from the sides which were finally protected by the overhanging portions of the individual plants. Only after 4 hours 
and 7 minutes was the loose soil entirely washed away. The surprising efficiency of these weeds, with a total dry weight of only $150 \mathrm{gm}$., in preventing erosion led to further studies with dandelion.

\section{DANDELION}

A third frame of soil, similar in source and treatment to those just described, was covered with the rosettes of the dandelion (Taraxacum officinale Weber) as shown in Figure 34. The plants were secured from an area of one-half square meter in an old lawn on moderately low soil. The taproots were severed just below the ground line in such a manner that the leaves remained intact and could be transferred to the experimental soil sample with slight change in position. Practically the entire soil surface was covered with foliage. Where 4 to 6 leaves overlapped, the force of the water was completely broken and no erosion occurred. Even the thickness of a single leaf afforded much protection. After continued erosion, channels formed at the edges of the rosettes. Finally only the columns of soil protected above by the thick foliage of the central portion of the rosettes were left, but after 3 hours and 11 minutes these too melted away.

\section{DISCUSSION AND CONCLUSIONS}

For convenience of comparison, the data on weeds are summarized in Table 15. The species studied rather naturally fall into five more or less

TABLE 15.-Rate of erosion of various soils when bare and when protected by a cover of weeds.

\begin{tabular}{|c|c|c|c|c|c|c|c|}
\hline \multirow[b]{2}{*}{ Cover } & \multirow[b]{2}{*}{$\begin{array}{l}\text { Ht., } \\
\text { in. }\end{array}$} & \multirow{2}{*}{$\begin{array}{l}\text { Cover } \\
\text { P. ct. }\end{array}$} & \multicolumn{2}{|c|}{ Dry wt., gm. } & \multicolumn{2}{|c|}{ Erosion tine, min. } & \multirow[b]{2}{*}{$\begin{array}{l}\text { Erosion } \\
\text { ratio }\end{array}$} \\
\hline & & & Tops & $\begin{array}{l}\text { Roots, } \\
\text { etc. }\end{array}$ & $\begin{array}{c}\begin{array}{c}\text { Without } \\
\text { tops }\end{array} \\
\end{array}$ & $\begin{array}{l}\text { With } \\
\text { tops }\end{array}$ & \\
\hline Rough pigweed. & 9 & 98 & 67 & 12 & 5.5 & 11.5 & $1: 2.1$ \\
\hline Rough pigweed. & 18 & 90 & 192 & 50 & 7.5 & 14.0 & $1: 1.9$ \\
\hline Rough pigweed. & 45 & 100 & 433 & 64 & 8.0 & 27.0 & $1: 3.4$ \\
\hline Field bindweed & 4 & 100 & 169 & 11 & 14.0 & 38.0 & $1: 2.7$ \\
\hline Field bindweed. & 5 & 100 & 122 & 23 & 18.0 & 45.0 & $1: 2.5$ \\
\hline Knotweed & 1.5 & 100 & & & 60.0 & $120+^{1}$ & $1: 5.3^{2}$ \\
\hline Little barley & 4 & 100 & 123 & 63 & 17.0 & 61 & $1: 3.6$ \\
\hline Tumbleweed & 18 & 90 & 512 & 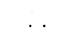 & $8.0^{3}$ & 46 & $1: 5.8$ \\
\hline Yellow foxtail (dead) & 20 & 98 & 263 & . & $8.0^{3}$ & 65 & $1: 8.1$ \\
\hline Crab grass (dead). & 3 & 100 & 167 & . & $13.0^{4}, 5$ & $205^{4,5}$ & $1: 15$ \\
\hline Spotted spurge .... & 0.5 & 100 & 150 & . & $12.5^{4}, 5$ & $247^{4}, 5$ & $1: 19$ \\
\hline Dandelion & 2 & 95 & 122 & . & $12.5^{4,5}$ & $191^{4,5}$ & $1: 15$ \\
\hline
\end{tabular}

\footnotetext{
1 Only 38 per cent of the soil was removed.

${ }^{2}$ Calculated.

${ }^{3}$ Bare field soil of undisturbed structure but without living roots.

4 Loose soil slightly compacted but without roots.

5 Eroded by artificial rain.
} 


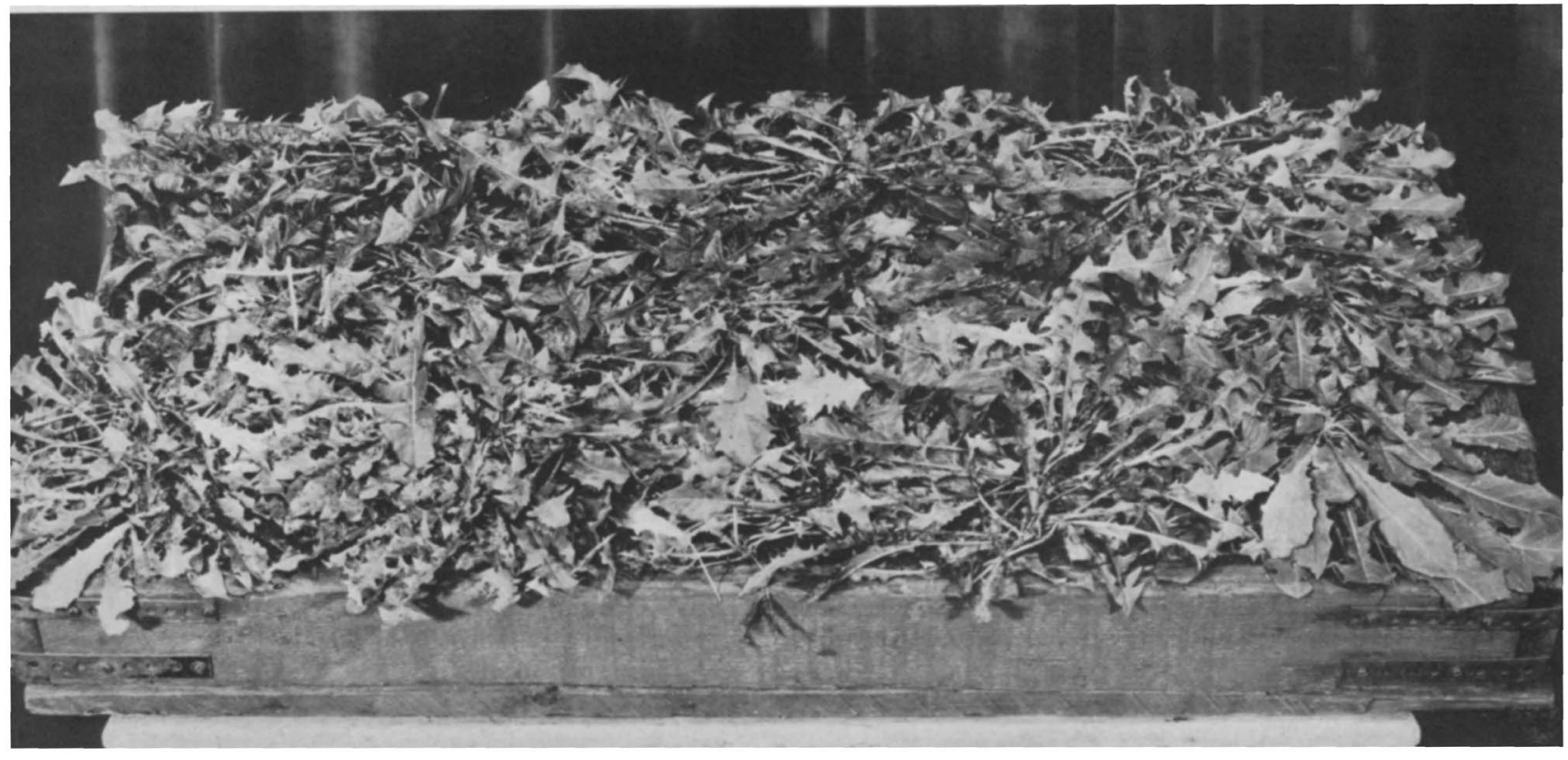

Fig. 34.-Sample of uncompacted soil covered with one-half square meter of natural growth of tops of dandelions, used in an experiment on erosion. 
distinct types, viz: the erect type, the tumbleweed type, the grass type, and the mat and rosette types.

The erect type is represented by the rough pigweed but includes a list of weeds of which sunflowers, lamb's quarters, cockleburs, ragweeds, and many others are representative. Pigweeds were only moderately effective when young since there was not sufficient rigidity offered after the plants lodged, hence the cover was moved by the force of the water. As the plants became older this difficulty was largely overcome and the leafy crowns offered much protection as is shown in Table 15. But since the lower parts of the stems had lost their leaves, because of the dense shade, the plants were again less efficient after lodging.

The tumbleweed employed is representative of a large group of similar, bushy, tumbling plants such as Russian thistles, species of Atriplex, Kochia, Cycloloma, and tumbling mustard. In this type the force of the water was first broken 12 to 24 or more inches from the soil surface, and the water was repeatedly retarded and deflected by a coarse network of branches which extended to the soil surface. The narrow leaves functioned in a manner similar to the stems. Together they constituted a continuous protecting framework which remained unbroken. The tumbleweed in the experiment afforded greater protection than the large rough pigweed, the erosion ratios being $1: 5.8$ and $1: 3.4$, respectively.

The grass type may be classed under the headings of seedlings and more mature grasses. The seedling little barley in the experiment might well have been replaced with similar results by downy brome grass, cheat or chess, foxtail, or dense growths of annual wire grass, poverty grass, or many other annual, weedy grasses. Characteristically the seedlings were so crowded, often 12 or more per square inch, that they formed dense mats. Under heavy watering they all lodged down the slope and for a long time constituted a thatch from which the water ran clear. In the case of little barley, downy brome grass, and others, they form an efficient protection to the soil in late summer, during the winter, and throughout the following spring. Such dense plant covers accumulate wind-blown and water-carried debris and also retain that which is formed in place. When, after a time, the water broke through the thinnest places in the plant mat, undercutting of soil beneath the whole group of plants began. Such seedlings form an excellent illustration of the fact that the functions of the community are often quite different from those of the individual.

The older grasses, because of their greater surface and more rigid framework, offer initial resistance at greater height from the soil surface. Where they are thickly spaced, as in the yellow foxtail, or where the interlapping branches spread widely as in crab grass, they furnish great protection against erosion either in the erect position or when lodged. These 
data indicate, as elsewhere, that the grass type is more efficient than either of the preceding types.

The mat type is represented by the spotted spurge, knotweed, and field bindweed. Other common weeds of this group are species of purslane and prostrate pigweed. The dandelion represents the rosette type as do also the plantains, sour docks, and mullein. Mat plants, such as many spurges, although anchored by a single taproot, lie firmly on the soil and exert a remarkable damming effect against surface erosion. Frequently little or no soil is left exposed and the plants may break the entire force of the water. In the rosettes of dandelion and others there may occur a protecting layer 5 or more leaves thick, and overlapping of adjacent plants may add to this number. Except for small interspaces between leaves and plants at the periphery of the rosette, erosion can scarcely occur. Even after the soil began to wash away, the leaves fell downward over the columns of soil held by the rosettes. These columns exerted their stabilizing effect on the whole area for a long time. Because of their intimate contact with the soil surface, mat and rosette plants rank with the grasses as the most efficient protectors of the soil.

Just as foresters have found that different types of forest litter vary greatly in their capacity to absorb water, prevent runoff, and promote percolation, so too debris from different kinds of weeds probably also varies in these respects. A cover of weeds retards both rate and depth of freezing and thereby aids in water absorption during winter rains and thaws. It tends to hold moisture in the form of snow and when it melts lessens runoff and thus increases water content of soil.

The wonders worked by litter are indeed remarkable. On a barren soil where the upper 6 inches had been washed away, 41 pounds of ovendry forest litter were placed over 36 square feet of soil. Although this material could hold but .35 inch of rain when fully saturated, yet it reduced rainfall runoff from 36.6 per cent (control plot) to 16.2 per cent of the total 55 inches precipitation. The greatest reduction in runoff occurred when the rains were hardest and the most water fell. Erosion was reduced from $70.5 \mathrm{lbs}$. to only $.84 \mathrm{lb}$. per acre (Meginnis, '35). Thus the capacity of litter to absorb rainfall is of little consequence compared with its power to bring about absorption of water by the soil. This is accomplished largely by keeping the soil pores from becoming clogged by silt particles being thrown into suspension, as regularly occurs when heavy rains beat upon bare soil. Weeds are not harvested except in times of great distress. They remain on and in the soil. They function during life and after death.

"Weeds are the wound dressers of the soil. Whenever man or nature makes a scar, the vigorous, coarse-fibered weeds find the spot and straightway mend the injury. Hated and much objurgated, the weed, of whatever breed, is one of the most useful forces in nature. The farmer regards it as a foe, the gardener as a nuisance. In truth, it is a friend that 
persists, regardless of ill treatment and attempts at extirpation. Soil, to preserve its strength, must be protected with some sort of covering, otherwise the rains leach it, or wash away the precious particles of mold that make it productive. Man neglects this factor in his dealings with the earth. Plowed fields are allowed to go uncovered after the crop is harvested. Washouts are left to take care of themselves. So is burned-over land. In all three instances great damage results, and much more would follow but for the energy of the weed family.

"How weeds seed so swiftly is one of the benign mysteries. Could man find it out he would soon become the destroyer he likes to be, to his own great harm. Therefore the weed keeps its secret. We only know that on every bare and neglected spot where it is possible for seed to lodge or root to hold, the weed appears and lustily seizes the bare spot. Soon verdure shows, the soil is held together against the shower. Nitrogen is coaxed from the air and distributed about the roots. The leaves and stalks decay in the fall and a little "top soil" is created, which grows with the seasons. In time enough is created to afford life to finer plants and the soft grasses. The wound is healed" (Seitz).

\section{EXPERIMENTS WITH BUCKBRUSH AND NATIVE GRASSES}

In order to determine the relative effectiveness of underground parts and tops of long established native vegetation, buckbrush, bluegrass, big bluestem, and slough grass were studied.

\section{BUCKBRUSH}

Buckbrush (Symphoricarpos vulgaris Michx.), also known as snowberry, coralberry, and wolfberry, is a common native shrub all over the Midwest. It is commonly found along forest borders, as an understory in much of the woodland fringing prairie streams, and occurs widely in ravines. From these places it spreads into upland pastures and, if abundant, shades out most of the native grasses.

Two pairs of samples, each pair of approximately the same density of stand and in close proximity, were obtained from a lowland area covered with a good growth of this shrub, 34 inches tall. The leaves were all mature but still green when the samples were taken in September (Fig. 35). The granular, black, alluvial soil was covered with the characteristic amount of leaves, twigs, etc., in various stages of decay. A thin, patchy stand of bluegrass occurred in the rather dense shade.

In clipping the tops, which had a dry weight of $400 \mathrm{gm}$., the grass and twigs were also removed, but the thin leaf mulch was left intact. This mulch was readily removed by the stream of water as was also the bare soil. The woody crowns and network of tough rhizomes and fibrous roots offered enough resistance so that complete erosion required 48 minutes. 
The underground parts did not thoroughly occupy the area as in the case of grasses (Fig. 36).

Under the unclipped plants only 0.5 inch of the soil had been removed at the end of an hour. ${ }^{1}$ The erect or spreading leafy stems broke the initial force of the water and the mulch served to dam back the eroding surface soil. The latter function was also performed by the underground parts as soon as they became exposed. Their dry weight $(610 \mathrm{gm}$.) exceeded that of the tops. The stream from the nozzle, which was now applied, penetrated between the branches and leaves in many places and the whole soil sample was gradually undermined and washed away. Final results were obtained, however, only after an additional hour and 45 minutes.

A second sample from which the tops were clipped, was very similar to the first. It had a dry weight of tops and underground parts of 475 $\mathrm{gm}$. and $680 \mathrm{gm}$., respectively. It was eroded by the stream from the open hose in 41 minutes. The sample with tops intact required in addition to the hour with the open hose, 1 hour and 37 minutes with the smaller stream of greater force.

BLUEGRASS

Samples of bluegrass (Poa pratensis L.) were secured on September 3 from moderately low land in an old pasture. The stand appeared thick; the green leaves, 9 to 12 inches in length, overlapped above the soil as is characteristic of this species. They, with old, dried leaves, formed a cover 2 inches thick. The dried plant cover weighed 201 gm., and the underground parts, consisting largely of fine roots and long, slender rhizomes, 269 gm.

Application of water, after the tops were removed, resulted at first in very muddy runoff water as the surface, which was not held by roots, washed away. After a few minutes the water became nearly clear and continued thus throughout the hour. The crowns were seen to be well distributed over the sample and a network of roots threaded it throughout. A second hour with the nozzle spreading the stream over 12.5 square inches showed little progress in soil removal. But as soon as the finer stream of greater force was applied the water became very muddy and the soil was washed away in 45 minutes.

Two hours of preliminary watering of the duplicate sample had little effect except to flatten the cover closer to the soil surface. The water ran nearly clear. Only when the water with the greater force was applied did erosion really begin. Three hours and 35 minutes of continuous application of this stream were required to remove completely the soil.

\footnotetext{
${ }^{1}$ In these experiments with the shrubs and tall grasses the hose was held at a height of 3 feet.
} 

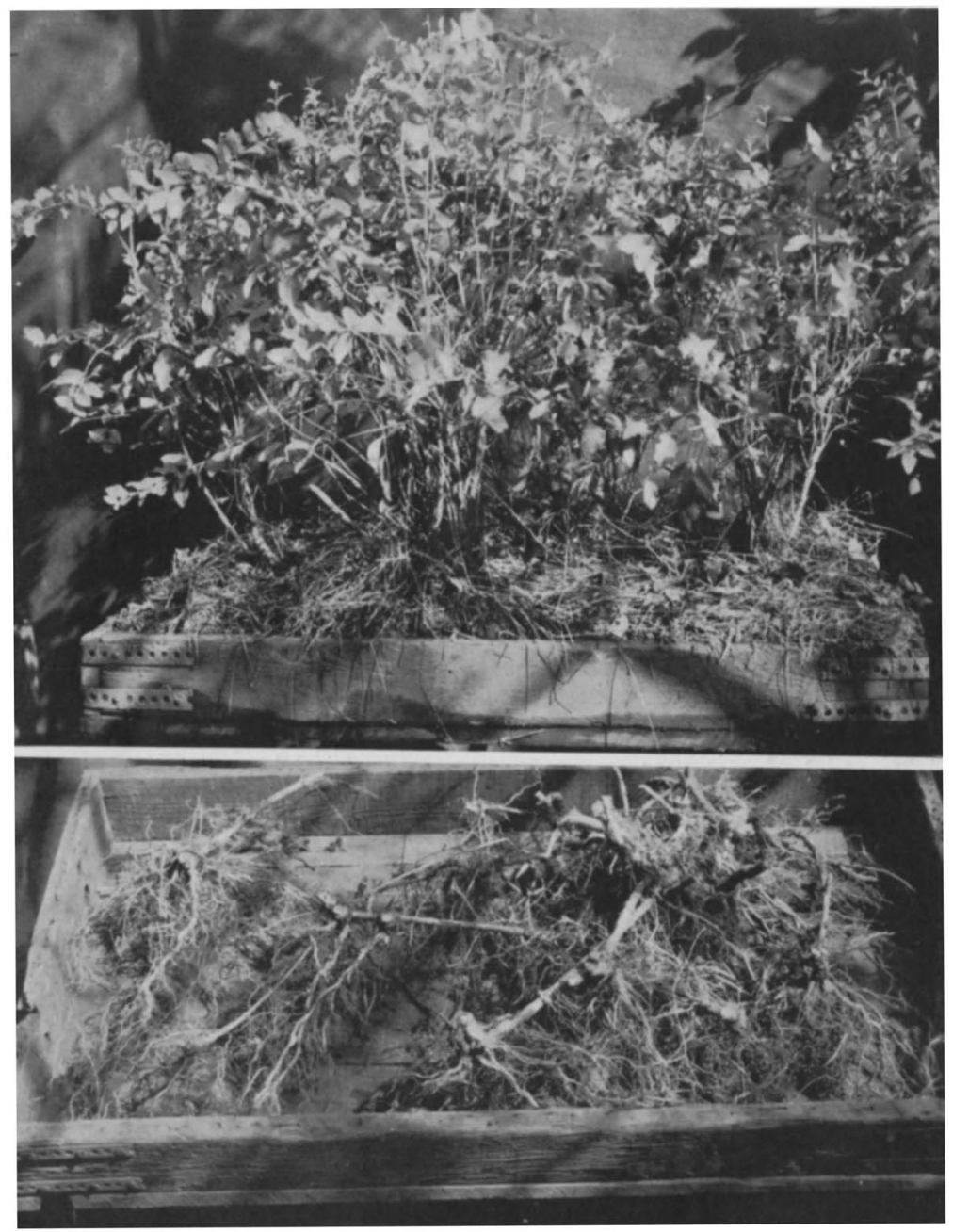

Fig. 35.-Natural growth of buckbrush with a thin layer of bluegrass beneath. Fig. 36.-Underground parts of buckbrush shown in figure 35 after the soil had been washed away.

BIG BLUESTEM

Big bluestem (Andropogon furcatus Muhl.) is a climax grass which forms nearly pure stands over wide lowland areas in the Midwest and covers many uplands eastward. Samples with tops removed had previously been eroded by Weaver and Harmon ('35) in 1934. A similar sample was 
secured a few feet from the place where these were taken on a level lowland prairie on a rather heavy Wabash silt loam soil. This was done on August 11, when the foliage was 3 feet high and the flower stalks 5 to 6 feet tall. The dense sod had completely concealed the soil. The tops of the adjacent one-half square meter weighed $448 \mathrm{gm}$. when oven dried.

"When water was applied (to the sample with tops removed) it became muddy for a period of 5 to 8 minutes, after which it remained clear throughout the first hour. This phenomenon . . . resulted from the fact that the surface 0.5 to 1 inch of soil has few roots and rhizomes. Once this loosely held earth is removed, the soil resists this simple flooding for very long periods of time. Even by the end of the second hour the mass of soil had not been greatly reduced. The compacted rhizomes and tough wiry roots maintained their position and formed an effective barrier between the force of the water and the soil. Only after 2 hours and 40 minutes with the small stream of water were the underground parts freed from the soil."

Unclipped plants soon lodged, leaving only the coarser stems erect. By the end of an hour practically no soil had been removed, the water running clear, but the tops had been compacted into a rather dense layer only 3 to 4 inches thick. The half erect stems aided in breaking the force of the water. No visible erosion occurred the second hour, but with the application of the finer stream the clear water became slightly turbid. After another hour the plant mass was beaten so thoroughly that it formed a compact cover only 1.5 to 2 inches thick. The hour following some of the root-crowns became visible. The cover was somewhat frayed and was beginning to lose its continuity. The runoff water became more turbid. After 7 hours about $3 / 8$ of the soil had been removed, and after 9 hours only about $1 / 3$ was left. The process of erosion continued at an increasing rate but only after 12 hours and 57 minutes of applying water, under the impact of 1.4 pounds force per 0.11 square inch of surface, was erosion complete.

\section{SLOUGH GRASS}

Two pairs of samples of slough grass (Spartina michauxiana Hitchc.) were secured during the third week in August from unbroken prairie bordering a ravine. The first pair was on slightly higher ground than the second, and had been mowed earlier in the season. The grass formed a fairly thick stand about 40 inches high. The cover was only about 70 per cent, and a sparse growth of bluegrass grew beneath. The remains of an early spring cutting had been left on the ground. A half-inch of alluvial soil had lodged among the stem-bases, perhaps during the preceding year. Upon removal of the tops and the application of water, this loose soil washed away rapidly. The old topsoil was then gradually removed so that at the end of an hour all but an inch had been eroded. The soil was not 
compact and offered slight resistance to erosion. The rhizomes and roots were far less bulky than those of big bluestem, although of greater weight, and held the soil poorly. One hour with the open hose and 45 minutes of the second hour's treatment resulted in complete erosion. The roots and rhizomes, when dried, weighed $506 \mathrm{gm}$. and other undecomposed debris $113 \mathrm{gm}$.

The undisturbed sample, with tops weighing approximately $287 \mathrm{gm}$. plus $283 \mathrm{gm}$. of dead plants on the ground, began to lodge as soon as water was applied. For a time it remained reclining 5 to 8 inches above the soil, but gradually flattened to a layer 3 to 4 inches thick. Runoff water was practically clear during the first two hours. When the stream with greater force was applied the water became muddy, the leaves were flattened and slightly torn, and a few stem crowns began to appear. Less soil was eroded during the fourth hour than the third, since the leaves became beaten into mats which were compacted into all the openings between the crowns so that the force of the water was almost entirely broken. Two more hours were required to erode the first half-inch, the water being only slightly discolored. The plant cover was now reduced to a half-inch or less in thickness and effectively prevented most of the water from reaching the soil. In another hour depressions began to be worn into the soil and over an area nearly two feet square the sod was disintegrating. Gradually the sod broke down as the hours passed. Erosion was especially accelerated after the sixth hour, but 8 hours and 45 minutes, in addition to the two preliminary ones, were required for complete erosion.

The second pair of samples was from an area where each stalk of grass had 5 to 6 green leaves 4 to 5.5 feet long and $1 / 3$ to nearly $1 / 2$ inch in width. Because of the dense shade under the partially lodged grass, which when erect reached a height of 7 to 8 feet, the basal leaves were no longer green but mostly still clung to the coarse stems. There was practically no undergrowth except a few stalks of the scouring rush. The total dry weight of the tops was $938 \mathrm{gm}$.

The unconsolidated surface half-inch of soil was soon washed away from the bared sample, but the network of rhizomes and roots (including dead but undecayed parts) was much more extensive. When dried, it weighed $742 \mathrm{gm}$. Erosion time was extended to 2 hours and 18 minutes with the stream of greater force.

The lodged plant cover afforded almost complete protection from erosion during the first 5 hours, the water running entirely clear. This condition prevailed for another 5-hour period. In fact, the efficiency of the thatched cover was so great that after a total of 22 hours not more than $1 / 8$ inch of the soil had been carried away. But upon removal of the cover the entire soil mass was eroded in 41 minutes. 


\section{DISCUSSION AND CONCLUSIONS}

A study of the results given in Table 16 reveals the fact that the shrub was far less efficient in the prevention of soil erosion than bluegrass. Erosion time with tops intact was 103 per cent in excess of that of the shrub, and with tops removed the soil was held nearly 3.5 times as long by the underground parts of the grass, despite the greater force of the water used in eroding the grass sod. Likewise, the native big bluestem was far more efficient than was the bluegrass, which has been widely introduced into the prairie region (Weaver and Fitzpatrick, '34). The underground parts alone, of this and other native grasses, have such a tenacious hold upon the soil that earlier investigators (Weaver and Harmon, '35)

TABLE 16.-Summary of experiments on rate of erosion.

\begin{tabular}{|c|c|c|c|c|c|c|c|c|c|c|}
\hline \multirow{3}{*}{$\begin{array}{l}\text { Vegetation } \\
\text { Buckbrush }\end{array}$} & \multirow{3}{*}{$\begin{array}{c}\begin{array}{c}\text { Ht., } \\
\text { in. }\end{array} \\
34\end{array}$} & \multicolumn{2}{|c|}{ Dry wt., gm. } & \multirow[b]{2}{*}{ Sample } & \multicolumn{6}{|c|}{ Erosion time } \\
\hline & & Tops & $\begin{array}{l}\text { Under- } \\
\text { ground } \\
\text { parts }\end{array}$ & & \multicolumn{2}{|c|}{$\begin{array}{l}12.7 \text { gal. per } \\
\text { min. 1 1 lb. on } \\
1.5 \text { sq. in. } \\
\text { Hrs. Min. }\end{array}$} & \multicolumn{2}{|c|}{$\begin{array}{c}4.8 \text { gal. per } \\
\text { min. 1.9 lbs. on } \\
12.5 \text { sq. in. } \\
\text { Hrs. Min. }\end{array}$} & \multicolumn{2}{|c|}{$\begin{array}{c}3.4 \text { gal. per } \\
\text { min. } 1.4 \mathrm{lbs} \text {. on } \\
0.11 \text { sq. in. } \\
\text { Hrs. Min. }\end{array}$} \\
\hline & & 400 & 610 & $\begin{array}{l}\text { Covered } \\
\text { Bare }\end{array}$ & 1 & 48 & . & . & 1 & 45 \\
\hline Buckbrush & 34 & 475 & 680 & $\begin{array}{l}\text { Covered } \\
\text { Bare }\end{array}$ & 1 & 41 & . & . . & 1 & 37 \\
\hline $\begin{array}{l}\text { Bluegrass } \\
\text { Big }\end{array}$ & $2^{1}$ & 201 & 269 & $\begin{array}{l}\text { Covered } \\
\text { Bare }\end{array}$ & $\begin{array}{l}1 \\
1\end{array}$ & . & $\begin{array}{l}1 \\
1\end{array}$ & . & 3 & $\begin{array}{l}35 \\
45\end{array}$ \\
\hline $\begin{array}{l}\text { Big } \\
\text { bluestem }\end{array}$ & 66 & 448 & 557 & Covered & $\begin{array}{l}1 \\
1\end{array}$ & $\begin{array}{l}\cdots \\
\cdots\end{array}$ & 1 & $\cdots$ & 12 & 57 \\
\hline $\begin{array}{l}\text { Slough } \\
\text { grass }\end{array}$ & 10 & 287 & 506 & $\begin{array}{l}\text { Bare } \\
\text { Covered }\end{array}$ & 1 & . & 1 & . & $\begin{array}{l}2 \\
8\end{array}$ & 40 \\
\hline $\begin{array}{l}\text { Slough } \\
\text { grass }\end{array}$ & 90 & 938 & 742 & $\begin{array}{l}\text { Bare } \\
\text { Covered } \\
\text { Bare }\end{array}$ & $\begin{array}{l}1 \\
1 \\
1\end{array}$ & • & $\begin{array}{l}1 \\
1\end{array}$ & $\begin{array}{l}45 \\
\cdots \\
\cdots\end{array}$ & $\frac{22}{2}+^{2}$ & 18 \\
\hline
\end{tabular}

2 Only 3 per cent of the soil had been removed.

were led to conclude that "the first line of defense against the elements is above ground; the more formidable one is the plant parts within the soil." They did no experimenting with tops intact. Data in Table 16 clearly reveal the much greater protection furnished by tops than roots. When compared with those of field crops they reveal how poorly indeed civilized man is protecting the soil which throughout the centuries has been held against erosion by nature's wonderfully developed prairie grasses. Even in the drier short-grass area of the Southwest, experiments, initiated because of the appalling losses of soil under cultivation, have shown that fully sodded buffalo grass is practically perfect in preventing runoff (Dickson, '29).

Slough grass, which grows in the most precarious places as regards flooding and runoff waters-sloughs, ravines, steep embankments along water courses, etc.-anchors much less firmly the soil by underground 
parts, but protects it most remarkably by its foliage, even against rushing flood water (Fig. 37). In the experiment, only 3 per cent of the looser top soil had been removed after 24 hours.

The practice of burning native grassland or other pastures is a direct aid to the forces of erosion. With certain exceptions, fire should not be used in a scheme of range and pasture management (Aldous, '34). Plant cover should be preserved. The best practice is to leave 15 to 25 per cent of the vegetation on the ground at the end of the growing season. If

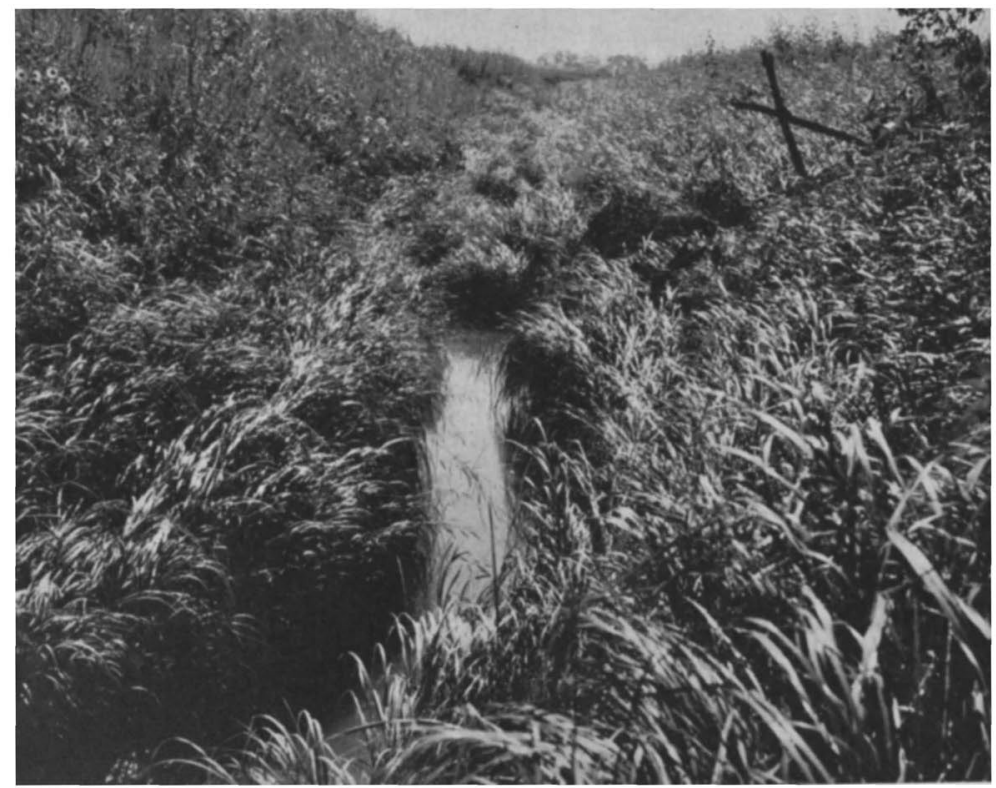

Fig. 37.- Slough grass protecting the steep banks of a deep ditch and effectively holding the soil in place.

grazed closely, underground parts are weakened, growth begins later in spring, and the cover is greatly depleted. Since the soil can be kept in optimum condition for absorption only by the continuous presence of a cover of vegetation, it is the business of the plant producer, whether in the rôle of agronomist, range manager, or plant ecologist, to maintain at all times a suitable covering of plants on the surface of the soil.

\section{RELATIVE AMOUNT OF LIVING UNDERGROUND PLANT MATERIALS}

Although the literature of soil science and agronomy furnishes many data on organic matter in soils, no studies have come to the attention of 
the writers where organic matter has been correlated with the amount of living underground plant parts. Studies on the relation of root distribution to organic matter in prairie soil have only recently been published (Weaver, Hougen, and Weldon, '35).

In the course of the present investigation, 150 field samples (i.e., about $1 / 50$ acre of soil) were taken and the amount of living underground parts to a depth of 4 inches ascertained. These data are given in Table 17. In

TABLE 17.-Actual and comparative dry weights of living underground plant parts in the surface 4 inches of soil.

\begin{tabular}{|c|c|c|c|c|}
\hline Plant & $\begin{array}{l}\text { Av. wt. gm. } \\
\text { per } 0.5 \text { sq. m. }\end{array}$ & $\begin{array}{l}\text { Wt. at maturity } \\
\text { gm. per } 0.5 \mathrm{sq} . \mathrm{m} .\end{array}$ & Lbs. per acre & $\begin{array}{l}\text { Per cent wt. of } \\
\text { native grasses } 1\end{array}$ \\
\hline Wheat on lowland. & 51 & 75 & 1,338 & $16^{*}$ \\
\hline Wheat on upland. & 36 & 43 & 767 & 12 \\
\hline Oats $\ldots \ldots \ldots \ldots$ & 40 & 49 & 874 & $11^{*}$ \\
\hline Alfalfa, young. . & 67 & 117 & 2,088 & 32 \\
\hline Alfalfa, old ... & 158 & 196 & 3,497 & $43^{*}$ \\
\hline Sorgo ....... & 60 & 74 & 1,320 & 20 \\
\hline Maize $\ldots \ldots \ldots$ & 31 & 65 & 1,160 & $14 *$ \\
\hline Sudan grass. & 49 & 77 & 1,374 & $17 *$ \\
\hline Sweet clover & $\ldots$ & 66 & 1,176 & 18 \\
\hline Rape $\ldots \ldots$. & & 44 & 785 & 12 \\
\hline Brome grass. & 185 & 220 & 3,926 & $48 *$ \\
\hline Rye $\ldots \ldots$ & 37 & 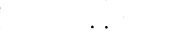 & 660 & $8^{*}$ \\
\hline Potatoes & $15^{2}$ & 18 & 321 & 5 \\
\hline Sweet potatoes. & $12^{3}$ & & 214 & 3 \\
\hline Peas ............ & . & 14 & 250 & 4 \\
\hline Tomatoes ...... & . & 13 & 232 & 4 \\
\hline Rough pigweed. & 42 & 64 & 1,142 & $14 *$ \\
\hline Field bindweed. & 17 & 23 & 410 & 6 \\
\hline Buckbrush & 645 & 680 & 12,134 & $148^{*}$ \\
\hline Bluegrass & & 269 & 4,800 & 59* \\
\hline Slough grass. & 624 & 742 & 13,240 & $161^{*}$ \\
\hline Big bluestem.. & 462 & 462 & 8,200 & $100^{*}$ \\
\hline Little bluestem & 376 & 376 & 6,600 & 100 \\
\hline
\end{tabular}

1 The average dry weight of big bluestem is considered 100 per cent for crops growing on lowlands formerly occupied by this species. These percentages are marked by an asterisk. Average dry weight of little bluestem is the basis for calculating percentage yield of underground parts on uplands.

Without tubers.

${ }^{3}$ Fibrous roots only.

column 2 the average weight in grams per one-half square meter for the several crops, etc., may readily be compared with that of the native grasses at the bottom of the table. Column 3 furnishes data for a similar comparison when the plants were mature. Among field crops, alfalfa with its 
large taproots ranks highest in both columns and corn (ave. wt.) and wheat on upland (wt. at maturity) lowest. The other field crops, as well as those of pasture, are intermediate. Brome grass is an exception; weight of the underground parts of this perennial exceeded that of all other crop plants examined. The garden crops are of low rank, probably because the shallower roots were destroyed by tillage. Nor do the weeds examined rank high, even the mature pigweed. Thus underground parts of all these field, garden, and pasture crops furnish only a small amount of plant materials compared with that regularly produced by native grasses.

The weight in pounds per acre and its percentage as compared with that of native grass types which formerly occupied these lowlands and uplands respectively, are given in columns 4 and 5.

Data for these native grasses are taken from the tables of Weaver and Harmon ('35) who secured at least six samples of each type in prairies adjacent to the fields where samples of crop plants were taken. The yield of big-bluestem prairie type, 8,200 pounds (4.1 tons) per acre, is taken as 160 per cent for lowlands. That of the upland, little-bluestem type, 6,600 pounds ( 3.3 tons) per acre, is likewise used as a similar basis for comparison.

Calculations were made on the basis of mature crops. Of the garden crops, not one furnished more than 5 per cent, ${ }^{1}$ and field crops, aside from old alfalfa, did not exceed 32 per cent as much underground material as is furnished by the original plant cover. Even 4-year-old alfalfa and brome grass fell below 50 per cent and all other species examined on cultivated land furnished less. The bluegrass sod afforded but 59 per cent and the coarse, heavy underground parts of buckbrush and slough grass alone exceed those of big bluestem.

The great reduction of living plant materials in fields and pastures is a matter for serious consideration both as regards binding of the soil and maintaining its fertility. It seems probable that decreases at greater depths are equal or even greater. There has been found in prairie, below 6 inches, an approximately linear relation between the amount of root materials and the amount of soil organic matter in the various soil horizons to a depth of 7 feet. In the surface soil the presence of a large amount of living rhizome and root material and the favorable conditions for the decomposition of dead organic matter increase the proportion of roots and rhizomes to soil organic matter (Weaver et al., '35).

Successful attempts to protect soil by increasing the density and duration of plant cover, automatically increase the underground parts. These are valuable assets to the soil not only when they are alive but also after death and decay. In these experiments, for example, samples of undisturbed field soil without living roots were eroded in 7 to 9 minutes.

\footnotetext{
${ }^{1}$ Tubers and fleshy roots of garden plants were not included.
} 
Erosion time of similar soil stabilized by underground parts of field crops was extended to 12 to 21 minutes. Where a good cover of tops also intervened between water and soil the time was often increased 3 to 8 fold. But the best growth of field crops is far inferior to the native sod in preventing the soil from washing away.

\section{SUMMARY}

Preventing or controlling the wastage of land through soil erosion is one of the major economic problems in America. Plant cover is the main controllable factor. An exact understanding of its effects is of extreme importance.

Relative efficiency of roots and tops acting together and underground parts alone in protecting the soil from erosion has been determined. Numerous crops of cultivated fields and gardens, pasture crops, weeds, and native grasses have been used.

A method of securing samples of undisturbed field soil with crops uninjured and in all stages of development has been devised. The samples were 1 meter long, $0.5 \mathrm{~m}$. wide, and $1 \mathrm{dm}$. deep, and weighed 170 to 200 pounds.

Samples were taken in pairs and transported to a washing rack with a slope of $10^{\circ}$. Plants were removed from one sample, after clipping closely to the soil surface, but left intact in the other. Time required to erode the soil of the two samples under the same conditions of watering was determined.

Water was applied at the rate of 12.7 gallons per minute under a total force of 1 pound over an area of approximately 1.5 square inches, the hose being moved constantly and uniformly. With certain grasses, etc., 3.4 gallons per minute were applied with a force of 1.39 pounds over an area of 0.11 square inches.

All living underground parts were recovered and dry weight determined separately from that of tops.

Upland soils were fine-textured Carrington silt loam; lowland soils, of a colluvial phase of Wabash silt loam, were similar in physical and chemical properties.

In preliminary experiments simulating rain, water was applied through a shower-bath nozzle under a pressure of $5 / 8$ pound over 133 square inches on loose field soil placed in sampling boxes.

Bare soil, consolidated by occasional watering during 4 weeks, eroded in 16 to 18 minutes. Held by roots of sunflowers, millet, or Sudan grass, 30 days old, erosion time increased to 2 to 4 hours. With tops also intact 35 or more per cent of the soil was left after 9 to 12 hours of watering. 
Lowland soil planted to winter wheat eroded in late fall in 7 and 11 minutes without and with tops, respectively. With the growth of the crop, underground parts alone more than doubled the efficiency of the soil in resisting erosion; protection afforded by maturing tops increased it 9 to 10 fold. The early root-top erosion ratio of 1:1.6 gradually increased to $1: 7$, but fell after harvest to $1: 1.2$. Thus the great importance of plant cover in protecting the soil was clearly revealed.

Rapid development of resistance to erosion by wheat grown on upland paralleled in general that on low ground. Samples of this more clayey soil with underground parts only eroded in 12 minutes in April and in 18 in July. With the rather poorly developed tops intact, erosion time was 15 and 87 minutes, respectively.

Prevention of erosion does not result so much from vertical thickness of cover as from one widely spread and continuous. A single leaf on the soil is effective as regards protection directly beneath it. Hence, broadcasting should afford greater soil stabilization than drilling seed thickly in rows.

Oats was similar to wheat but less efficient in retarding erosion. This resulted from the much lighter cover. During 32 days of growth, resistance to erosion was increased 3.3 times.

A good stand of young alfalfa, seeded in early fall, held only poorly the upland soil the following spring. Erosion time with and without tops was 8 and 7 minutes, respectively. By fall of a dry summer the time had increased to 48 and 18 minutes, and the erosion ratio from 1:1.1 to 1:2.7.

Four-year-old alfalfa on lowland soil was no more efficient than yearold alfalfa on upland, even when 28 inches tall and presenting a complete cover. Erosion time with tops never exceeded 43 minutes; without tops the maximum was 21 minutes. The highest erosion ratio was 1:2.8. Alfalfa was less efficient than fully grown wheat but difference in favor of the grass is overbalanced by the much longer duration of the legume.

Sorgo retarded erosion because of the large production of long leaves which broke the force of the water and conducted it gently to the soil. Strong stem-bases and abundant coarse roots anchored the soil. Erosion time with tops was 98 minutes.

Roots of young field corn were very inefficient in stabilizing soil. Compared with soil without roots the ratio was 1:1.07. This increased slowly to $1: 2.1$ in late summer when brace roots were formed.

The character of the crop is a principal factor in erosion control. The effect with plant cover intact exceeds that of underground parts alone 3 to 7 times. Maximum protection was afforded by winter wheat and sorgo; oats and alfalfa offered less.

Close spacing of rows or broadcasting would result in greatly increased soil protection. Any practice which removes plant cover or debris is undesirable from the viewpoint of soil conservation. 
A good stand of Sudan grass was more efficient in retarding erosion than any of the field crops examined. This resulted from the rapid growth of an abundance of long leaves, tillering which promoted close spacing of stems, and early development of a strong, fibrous root system. Erosion time without tops was increased 2.5 times in 35 days; with tops intact it was increased more than 12 fold.

Sweet clover and rape offered good resistance to soil removal when the plants covered the soil. The erosion ratio of roots alone to roots reinforced by tops was $1: 4.3$ and $1: 6.6$, respectively.

Well established Hungarian brome grass was the most efficient soil protector found among pasture plants. The root-mat approached native prairie grasses in its efficiency as a soil binder. Two hours plus 25 minutes with nozzle attached were required to erode a sample with tops removed, and 2 hours plus 3 hours and 5 minutes, with tops intact.

Rye, drilled thickly for fall and spring pasture, is an efficient cover crop during a season when most crops do not thrive.

Pasture crops of long duration are the more efficient soil protectors and, among these, sod-forming grasses are best. Their effect is direct and continuous over the whole area. Rapid reestablishment of a cover in spring, and accumulation of litter are important factors in protecting the soil.

Increasing pasture acreage, maintaining a plant cover at all times, and improvement of overgrazed pastures are chief weapons against wastage of soil fertility or soil itself through erosion.

Among a group of six garden crops, tomatoes afforded the greatest protection. Without tops the soil was held for 13 minutes, but the bushy plants delayed erosion for one hour and 6 minutes.

Carrots were slightly less efficient than tomatoes. The underground parts alone held the soil for 11 minutes, the widely spreading tops for 49 minutes.

Sweet potato vines efficiently retarded soil erosion, but underground parts alone were not very effective. Erosion ratio was 1:4.6.

Protection afforded by potatoes varied directly with the extent of tops. Even dead vines were efficient. Erosion time ranged from 18 to 35 minutes. Underground parts alone were too meager to retard greatly erosion.

Peas and parsnips were the least efficient of the garden crops studied.

Fully grown garden crops usually held the soil less firmly than mature field crops. Among the latter average erosion time with underground parts alone was 80 per cent greater.

Rough pigweed was of some value as a soil protector when young. With mature tops intact the time of erosion was prolonged about 5 fold.

Field bindweed held the soil 14 to 18 minutes with underground parts alone. Erosion time was increased to 38 to 45 minutes when a complete cover of foliage protected the soil. 
Knotweed is an indicator of hard, trampled soil. Samples with tops removed were eroded only after one hour. The protection afforded by the leafy, prostrate tops was shown by 38 per cent of the soil remaining after 2 hours of washing.

Soil protected by the abundant roots of a dense growth of little barley was eroded in 17 minutes. With tops intact the time was prolonged to one hour.

Tumbleweed represents a type that is very efficient in breaking the force of the water. Tops placed on bare field soil of undisturbed structure, which unprotected eroded in 8 minutes, increased erosion time nearly 6 fold.

A thick, normal growth of dried yellow foxtail prolonged erosion time of bare field soil from 8 minutes to 1 hour and 5 minutes.

Dead crab grass from one-half square meter of upland soil, placed on a sample of loose field soil, prolonged erosion time from 13 minutes to 3 hours and 25 minutes. Both samples (like the following) were eroded by artificial rain.

Living mats of the prostrate spotted spurge protected loose soil from erosion so effectively that the 12.5 minute period for eroding bare soil was prolonged to 4 hours and 7 minutes.

Rosettes of a thick growth of dandelion were cut at the ground line and placed on a sample of loose soil. Three hours and 11 minutes were required to erode a sample which without cover washed away in 12.5 minutes.

All weeds are of some value as soil conservers, many are extremely efficient. Weeds are the wound dressers of the soil. Remaining on the ground after maturity, they function during life and after death.

Of well established types of native vegetation, buckbrush was least efficient in preventing erosion.

Samples of bluegrass sod were eroded in 2 hours with the open hose plus 45 minutes with the finer stream. With tops intact, 2 hours plus 3 hours and 45 minutes were required.

Soil was removed from the underground parts of big bluestem in 2 hours plus 2 hours and 40 minutes. Complete erosion with tops intact required 2 hours plus 12 hours and 57 minutes.

Without tops, slough grass held the soil 2 hours plus 2 hours and 18 minutes. With tops intact, only 3 per cent of the soil was removed by 24 hours of washing.

The most formidable line of defense by the grasses against erosion is above ground, although the soil is also held in a remarkable manner by roots and rhizomes. The foliage of slough grass is especially adapted to protect the soil even against rushing flood waters. 
Weakening grasses by overgrazing, trampling, and injudicious burning should be avoided. A good plant cover should at all times be maintained.

Native upland prairies of little-bluestem type have 6,600 pounds per acre of living underground materials in the surface 4 inches of soil. This increases to 8,200 pounds in the lowland, big-bluestem type. Bluegrass pastures furnished 59 per cent and slough grass 148 per cent as much as big bluestem.

Old alfalfa furnished 43 per cent as much as big bluestem and wheat only 16 per cent. Most other field crops produced less. Production of underground parts by garden crops was low, as was also that of weeds.

A heavy sod of brome grass produced 48 per cent and Sudan grass only 17 per cent as much underground parts as big bluestem. These, with yellow sweet clover (18 per cent), gave the highest amounts among the pasture crops.

The great reduction of living plant materials in fields and pastures is a matter for serious consideration both as regards binding of the soil and the maintenance of fertility. Protecting the soil by increasing the density and duration of plant cover automatically increases the underground parts.

\section{LITERATURE CITED}

Aldous, A. E. 1934. Effect of burning on Kansas bluestem pastures. Kans. Agr. Exp. Sta. Tech. Bull. 38.

Alway, F. J., and Russel, J. C. 1916. Use of the moisture equivalent for the indirect determination of the hygroscopic coefficient. Jour. Agr. Res. 6:833.

Bartel, F. O. 1925. First Progress Report on soil erosion experiments. N. C. Exp. Sta. Farm. U. S. Dept. Agr., Bur. Pub. Roads, Div. Agr. Eng.

Bartel, F. O. 1935. Results of recent engineering studies in soil erosion control. Agr. Eng. 16:304-307.

Bates, C. G., and Zeasman, O. R. 1930. Soil erosion-a local and national problem. Wis. Agr. Exp. Sta. Res. Bull. 99.

Bennett, H. H. 1931. Cultural changes in soils from the standpoint of erosion. Jour. Amer. Soc. Agron. 23:434-454.

Bennett, H. H. 1934. Dynamic action of rains in relation to erosion in the humid region. Trans. Amer. Geophysical Union. Part 2:474-488.

Bouyoucos, G. J. 1935. The clay ratio as a criterion of susceptibility of soils to erosion. Jour. Amer. Soc. Agron. 27:738-741.

Dickson, R. E. 1929. The results and significance of the Spur (Texas) run-off and erosion experiments. Jour. Amer. Soc. Agron. 21:413-422.

Duley, F. L., and Miller, M. F. 1923. Erosion and surface runoff under different soil conditions. Mo. Agr. Exp. Sta. Res. Bull. 63.

Forsling, C. L. 1931. A study of the influence of herbaceous plant cover on surface runoff and soil erosion in relation to grazing on the Wasatch Plateau in Utah. U. S. Dept. Agr. Tech. Bull. 220.

Holland, T. H. 1926. Soil erosion experiments on the Exp. Sta. Peradeniya. Ceylon Dept. Agr. Yearbook.

Kiesselbach, T. A. 1918. Studies concerning the elimination of experimental error in comparative crop tests. Nebr. Agr. Exp. Sta. Res. Bull. 13.

Lowdermilk, W. C. 1930. Influence of forest litter on runoff, percolation, and erosion. Jour. For. 28:474-491. 
Lutz, J. F. 1934. The physico-chemical properties of soils affecting soil erosion. Mo. Agr. Exp. Sta. Res. Bull. 212.

McIntyre, A. C. 1935. Trees and erosion control. Amer. Soil Survey Assoc. Bull. $16: 110-114$.

Meginnis, H. G. 1935. Influence of forest litter on surface run-off and soil erosion. Amer. Soil Survey Assoc. Bull. 16:115-118.

Middleton, H. E. 1930. Properties of soils which influence soil erosion. U. S. Dept. Agr. Tech. Bull. 178.

Middleton, H. E., et al. 1934. The physical and chemical characteristics of the soils from the erosion experiment stations-second report. U. S. Dept. Agr. Tech. Bull. 430.

Miller, M. F., and Krusekopf, H. H. 1930. Experiment Station Research. Mo. Agr. Exp. Sta. Bull. 285:110.

Miller, M. F., and Krusekopf, H. H. 1932. The influence of systems of cropping and methods of culture on surface runoff and soil erosion. Mo. Agr. Exp. Sta. Res. Bull. 177.

Peralta, F. de. 1935. Some principles of competition as illustrated by Sudan grass, Holcus sorghum sudanensis (Piper) Hitchc. Ecol. Mon. 5:355-404.

Ramser, C. E. 1930. Erosion control on the Federal projects. Agr. Eng. 11:135-140.

Roe, H. B. 1933. Soil erosion-causes and methods of control. Minn. Agr. Exp. Sta. Special Bull. 160.

Sampson, A. W., and Weyl, L. H. 1918. Range preservation and its relation to erosion control on western grazing lands. U. S. Dept. Agr. Bull. 675.

Sexton, H. D., and Diseker, E. G. 1933. A proposed system of erosion control. Agr. Eng. 14:150-152.

Uhland, R. E. 1935. The effect of plant cover on soil and water losses. Symposia commemorating six decades of the modern era in botanical science. Vol. 1, No. $2: 115-122$.

Weaver, J. E., and Fitzpatrick, T. J. 1934. The prairie. Ecol. Mon. 4:111-295.

Weaver, J. E., and Harmon, G. W. 1935. Quantity of living plant materials in prairie soils in relation to runoff and soil erosion. Conserv. and Survey Div., Univ. Nebr., Bull. 8.

Weaver, J. E., Hougen, V. H., and Weldon, M. D. 1935. Relation of root distribution to organic matter in prairie soil. Bot. Gaz. 96:389-420.

Weaver, J. E., and Noll, W. 1935. Comparison of runoff and erosion in prairie, pasture, and cultivated land. Conserv. and Survey Div., Univ. Nebr., Bull. 11.

Winters, N. E. 1930. Okla. Exp. Sta. Ann. Rept. 1926-30:12. 